Dear Author,

Please, note that changes made to the HTML content will be added to the article before publication, but are not reflected in this PDF.

Note also that this file should not be used for submitting corrections. 


\section{Nonsingular crack modelling in orthotropic plates by four equivalent single layers}

Q5

\section{A R T I C L E I N F O}

\section{Article history:}

Received 4 March 2015

Accepted 8 August 2015

Available online $\mathrm{xxx}$

\section{Keywords:}

Delamination

Mixed mode II/III fracture

Energy release rate

Second-order plate theory

03 Theoreom of autocontinuity

\begin{abstract}
A B S T R A C T
In this work the second- and third-order laminated plate theories are applied to model delaminated composite plates with material orthotropy. The method of four equivalent single layers is proposed and a general third-order displacement field is utilized in each layer. The kinematic continuity between the layers is established by the system of exact kinematic conditions. Apart from the continuity of the inplane displacements between the interfaces of the layers even the continuity of shear strains, their derivatives and curvatures is imposed. As a novelty a so-called shear strain control condition is introduced, which means that the shear strains at two or more points located along the thickness are imposed to be the same. Using the proposed conditions the equilibrium equations are derived for the delaminated and undelaminated regions of the plate. Plates with different boundary conditions are solved as examples and the theorem of autocontinuity is introduced, which is essentially related to the continuity conditions between the delaminated and undelaminated parts. The stress and displacement fields as well as the J-integral are determined in the examples and compared to finite element calculations. The results indicate that the control condition works very well in the case of the second-order plate theory, in contrast it is rather a disadvantage in the case of the third-order approximation.
\end{abstract}

(C) 2015 Published by Elsevier Masson SAS.

\section{Introduction}

Anisotropic composites (Chaudhuri and Balaraman, 2007; Czigány and Deák, 2012; Mészáros et al., 2013) are often utilized in air-, spacecraft (Smojver and Ivančević, 2010; Ivančević and Smojver, 2011; Smojver and Ivančević, 2011, 2012; Langdon et al., 2014) and sport industry (Jiang, 2014; Li and Jing, 2014; Su, 2014; Zhang, 2014; Tang, 2014), composite panels are also applied in cars and vehicles (Norhidayah et al., 2014; Wennberg and Stichel, 2014; Khan et al., 2014), ships (Chirica et al., 2011; Chirica, 2013), pressure vessels (Gheshlaghi et al., 2006) and many other engineering applications (Goch et al., 2012). The mechanical behavior of laminated composite plates and shells can be described by different theories. The classical laminated plate theory (CLPT) is based on the Kirchhoff assumption and so, it does not take the shear deformation into account (Radosavljević and Dražić, 2010; Eftekhari and Jafari, 2012; Hajheidari and Mirdamadi, 2013). The first-order shear deformation (FSDT or Mindlin) theory assumes constant shear strain distribution over the thickness of the plate (Kreja and

E-mail address: szeki@mm.bme.hu.

URL: http://www.mm.bme.hu/ szeki
Schmidt, 2006; Endo and Kimura, 2007; Assie et al., 2012; Batista, 2012; Nanda and Sahu, 2012; Sabik and Kreja, 2013; Endo, 2015). As a next step, the second-order plate theory (SSDT) proposes that the in-plane displacements are captured by quadratic functions in terms of the through-thickness coordinate (Baddour, 2011; Izadi and Tahani, 2010; Shahrjerdi et al., 2011, 2010). The third-order shear deformation plate theory (TSDT) (Talha and Singh, 2010; Aragh et al., 2013) as well as the refined Reddy third-order theory (Thai et al., 2012; Oktem et al., 2013; Taj et al., 2013; Batista, 2012; Bodaghi and Saidi, 2010; Thai et al., 2012) are also very common to describe the mechanical behavior of anisotropic plates and shells.

The 3D and elasticity based solutions (Alibeigloo and Zanoosi, 2013; Chang and Tarn, 2012; Yang et al., 2012) are also available in the literature, as well as the different layerwise approximations (Arya et al., 2002; Ferreira et al., 2011; Ovesy et al., 2015; Saeedi et al., 2012a,b, 2013a,b; Lerpiniere et al., 2014; Sahoo and Singh, 2014b). Other higher-order theories (Steigmann, 2012; Xiang et al., 2012; Shi, 2007; Zhao et al., 2013; Lu et al., 2013; Shimpi and Patel, 2006) and those based on trigonometric or other appropriate functions (Thai and Vo, 2013; Thai and Choi, 2013; Sahoo and Singh, 2014a, 2013a,b) are useful in the case of functionally graded (FGM) plates. 
It is clear that many plate and shell theories are proposed in the literature, however, the application of these theories to model delaminations is started only few years ago. The delamination is a typical and common damage mode in composite laminates. The presence of delaminations (Rizov, 2012a,b; Ahn et al., 2012) and cracks (Hajikazemi and Sadr, 2014b,a) in the material reduces the stiffness, strength and lifetime, it also changes the dynamic properties and the behavior of the structure against the loss of stability. Therefore it is essential to develop new models for the delamination analysis of composite materials. In this respect the work by Davidson et al. (2000) is noteworthy. It has also to be mentioned that coupled multilayer/interface models have already been introduced in the literature, which are able to provide accurate energy release rate (ERR) calculations compared to FE models using solid type elements (Bruno and Greco, 2001; Bruno et al., 2003, 2005). An important aspect of these formulations is that it avoids the complications arising from the oscillatory singularities for a delamination between different materials.

The delaminations may take place because of low-velocity impact (Ganapathy and Rao, 1998; Rizov et al., 2005; Christoforou et al., 2008; Burlayenko and Sadowski, 2012; Zammit et al., 2011; Wang et al., 2012; Goodmiller and TerMaath, 2014), manufacturing defects (Zhang and Fox, 2007; Zhou et al., 2013) and free edge effects (Sarvestani and Sarvestani, 2012; Ahn et al., 2013). The resistance against the delamination is characterized by mode-I (Jumel et al., 2011a,b; Salem et al., 2013; Kim et al., 2011; Peng et al., 2011; Gracia et al., 2015) mode-II (Arrese et al., 2010; Argüelles et al., 2011; Petrova et al., 2012; Petrova and Sadowski, 2012; Yoshihara and Satoh, 2009; Rizov and Mladensky, 2012) mode-III (Rizov et al., 2006; Szekrényes, 2009a, 2011a,b; Johnston et al., 2014; Johnston and Davidson, 2014; Rodríguez-González et al., 2014; Khoshravan and Moslemi, 2014; López-Menéndez et al., 2014; Marat-Mendes and Freitas, 2009; Mehrabadi and Khosravan, 2013; Yoshihara, 2006) mixed-mode I/II (de Baere et al., 2012; Davidson et al., 2009; Fernández et al., 2013; Islam and Kapania, 2014; Peng et al., 2012; Kenane et al., 2010; Marat-Mendes and Freitas, 2010; Nikbakht et al., 2010; Nikbakht and Choupani, 2008; Plain and Tong, 2011; Liu et al., 2015; Pereira et al., 2014) mixedmode II/III (Szekrényes, 2007; Kondo et al., 2011, 2010; Mladensky and Rizov, 2013; Kotousov et al., 2013, 2012; Szekrényes, 2012; Mehrabadi, 2013, 2014; Miura et al., 2012; Takeda et al., 2013; Suemasu et al., 2010) mixed-mode I/III (Miura et al., 2014; Szekrényes, 2009b) and mixed-mode I/II/III (Davidson and Sediles, 2011; Szekrényes, 2011a,b) fracture test.

The previous developments - that this paper is based on - are summarized as follows: In some recent papers the so-called interface constraints were applied to model delaminated composite plates by CLPT, FSDT, SSDT and TSDT with midplane cracks and symmetric lay-up (Szekrényes, 2014a,c,e, 2013a). Later, the models were generalized to asymmetrically delaminated plates and the socalled system of exact kinematic conditions (SEKC) was proposed for the FSDT (Szekrényes, 2013b), SSDT (Szekrényes, 2014b) and Reddy third-order theory (Szekrényes, 2014d). In these papers the method of two equivalent single layers (2ESLs) was applied, i.e. the whole plate was divided into two parts in the plane of the delamination: a top and a bottom plate was analyzed. Simply supported plates were investigated with straight widthwise delamination. Among the mentioned models Reddy third-order theory was found to be the most promising, however, it will be shown in this paper that a better performance can be achieved by the present method.

The novelty of this paper is the proposed method of four equivalent single layers (4ESLs). The top and bottom plates are captured by two ESLs including the proper kinematic continuity. Furthermore, the updated form of the SEKC is presented including the conditions of continuous shear strain, its derivative and curvature at the interface planes and a so-called shear strain control condition. From the point of view of the continuity conditions between the delaminated and undelaminated regions the theorem of autocontinuity is formulated. The novel technique is applied to delaminated Lévy plates with different geometry and boundary conditions.

\section{Semi-layerwise laminated plate theory - the method of four ESLS}

Fig. 1 shows the section of the layered plate element in the $X-Z$ plane, while in Fig. 2 the $Y-Z$ plane is shown. The elements contain an interfacial delamination parallel to the $Y$ axis, i.e. it goes across the entire plate width. The delamination divides the plate into a top and a bottom subplate. Each subplate is modelled by further two ESLs. The interface planes between the ESLs are called the perturbation planes. In accordance with the literature review, it is clear that the ESLs can be captured by different plate theories. In this work we apply the SSDT and TSDT theories. The general third-order Taylor series expansion of the displacement functions results in the following displacement field (Talha and Singh, 2010; Panda and Singh, 2011; Singh and Panda, 2014; Panda and Singh, 2009):

$$
\begin{aligned}
\begin{aligned}
u_{i}\left(x, y, z^{(i)}\right)= & u_{0}(x, y)+u_{0 i}(x, y)+\theta_{(x) i}(x, y) z^{(i)}+\phi_{(x) i}(x, y)\left(z^{(i)}\right)^{2} \\
& +\lambda_{(x) i}(x, y)\left(z^{(i)}\right)^{3}
\end{aligned} \\
\begin{aligned}
v_{i}\left(x, y, z^{(i)}\right)= & v_{0}(x, y)+v_{0 i}(x, y)+\theta_{(y) i}(x, y) z^{(i)}+\phi_{(y) i}(x, y)\left(z^{(i)}\right)^{2} \\
& +\lambda_{(y) i}(x, y)\left(z^{(i)}\right)^{3}
\end{aligned} \\
\begin{aligned}
w_{i}(x, y)=w_{i}(x, y)
\end{aligned}
\end{aligned}
$$

where $i$ is the index of the actual ESL, $z^{(i)}$ is the local through thickness coordinate of the $i$ th ESL (refer to Fig. 1 ), $u_{0}$ and $v_{0}$ are the global, $u_{0 i}$ and $v_{0 i}$ are the local membrane displacements, moreover, $\theta$ means the rotations of the cross sections about the $X$ and $Y$ axes (refer to Fig. 1), $\phi$ denotes the second-order, $\lambda$ represents the thirdorder terms in the displacement functions. The displacement functions of SSDT can be obtained by reducing Eq. (1) and taking $\lambda_{(x)}$ $i=\lambda_{(y) i}=0$ (Izadi and Tahani, 2010; Baddour, 2011; Petrolito, 2014).

\section{The system of exact kinematic conditions - SEKC}

The system of exact kinematic conditions has been developed in (Szekrényes, 2013b) for first-order Mindlin plates and it was subsequently extended to second- (Szekrényes, 2014b) and third-order plates (Szekrényes, 2014d). In the mentioned papers the plate was divided into two ESLs in the undelaminated portion. Among these proposed solutions, Reddy's theory provided the best agreement with the finite element (FE) results (based on the virtual crack closure technique (VCCT, (Bonhomme et al., 2010; Valvo, 2012)) for asymmetrically delaminated composite plates. In spite of that, if the delamination is very close to the free surface of the plate, then even Reddy's theory leads to inaccurate results. The aim of this paper is to model the delaminated plate by 4ESLs and to introduce the necessary conditions to obtain the best possible solutions under assumed plane stress state.

We assume that a plate consisting of orthotropic plies contains a single through-width delamination. The delamination front is parallel to the $Y$ axis. A displacement field given by Eq. (1) is associated to each ESLs. The kinematic continuity between the adjacent ESLs is established by the SEKC requirements. The first set of conditions formulates the continuity of the in-plane displacements between the neighboring plies as:
66 


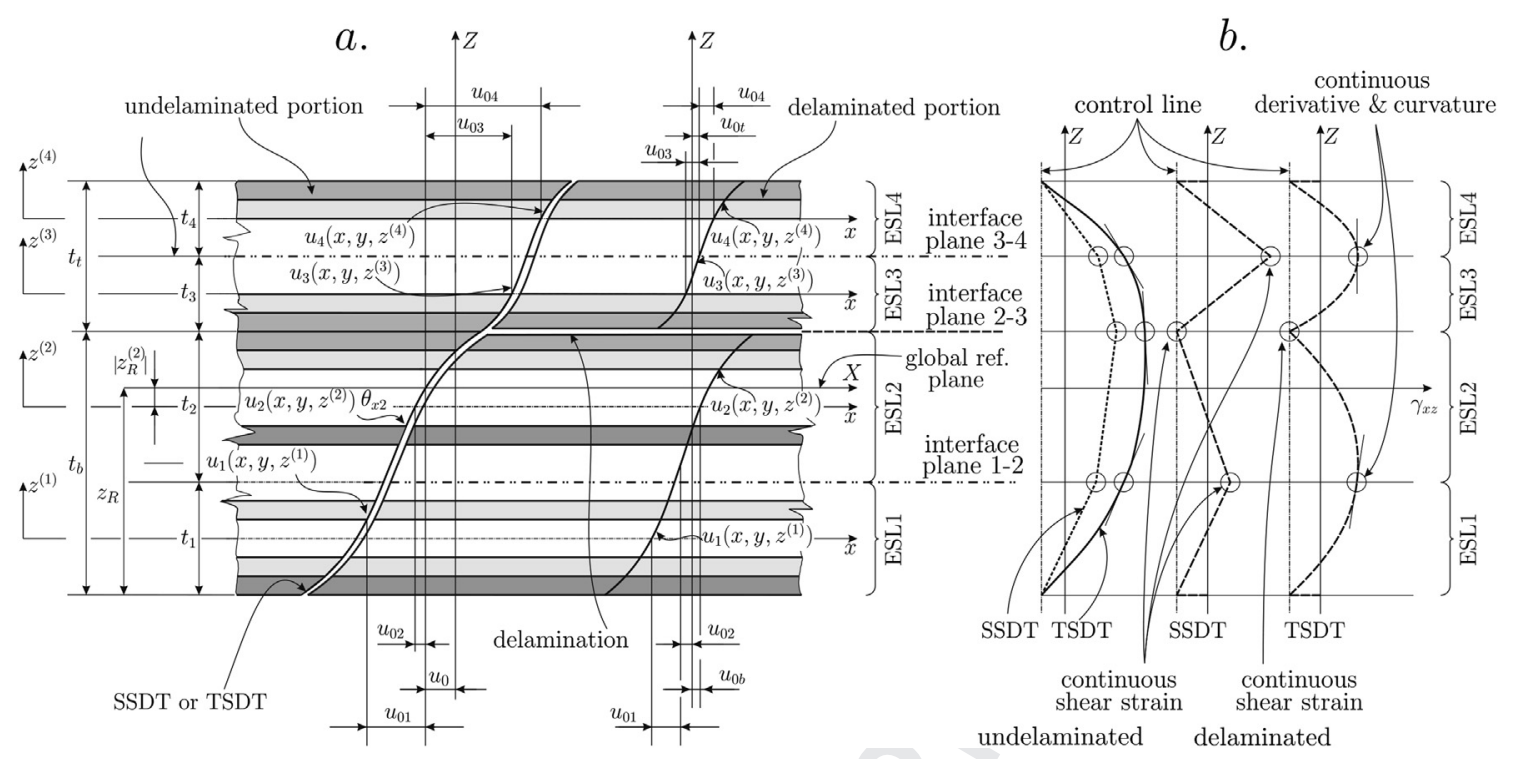

Fig. 1. Cross sections and deformation of the top and bottom plate elements of a delaminated plate in the $X-Z$ plane (a). Distribution of the transverse shear strains by SSDT and TSDT (b).

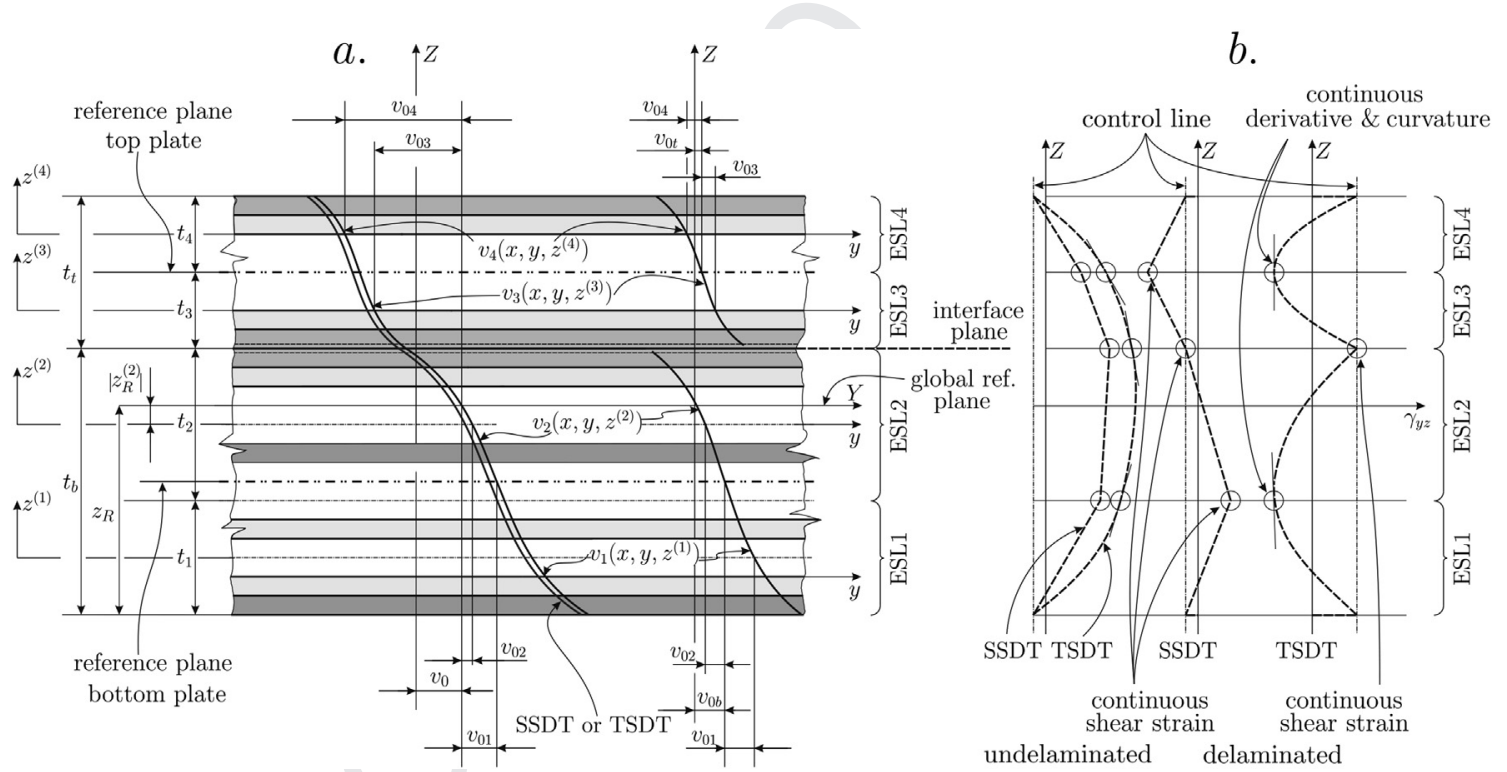

Fig. 2. Cross sections and deformation of the top and bottom plate elements of a delaminated plate in the $Y-Z$ plane (a). Distribution of the transverse shear strains by SSDT and TSDT (b).

$\left.\left(u_{(i)}, v_{(i)}, w_{(i)}\right)\right|_{\mathcal{Z}^{(i)}=t_{i} / 2}=\left.\left(u_{(i+1)}, v_{(i+1)}, w_{(i+1)}\right)\right|_{z^{(i+1)}=-t_{i+1} / 2}$

where $t$ is the thickness of the specified layer. The second set of conditions defines the global membrane displacements $\left(u_{0}, v_{0}\right)$ at the reference plane of the actual region. If the location of the reference plane is $z_{R}^{(k)}$ and is located in the $k$ th layer, then the relevant conditions become:

$\left.u_{(k)}\right|_{\mathcal{Z}^{(k)}=z_{R}^{(k)}}-u_{0}=0,\left.v_{(k)}\right|_{\mathcal{Z}^{(k)}=z_{R}^{(k)}}-v_{0}=0$

The two sets of conditions given by Eqs. (2)-(3) are sufficient to develop semi-layerwise models using the FSDT. If the SSDT or TSDT is applied, then we can impose the shear strain continuity at the interface planes. In accordance with Figs. $1 \mathrm{~b}$ and $2 \mathrm{~b}$ these conditions are formulated as:

$\left.\left(\gamma_{x z(i)}, \gamma_{y z(i)}\right)\right|_{z^{(i)}=t_{i} / 2}=\left.\left(\gamma_{x z(i+1)}, \gamma_{y z(i+1)}\right)\right|_{z^{(i+1)}=-t_{i+1} / 2}$

For the TSDT theory two more sets of conditions are reasonable to introduce. The imposition of continuous shear strain derivatives and curvatures prevent the unwanted oscillations in the stress distributions (see Figs. $1 \mathrm{~b}$ and 2b):

$\left.\left(\frac{\partial \gamma_{x z(i)}}{\partial z^{(i)}}, \frac{\partial \gamma_{y z(i)}}{\partial z^{(i)}}\right)\right|_{z^{(i)}=t_{i} / 2}=\left.\left(\frac{\partial \gamma_{x z(i+1)}}{\partial z^{(i+1)}}, \frac{\partial \gamma_{y z(i+1)}}{\partial z^{(i+1)}}\right)\right|_{z^{(i+1)}=-t_{i+1} / 2}$ 
and:

$\left.\left(\frac{\partial^{2} \gamma_{x z(i)}}{\partial\left(z^{(i)}\right)^{2}}, \frac{\partial^{2} \gamma_{y z(i)}}{\partial\left(z^{(i)}\right)^{2}}\right)\right|_{z^{(i)}=t_{i} / 2}=\left.\left(\frac{\partial^{2} \gamma_{x z(i+1)}}{\partial\left(z^{(i+1)}\right)^{2}}, \frac{\partial^{2} \gamma_{y z(i+1)}}{\partial\left(z^{(i+1)}\right)^{2}}\right)\right|_{z^{(i+1)}=-t_{i+1} / 2}$

An important addition compared to previous papers is the socalled shear strain control condition (SSCC). In accordance with Reddy theory the top and bottom surfaces of the plate are tractionfree (zero shear stresses). If two ESLs are applied this condition involves a little over-stiffening of the system. Moreover, if the system is modelled by 4ESLs the traction-free conditions leads to overconstraining the model and wrong results are obtained. Therefore, instead of imposing zero stresses at the free surfaces we impose the identical shear strain values at the boundary planes. Figs. 1a and 2a show the so-called control line and the controlled shear strain distributions. The set of conditions applied is:

$\left.\left(\gamma_{x z(l)}, \gamma_{y z(l)}\right)\right|_{z^{(l)}=-t_{l} / 2}=\left.\left(\gamma_{x z(m)}, \gamma_{y z(m)}\right)\right|_{z^{(m)}=-t_{m} / 2}$

where $l$ and $m$ denote the boundaries, where the shear strains are equal to each other. The SEKC can be applied for the undelaminated and delaminated portions of the plate. Moreover these conditions can be implemented into any plate theory.

\section{Development of kinematically admissible displacement fields}

The SEKC is applied to the problem shown in Figs. 1 and 2. Using the conditions defined by Eqs. (2)-(7) we can eliminate certain parameters from Eq. (1), which involves 34 parameters altogether plus the deflections $\left(w_{i}(x, y)\right)$. This step is called parameter elimination. The parameters to be eliminated are chosen in order to obtain a system of equations, which contain linearly independent equations. However, the global membrane parameters should be remaining or primary parameters, the local membrane displacements are typically secondary parameters, that should be eliminated from the displacement field. In the subsequent sections the undelaminated and delaminated regions are discussed separately. In the first step, the TSDT solution is presented, then in the second step the SSDT field equations are obtained by the reduction of the TSDT equations.

\subsection{Undelaminated plate region}

The transition zone around the delamination front in the $X-Z$ plane of the composite plate is shown in Fig. 1a. The distribution of the in-plane displacement functions is quadratic in the case of the SSDT and cubic for the TSDT. The corresponding shear strain distributions are shown in Fig. 1b: it is piecewise linear by SSDT and piecewise quadratic by TSDT with continuous derivatives and curvatures in the latter case. In accordance with Figs. 1a and 2a, the following conditions are formulated between the four ESLs (continuity of in-plane displacement at the interface planes):

$\left.\left(u_{1}, v_{1}, w_{1}\right)\right|_{z^{(1)}=t_{1} / 2}=\left.\left(u_{2}, v_{2}, w_{2}\right)\right|_{z^{(2)}=-t_{2} / 2}$
$\left.\left(u_{2}, v_{2}, w_{2}\right)\right|_{z^{(2)}=t_{2} / 2}=\left.\left(u_{3}, v_{3}, w_{3}\right)\right|_{z^{(3)}=-t_{3} / 2}$
$\left.\left(u_{3}, v_{3}, w_{3}\right)\right|_{z^{(3)}=t_{3} / 2}=\left.\left(u_{4}, v_{4}, w_{4}\right)\right|_{z^{(4)}=-t_{4} / 2}$

The reference plane belongs to the second ESL, therefore, the following condition is imposed:

$\left.\left(u_{2}, v_{2}\right)\right|_{z^{(2)}=z_{R}^{(2)}}=\left(u_{0}(x, y), v_{0}(x, y)\right)$ where the $z_{R}^{(2)}=1 / 2\left(t_{3}+t_{4}-t_{1}\right)$ in accordance with Fig. 1a and actually coincides with the global midplane of the model (Reddy, 2004). The next set of conditions imposes the continuous shear strains at the interface planes:

$$
\begin{aligned}
& \left.\left(\gamma_{x z(1)}, \gamma_{y z(1)}\right)\right|_{z^{(1)}=t_{1} / 2}=\left.\left(\gamma_{x z(2)}, \gamma_{y z(2)}\right)\right|_{z^{(2)}=-t_{2} / 2} \\
& \left.\left(\gamma_{x z(2)}, \gamma_{y z(2)}\right)\right|_{z^{(2)}=t_{2} / 2}=\left.\left(\gamma_{x z(3)}, \gamma_{y z(3)}\right)\right|_{z^{(3)}=-t_{3} / 2} \\
& \left.\left(\gamma_{x z(3)}, \gamma_{y z(3)}\right)\right|_{z^{(3)}=t_{3} / 2}=\left.\left(\gamma_{x z(4)}, \gamma_{y z(4)}\right)\right|_{z^{(4)}=-t_{4} / 2}
\end{aligned}
$$

As discussed previously, the oscillations in the shear strain distribution can be reduced by ensuring continuous shear strain derivatives at the interface planes $1-2$ and 3-4:

$$
\begin{aligned}
& \left.\left(\frac{\partial \gamma_{x z(1)}}{\partial z^{(1)}}, \frac{\partial \gamma_{y z(1)}}{\partial z^{(1)}}\right)\right|_{z^{(1)}=t_{1} / 2}=\left.\left(\frac{\partial \gamma_{x z(2)}}{\partial z^{(2)}}, \frac{\partial \gamma_{y z(2)}}{\partial z^{(2)}}\right)\right|_{z^{(2)}=-t_{2} / 2} \\
& \left.\left(\frac{\partial \gamma_{x z(3)}}{\partial z^{(3)}}, \frac{\partial \gamma_{y z(3)}}{\partial z^{(3)}}\right)\right|_{z^{(3)}=t_{2} / 2}=\left.\left(\frac{\partial \gamma_{x z(4)}}{\partial z^{(4)}}, \frac{\partial \gamma_{y z(4)}}{\partial z^{(4)}}\right)\right|_{z^{(4)}=-t_{4} / 2}
\end{aligned}
$$

furthermore, by imposing continuous shear strain curvatures in the same planes by using the conditions below:

$$
\begin{aligned}
& \left.\left(\frac{\partial^{2} \gamma_{x z(1)}}{\partial\left(z^{(1)}\right)^{2}}, \frac{\partial^{2} \gamma_{y z(1)}}{\partial\left(z^{(1)}\right)^{2}}\right)\right|_{z^{(1)}=t_{1} / 2}=\left.\left(\frac{\partial^{2} \gamma_{x z(2)}}{\partial\left(z^{(2)}\right)^{2}}, \frac{\partial^{2} \gamma_{y z(2)}}{\partial\left(z^{(2)}\right)^{2}}\right)\right|_{z^{(2)}=-t_{2} / 2} \\
& \left.\left(\frac{\partial^{2} \gamma_{x z(3)}}{\partial\left(z^{(3)}\right)^{2}}, \frac{\partial^{2} \gamma_{y z(3)}}{\partial\left(z^{(3)}\right)^{2}}\right)\right|_{z^{(3)}=t_{3} / 2}=\left.\left(\frac{\partial^{2} \gamma_{x z(4)}}{\partial\left(z^{(4)}\right)^{2}}, \frac{\partial^{2} \gamma y z(4)}{\partial\left(z^{(4)}\right)^{2}}\right)\right|_{z^{(4)}=-t_{4} / 2}
\end{aligned}
$$

To further reduce the number of parameters in the displacement field and to obtain more accurate results, the SSCC is applied at the top and bottom boundaries:

$$
\left.\left(\gamma_{x z(1)}, \gamma_{y z(1)}\right)\right|_{z^{(1)}=-t_{1} / 2}=\left.\left(\gamma_{x z(4)}, \gamma_{y z(4)}\right)\right|_{z^{(4)}=t_{4} / 2}
$$

In Eq. (1) the displacement functions are modified in order to satisfy Eqs. (8)-(13). In the general sense, by applying the SSDT and TSDT theories the in-pane displacement functions can be written as:

$$
\begin{aligned}
& u_{i}=u_{0}+\left(K_{i j}^{(0)}+K_{i j}^{(1)} z^{(i)}+K_{i j}^{(2)}\left(z^{(i)}\right)^{2}+K_{i j}^{(3)}\left(z^{(i)}\right)^{3}\right) \psi_{(x) j} \\
& v_{i}=v_{0}+\left(K_{i j}^{(0)}+K_{i j}^{(1)} z^{(i)}+K_{i j}^{(2)}\left(z^{(i)}\right)^{2}+K_{i j}^{(3)}\left(z^{(i)}\right)^{3}\right) \psi_{(y) j}
\end{aligned}
$$

where the matrices denoted by $K_{i j}$ are related to the geometry (ESL thicknesses), $i$ refers to the ESL number, $j$ defines the component in $\psi$, which is the vector of primary parameters, finally $w_{i}(x, y)=w(x, y)$ for each ESLs, i.e. the transverse normals of each ESL are inextensible (Reddy, 2004).

\subsubsection{Third-order plate theory}

Using the conditions above (Eqs. (8)-(13)) we can eliminate twentyfour parameters from Eq. (1), the secondary parameters are: $u_{0 i}, v_{0 i}, \theta_{(x) i}, \theta_{(y) i}, \phi_{(x) i}, \phi_{(y) i}$ for $i=1,3, \lambda_{(x) i}, \lambda_{(y) i}$ for $i=1 \ldots 4$. The primary parameters are: $u_{0}, v_{0}, \theta_{(x) i}, \theta_{(y) i}$ for $i=2,4$ and $\phi_{(x) i}, \phi_{(y) i}$ for $i=2,4$. The nonzero elements of the matrices $K_{i j}^{(0)}, K_{i j}^{(1)}, K_{i j}^{(2)}$ and $K_{i j}^{(3)}$ are defined in Appendix A. The vector of primary parameters is: $\psi_{(\mathrm{p})}=\left(\theta_{(\mathrm{p}) 2} \phi_{(\mathrm{p}) 2} \theta_{(\mathrm{p}) 4} \phi_{(\mathrm{p}) 4}\right)<\mathrm{SUP}>\mathrm{T}</ \mathrm{SUP}>$ with $p=x$ or $y$. 


\subsubsection{Second-order plate theory}

In this case $\lambda_{(x) i}=0$ and $\lambda_{(y)} \mathrm{i}=0$ in Eq. (1). Eqs. (8)-(9) apply together with Eq. (10) (shear strain continuity), however Eqs. (11) and (12) are omitted. Therefore we can eliminate sixteen parameters from Eq. (1), the secondary parameters are: $u_{0 i}, v_{0 i}, \theta_{(x) i}, \theta_{(y) i}$, $\phi_{(x) i}, \phi_{(y) i}$ for $i=1,3$. The primary parameters are: $u_{0}, v_{0}, \theta_{(x) i}, \theta_{(y) i}$ for $i=2,4, \phi_{(x) i}$ and $\phi_{(y) i}$ for $i=2,4$. The nonzero elements of the matrices $K_{i j}^{(0)}, K_{i j}^{(1)}$ and $K_{i j}^{(2)}$ are defined in Appendix B. Obviously $K_{i j}^{(3)}=0$ in this case. The vector of primary parameters becomes: $\psi(\mathrm{p})=\left(\theta_{(\mathrm{p}) 2} \phi_{(\mathrm{p}) 2} \theta_{(\mathrm{p}) 4} \phi_{(\mathrm{p}) 4}\right)<\mathrm{SUP}>\mathrm{T}</ \mathrm{SUP}>$ with $p=x$ or $y$, i.e. the same as that for the TSDT.

\subsection{Delaminated plate portion}

In the delaminated portion (refer to Figs. $1 \mathrm{~b}$ and $2 \mathrm{~b}$ ) the top and bottom plates are modelled by two ESLs, and thus the first and third of Eq. (8) still hold. It is important to note that in accordance with Eq. (8) the transverse deflections of the top and bottom plates of the delaminated region are identical (constrained mode model, (Szekrényes, 2014d)). In other words, the crack opening is eliminated in the plate, and the problem provides essentially mixedmode II/III fracture without the presence of mode-I. The aim is to predict the mechanical fields in the plate as accurately as possible compared to FE calculations. If this is done for mixed-mode II/III, then the model can be extended to general mixed-mode I/II/III case in the course of the further research work. The definition of the top and bottom reference planes involve:

$$
\begin{aligned}
& \left.\left(u_{1}, v_{1}\right)\right|_{Z^{(1)}=t_{2} / 2}=\left(u_{0 b}(x, y), v_{0 b}(x, y)\right) \\
& \left.\left(u_{3}, v_{3}\right)\right|_{Z^{(3)}=t_{4} / 2}=\left(u_{0 t}(x, y), v_{0 t}(x, y)\right)
\end{aligned}
$$

where $u_{0 b}$ and $u_{0 t}$ are the global membrane displacements of the bottom and top layers in accordance with Figs. 1 and 2. Furthermore, the first and third of Eq. (10) apply again, as well as Eqs. (11) and (12) leading to eleven conditions altogether. Three more equations are formulated by using the shear strain control conditions:

$$
\begin{aligned}
& \left.\left(\gamma_{x z(1)}, \gamma_{y z(1)}\right)\right|_{z^{(1)}=-t_{1} / 2}=\left.\left(\gamma_{x z(2)}, \gamma_{y z(2)}\right)\right|_{z^{(2)}=t_{2} / 2} \\
& \left.\left(\gamma_{x z(3)}, \gamma_{y z(3)}\right)\right|_{z^{(3)}=-t_{3} / 2}=\left.\left(\gamma_{x z(4)}, \gamma_{y z(4)}\right)\right|_{z^{(4)}=t_{4} / 2} \\
& \left.\left(\gamma_{x z(1)}, \gamma_{y z(1)}\right)\right|_{z^{(1)}=-t_{1} / 2}=\left.\left(\gamma_{x z(4)}, \gamma_{y z(4)}\right)\right|_{z^{(4)}=t_{4} / 2}
\end{aligned}
$$

i.e., instead of imposing traction-free boundaries we control the strain distribution by having equal values at the boundaries.

\subsubsection{Third-order plate theory}

The first and third in Eq. (8) hold, moreover Eq. (14) is implied, again the first and third of Eq. (10) are utilized together with Eqs. (11) and (12) and Eqs. (15) and (16) leading to 26 conditions altogether. The secondary parameters are: $u_{0 i}, v_{0 i}, \phi_{(x) i}, \phi_{(y) i}$ for $i=1 \ldots 3$, $\lambda_{(x) i}, \lambda_{(y) i}$ for $i=1 \ldots 4$. The primary parameters are: $u_{0 t}, v_{0 t}, u_{0 b}, v_{0 b}$, $\theta_{(x) i}, \theta_{(y) i}$ for $i=2,4$ and $\phi_{(x) i}, \phi(y) i$ for $i=4$. The modified displacement field has the same form as that given by Eq. (14), the coefficients denoted by $K$ are placed in Appendix A and: $\psi_{(\mathrm{p})}=\left(\theta_{(\mathrm{p}) 2}\right.$ $\left.\theta_{(\mathrm{p}) 4} \phi(\mathrm{p}) 4\right)<\mathrm{SUP}>\mathrm{T}</$ SUP $>$, where $p=x$ or $y$.

\subsubsection{Second-order plate theory}

In this case $\lambda_{(x) i}=0$ and $\lambda_{(y) i}=0$ in Eq. (1). The first and third in Eq. (8) hold, moreover Eq. (14) is implied, again the first and third of Eq. (10) is utilized, however Eqs. (11) and (12) are omitted. The strain control conditions are applied through Eq. (16). Therefore we can eliminate eighteen parameters from Eq. (14), the secondary parameters are: $u_{0 i}, v_{0 i}, \phi_{(x) i}, \phi_{(y) i}$ for $i=1,3$ and 4 , and $\theta_{(x) i}, \theta_{(y) i}$ for $i=1,3$ respectively. The primary parameters are: $u_{0 t}, v_{0 t}, u_{0 b}, v_{0 b}, \theta_{(x)}$ ${ }_{i}, \theta_{(y) i}$ for $i=2,4, \phi_{(x) i}$ and $\phi_{(y) i}$ for $i=2$. The elements of the matrices $K_{i j}^{(0)}, K_{i j}^{(1)}$ and $K_{i j}^{(2)}$ are defined in Appendix B. Apparently $K_{i j}^{(3)}=0$ in this case. The vector of primary parameters takes the form: $\psi(\mathrm{p})=\left(\theta_{(\mathrm{p}) 2} \phi_{(\mathrm{p}) 2} \theta_{(\mathrm{p}) 4}\right)<\mathrm{SUP}>\mathrm{T}</ \mathrm{SUP}>$, where $p=x$ or $y$.

\section{Equilibrium equations}

The strain field in an elastic body in terms of the displacement field is obtained by the following equation (Chou and Pagano, 1967):

$\varepsilon_{i j}=\frac{1}{2}\left(u_{i, j}+u_{j, i}\right)$

where $\varepsilon_{i j}$ is the strain tensor, $u_{i}$ is the displacement vector field. By assuming plane stress state in the plate the vector of in-plane strains becomes (Reddy, 2004):

$$
\begin{aligned}
\left\{\begin{array}{c}
\varepsilon_{x} \\
\varepsilon_{y} \\
\gamma_{x y}
\end{array}\right\}_{(i)}= & \left\{\begin{array}{c}
\varepsilon_{x}^{(0)} \\
\varepsilon_{y}^{(0)} \\
\gamma_{x y}^{(0)}
\end{array}\right\}_{(i)}+z^{(i)} \cdot\left\{\begin{array}{c}
\varepsilon_{x}^{(1)} \\
\varepsilon_{y}^{(1)} \\
\gamma_{x y}^{(1)}
\end{array}\right\}_{(i)}+\left[z^{(i)}\right]^{2} \cdot\left\{\begin{array}{c}
\varepsilon_{x}^{(2)} \\
\varepsilon_{y}^{(2)} \\
\gamma_{x y}^{(2)}
\end{array}\right\}_{(i)} \\
& +\left[z^{(i)}\right]^{3} \cdot\left\{\begin{array}{c}
\varepsilon_{x}^{(3)} \\
\varepsilon_{y}^{(3)} \\
\gamma_{x y}^{(3)}
\end{array}\right\}_{(i)}
\end{aligned}
$$

The vector of transverse shear strains is:

$\left\{\begin{array}{l}\gamma_{x z} \\ \gamma_{y z}\end{array}\right\}_{(i)}=\left\{\begin{array}{l}\gamma_{x z}^{(0)} \\ \gamma_{y z}^{(0)}\end{array}\right\}_{(i)}+z^{(i)} \cdot\left\{\begin{array}{l}\gamma_{x z}^{(1)} \\ \gamma_{y z}^{(1)}\end{array}\right\}_{(i)}+\left[z^{(i)}\right]^{2} \cdot\left\{\begin{array}{l}\gamma_{x z}^{(2)} \\ \gamma_{y z}^{(2)}\end{array}\right\}_{(i)}$

By using the constitutive equations (Kollár and Springer, 2003; Reddy, 2004) the stress resultants are calculated by integrating the stresses over the thicknesses of each ESL:

$$
\begin{aligned}
& \left\{\begin{array}{c}
N_{\alpha \beta} \\
M_{\alpha \beta} \\
L_{\alpha \beta} \\
P_{\alpha \beta}
\end{array}\right\}_{(i)}=\int_{-t_{i} / 2}^{t_{i} / 2} \sigma_{\alpha \beta}\left\{\begin{array}{c}
1 \\
z \\
z^{2} \\
z^{3}
\end{array}\right\}^{(i)} d z^{(i)}, \\
& \left\{\begin{array}{l}
Q_{\alpha} \\
R_{\alpha} \\
S_{\alpha}
\end{array}\right\}_{(i)}=\int_{-t_{i} / 2}^{t_{i} / 2} \sigma_{\alpha z}\left\{\begin{array}{c}
1 \\
z \\
z^{2}
\end{array}\right\} d z^{(i)}
\end{aligned}
$$

where $\alpha$ and $\beta$ takes $x$ or $y$. The relationship between the strain field and the stress resultants is (Szekrényes, 2014d):

$$
\left.\left\{\begin{array}{l}
\{N\} \\
\{M\} \\
\{L\} \\
\{P\}
\end{array}\right\}_{(i)}=\left[\begin{array}{llll}
{[A]} & {[B]} & {[D]} & {[E]} \\
{[B]} & {[D]} & {[E]} & {[F]} \\
{[D]} & {[E]} & {[F]} & {[G]} \\
{[E]} & {[F]} & {[G]} & {[H]}
\end{array}\right]_{(i)}\left\{\begin{array}{l}
\left\{\varepsilon^{(0)}\right\} \\
\left\{\varepsilon^{(1)}\right. \\
\left\{\varepsilon^{(2)}\right. \\
\left\{\varepsilon^{(3)}\right.
\end{array}\right\}\right\}_{(i)}
$$

$$
\left.\left\{\begin{array}{l}
\{Q\} \\
\{R\} \\
\{S\}
\end{array}\right\}_{(i)}=\left[\begin{array}{lll}
{[A]^{*}} & {[B]^{*}} & {[D]^{*}} \\
{[B]^{*}} & {[D]^{*}} & {[E]^{*}} \\
{[D]^{*}} & {[E]^{*}} & {[F]^{*}}
\end{array}\right]_{(i)}\left\{\begin{array}{l}
\left\{\gamma^{(0)}\right\} \\
\left\{\gamma^{(1)}\right. \\
\left\{\gamma^{(2)}\right.
\end{array}\right\}\right\}_{(i)}
$$

where: 
$[. .]^{*}=\left[\begin{array}{cc}(.)_{55} & 0 \\ 0 & (.)_{44}\end{array}\right]$

furthermore: $\{N\}_{(i)}^{\mathrm{T}}=\left\{\begin{array}{lll}N_{x} & N_{y} & N_{x y}\end{array}\right\}_{(i)}$ is the vector of in-plane forces, $\{M\}_{(i)}^{\mathrm{T}}=\left\{\begin{array}{lll}M_{x} & M_{y} & M_{x y}\end{array}\right\}_{(i)}$ is the vector of bending and twisting moments, $\{Q\}_{(i)}^{\mathrm{T}}=\left\{\begin{array}{ll}Q_{x} & Q_{y}\end{array}\right\}_{(i)}$ is the vector of transverse shear forces, and finally $\{L\}_{(i)}^{\mathrm{T}}=\left\{\begin{array}{lll}L_{x} & L_{y} & L_{x y}\end{array}\right\}_{(i)}$, $\{P\}_{(i)}^{\mathrm{T}}=\left\{\begin{array}{lll}P_{x} & P_{y} & P_{x y}\end{array}\right\}_{(i)} \quad$ and $\quad\{R\}_{(i)}^{\mathrm{T}}=\left\{\begin{array}{ll}R_{x} & R_{y}\end{array}\right\}_{(i)}$, $\{S\}_{(i)}^{\mathrm{T}}=\left\{\begin{array}{ll}S_{x} & S_{y}\end{array}\right\}_{(i)}$ are the vectors of higher-order stress resultants. In Eq. (21) $A_{i j}$ is the extensional, $B_{i j}$ is coupling, $D_{i j}$ is the bending, $E_{i j}, F_{i j}, F_{i j}$ and $H_{i j}$ are higher-order stiffnesses (Szekrényes, 2014d):

$$
\left(A_{i j}, B_{i j}, D_{i j}, E_{i j}, F_{i j}, G_{i j}, H_{i j}\right)_{(i)}=\sum_{k=1}^{N_{l}} \int_{z_{k}}^{z_{k+1}} \bar{C}_{i j}^{(k)}\left(1, z, z^{2}, z^{3}, z^{4}, z^{5}, z^{6}\right)^{(i)} d z^{(i)}
$$

The stiffnesses above have to be calculated with respect to the local reference planes of each ESL. The equilibrium equations of the plate system can be obtained by using the virtual work principle (Reddy, 2004). Since this step was shown many times in previous papers (Szekrényes, 2013b, 2014d,b), here only the final results are given. We define the following vectors in order to give the equilibrium equations in compact form:

$\mathbf{N}_{i}^{(x, x y)}=\left(\begin{array}{ll}N_{x} & N_{x y}\end{array}\right)_{(i)}^{T}, \mathbf{N}_{i}^{(x y, y)}=\left(\begin{array}{ll}N_{x y} & N_{y}\end{array}\right)_{(i)}^{T}$

$\mathbf{M}_{i}^{(x, x y)}=\left(\begin{array}{ll}M_{x} & M_{x y}\end{array}\right)_{(i)}^{T}, \quad \mathbf{M}_{i}^{(x y, y)}=\left(\begin{array}{ll}M_{x y} & M_{y}\end{array}\right)_{(i)}^{T}$

The higher-order stress resultants become:

$\mathbf{L}_{i}^{(x, x y)}=\left(\begin{array}{ll}L_{x} & L_{x y}\end{array}\right)_{(i)}^{T}, \quad \mathbf{L}_{i}^{(x y, y)}=\left(\begin{array}{ll}L_{x y} & L_{y}\end{array}\right)_{(i}^{T}$

$\mathbf{P}_{i}^{(x, x y)}=\left(\begin{array}{ll}P_{x} & P_{x y}\end{array}\right)_{(i)}^{T}, \quad \mathbf{P}_{i}^{(x y, y)}=\left(\begin{array}{ll}P_{x y} & P_{y}\end{array}\right)_{(i)}^{T}$

Finally, the vectors of shear and higher-order forces become:

$$
\mathbf{Q}_{i}=\left(\begin{array}{ll}
Q_{x} & Q_{y}
\end{array}\right)_{(i)}^{T}, \mathbf{R}_{i}=\left(\begin{array}{ll}
R_{x} & R_{y}
\end{array}\right)_{(i)}^{T}, \mathbf{S}_{i}=\left(\begin{array}{ll}
S_{x} & S_{y}
\end{array}\right)_{(i)}^{T}
$$

In the sequel the equilibrium equations are derived separately for the undelaminated and delaminated parts.

\subsection{Undelaminated portion}

Formulating the total potential energy of the undelaminated plate portion based on the displacement field satisfying the SEKC requirements (Eq. (14)) the equilibrium equations can be obtained by variational calculus (Reddy, 2004). The equilibrium of the inplane forces involves the equations above independently of the applied theory (SSDT or TSDT):

$\delta u_{0}: \quad \sum_{i=1}^{4} \nabla \cdot \mathbf{N}_{i}^{(x, x y)}=0, \delta v_{0}: \quad \sum_{i=1}^{4} \nabla \cdot \mathbf{N}_{i}^{(x y, x)}=0$

where $\nabla$ is the Hamilton differential operator (Chou and Pagano, 1967). In the general sense (using SSDT or TSDT) the number of primary parameters (ignoring the global membrane displacements) in the displacement field is $k$ (which is equal to the number of elements in $\left.\psi_{(p)}\right)$, the first variation of the total potential energy results in the following equations:

$$
\begin{aligned}
& \left.\begin{array}{l}
\delta \psi_{(x) k}: \\
\delta \psi_{(y) k}:
\end{array}\right\} \sum_{i=1}^{4} K_{i k}^{(0)}\left(\begin{array}{c}
\nabla \cdot \mathbf{N}_{i}^{(x, x y)} \\
\nabla \cdot \mathbf{N}_{i}^{(x y, y)}
\end{array}\right)+K_{i k}^{(1)}\left(\begin{array}{c}
\nabla \cdot \mathbf{M}_{i}^{(x, x y)} \\
\nabla \cdot \mathbf{M}_{i}^{(x y, y)}
\end{array}\right) \\
& +K_{i k}^{(2)}\left(\begin{array}{c}
\nabla \cdot \mathbf{L}_{i}^{(x, x y)} \\
\nabla \cdot \mathbf{L}_{i}^{(x y, y)}
\end{array}\right)+K_{i k}^{(3)}\left(\begin{array}{c}
\nabla \cdot \mathbf{P}_{i}^{(x, x y)} \\
\nabla \cdot \mathbf{P}_{i}^{(x y, y)}
\end{array}\right)+K_{i k}^{(1)}\left(\begin{array}{c}
Q_{i x} \\
Q_{i y}
\end{array}\right) \\
& -2 K_{i k}^{(2)}\left(\begin{array}{c}
R_{i x} \\
R_{i y}
\end{array}\right)-3 K_{i k}^{(3)}\left(\begin{array}{c}
S_{i x} \\
S_{i y}
\end{array}\right)=0
\end{aligned}
$$

where $\psi_{(x) k}$ and $\psi_{(y) k}$ denote the primary parameters. In the TSDT formulation there are four primary parameters (apart from $u_{0}$ and $v_{0}$ ), refer to Section 4.1.1. The variation of the total potential energy with respect to the $w(x, y)$ plate deflection leads to:

$\delta w: \quad \sum_{i=1}^{4} \nabla \cdot \mathbf{Q}_{i}-q=0$

where $q$ is the parameter of the external load. Apparently, the differences among the equilibrium equations of SSDT and TSDT are the matrices defined in Appendices A and B.

\subsection{Delaminated portion}

The delaminated region consists of a top and a bottom plate. Each subplate is modelled by two ESLs. Therefore, the global membrane displacements $u_{0}, v_{0}$ are replaced by $u_{0 b}, v_{0 b}$ for ESL1 and ESL2, moreover by $u_{0 t}, v_{0 t}$ for ESL3 and ESL4 in accordance with Figs. 1 and 2. Thus, the equilibrium equations of in-plane forces take the form below:

$$
\begin{array}{lll}
\delta u_{0 b}: & \sum_{i=1}^{2} \nabla \cdot \mathbf{N}_{i}^{(x, x y)}=0, \delta u_{0 t}: & \sum_{i=3}^{4} \nabla \cdot \mathbf{N}_{i}^{(x, x y)}=0 \\
\delta v_{0 b}: & \sum_{i=1}^{2} \nabla \cdot \mathbf{N}_{i}^{(x y, x)}=0, \delta v_{0 t}: & \sum_{i=3}^{4} \nabla \cdot \mathbf{N}_{i}^{(x y, x)}=0
\end{array}
$$

The form of the other equilibrium equations are the same as those given by Eqs. (29) and (30). The number of primary parameters in $\psi_{(p)}$ is three, refer to Section 4.2.1. In the case of the SSDT theory, the constants denoted by $K_{i j}^{(3)}$ are zero.

\section{Examples - Lévy plates}

In this paper we consider laminated orthotropic plates with different (Lévy type) boundary conditions and asymmetric delamination shown in Fig. 3a and b (with simply supported edges). The plates are loaded by a concentrated force. Some of the problems have been solved in some previous papers (Szekrényes, 2013b, 2014d,b) by using the method of two ESLs. In accordance with Lévy plate formulation (Bodaghi and Saidi, 2010; Hosseini-Hashemi et al., 2011; Thai and Kim, 2012; Kapuria and Kumari, 2012) the primary displacement parameters and the external load parameter, $q$ in Eq. (30) are expressed by trial functions:

$$
\begin{aligned}
\left\{\begin{array}{c}
\theta_{x}(x, y) \\
\theta_{y}(x, y) \\
\phi_{x}(x, y) \\
\phi_{y}(x, y)
\end{array}\right\} & =\sum_{n=1}^{\infty}\left\{\begin{array}{c}
X_{n}(x) \sin \beta y \\
Y_{n}(x) \cos \beta y \\
T_{x n}(x) \sin \beta y \\
T_{y n}(x) \cos \beta y
\end{array}\right\},\left\{\begin{array}{c}
u_{0}(x, y) \\
v_{0}(x, y) \\
q(x, y) \\
w(x, y)
\end{array}\right\} \\
& =\sum_{n=1}^{\infty}\left\{\begin{array}{c}
U_{0 n}(x) \sin \beta y \\
V_{0 n}(x) \cos \beta y \\
Q_{n}(x) \sin \beta y \\
W_{n}(x) \sin \beta y
\end{array}\right\}
\end{aligned}
$$

where $\beta=n \pi / b$. By taking back the solution in Eq. (32) into the equilibrium equations given by Eqs. (28)-(31) it is possible to 

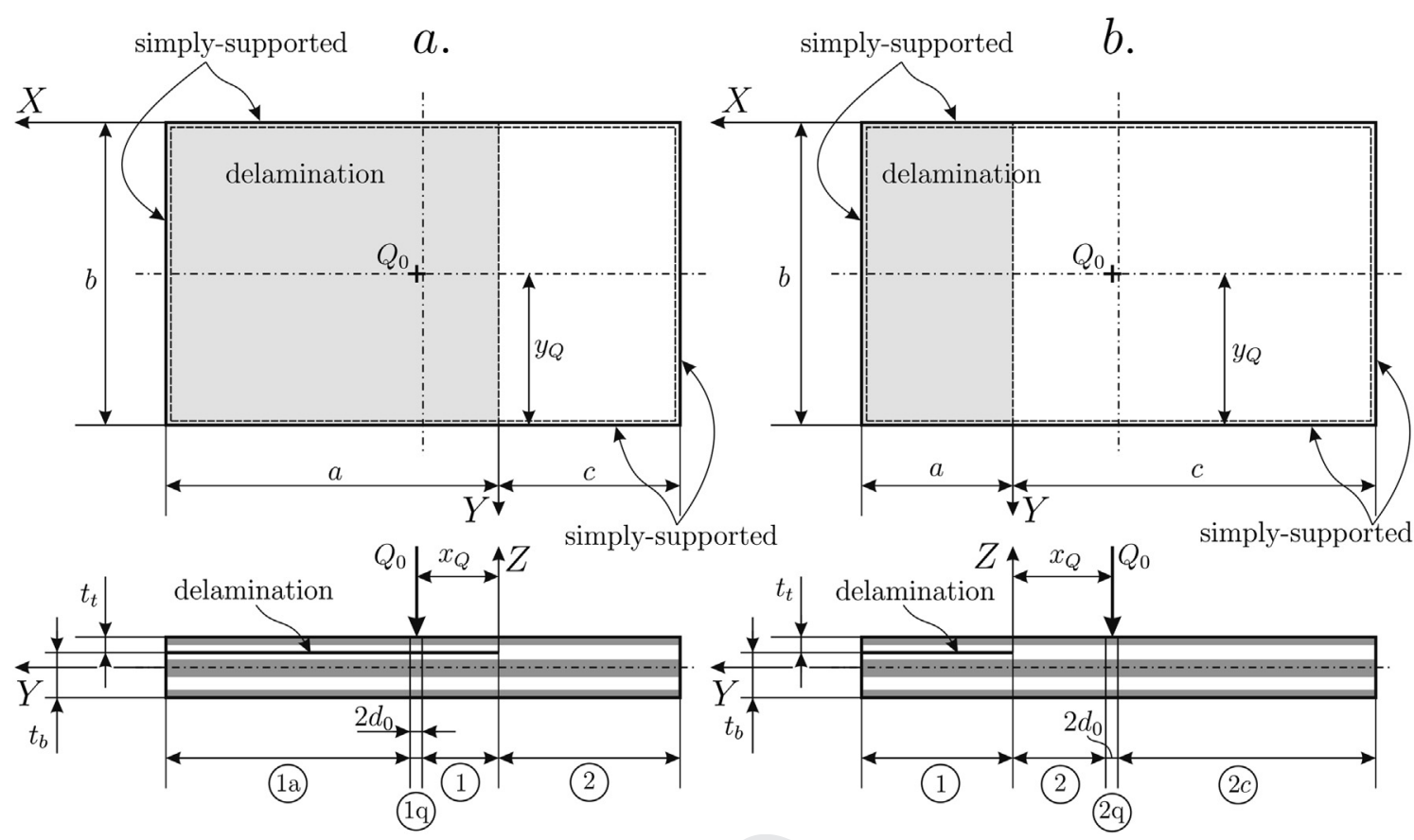

Fig. 3. Simply supported delaminated composite plates subjected to a concentrated force

reduce the system of PDEs to system of ODEs, which can be solved by the state-space approach (Jianqiao, 2003). The stress resultants can be expressed in terms of the displacement parameters through Eqs. (21) and (22). The state-space model takes the form below (Jianqiao, 2003; Reddy, 2004):

$$
\mathbf{Z}^{\prime}=\mathbf{T Z}+\mathbf{F}
$$

where $\mathbf{Z}$ is the state vector, $\mathbf{T}$ is the system matrix, $\mathbf{F}$ is the vector of particular solutions. The general solution of Eq. (33) becomes (Jianqiao, 2003):

$\mathbf{Z}(x)=e^{\mathbf{T} x}\left(\mathbf{K}+\int_{x^{*}}^{x} e^{-\mathbf{T} \xi} \mathbf{F}(\xi) d \xi\right)=\mathbf{G}(x) \mathbf{K}+\mathbf{H}(x)$

where $\mathbf{K}$ is the vector of constants. The parameters of the displacement field can be expressed through:

$Z_{i}^{(d)}=\sum_{j=1}^{r} G_{i j}^{(d)} K_{j}^{(d)}+H_{j}^{(d)}, Z_{i}^{(u d)}=\sum_{j=1}^{s} G_{i j}^{(u d)} K_{j}^{(u d)}+H_{j}^{(u d)}$

where subscript $(d)$ refers to the delaminated, while $(u d)$ refers the undelaminated plate portion, $r=s=22$ are the size of vectors and matrices, respectively. The state-space model is available in many papers (Szekrényes, 2013a, 2014e,d,c), therefore the vectors and matrices in Eqs. (33)-(35) are discussed here only briefly.

\subsection{Undelaminated region}

In the case of both the SSDT and TSDT the state vector contains the parameters of vector $\psi$ (refer to Sections 4.1.1-4.1.3), the global membrane parameters $u_{0}$ and $v_{0}$, the deflection $w$ and the first derivatives of all these parameters leading to (using the Lévy solution): $\mathbf{Z}<S U P>T</ S U P>=\left(U_{0 n}, U_{0 n}^{\prime}, V_{0 n}, V_{0 n}^{\prime}, X_{i n}, X_{i n}^{\prime}, Y_{i n}, Y_{i n}^{\prime}, T_{x i n}\right.$,
$T_{\text {xin }}^{\prime}, T_{\text {yin }}, T^{\prime}{ }_{y i n}, W_{n}, W_{n}^{\prime}$ ) for $i=2,4$, i.e. the vector $\mathbf{Z}$ contains 22 elements, while the system matrix size is $22 \times 22$.

\subsection{Delaminated region}

The state vector of both the SSDT and TSDT model of the delaminated part contains the following elements $\mathbf{Z}^{\mathrm{T}}=\left(U_{0 b n}, U_{0 b n}^{\prime}\right.$, $V_{0 b n}, V_{0 b n}^{\prime}, U_{0 t n}, U_{0 t n}^{\prime}, V_{0 t n}, V_{0 t n}^{\prime}, X_{i n}, X_{i n}^{\prime}, Y_{i n}, Y_{i n}^{\prime}, T_{x 4}, T^{\prime}{ }_{x 4}, T_{y 4}, T_{y 4}^{\prime}, W_{n}$, $\left.W_{n}^{\prime}\right)$ for $i=2,4$, i.e. the size of vector $\mathbf{Z}$ is 22 , the system matrix size is $22 \times 22$ (similarly to the undelaminated portion).

In the next sections the boundary and continuity conditions are given for the TSDT model, the conditions for the SSDT are the same by taking $K_{i j}^{(3)}=0$ in all of the equations.

\section{Boundary conditions}

The B.C.s of the problem in Fig. 3a at $x=a$ in the delaminated portion are determined through the displacement parameters:

$\left.\left(w, v_{0 b}, v_{0 t}, \theta_{y 2}, \theta_{y 4}, \phi_{y 4}\right)^{(1 a)}\right|_{x=a}=0$

and the stress resultants:

$\left.\left(N_{x 1}+N_{x 2}, N_{x 3}+N_{x 4}, M_{x 1}+M_{x 2}, M_{x 3}+M_{x 4}, L_{x 4}\right)^{(1 a)}\right|_{x=a}=0$

At $x=-c$ we have:

$\left.\left(w, v_{0}, \theta_{y 2}, \theta_{y 4}, \phi_{y 2}, \phi_{y 4}\right)^{(2)}\right|_{x=-c}=0$

and:

$\left.\left(M_{x 1}+M_{x 2}, M_{x 3}+M_{x 4}, L_{x 2}, L_{x 4}, N_{x 1}+N_{x 2}+N_{x 3}+N_{x 4}\right)^{(2)}\right|_{x=-c}=0$ 


\section{Continuity conditions between regions (1) and (2)}

The conditions between regions (1) and (2) (refer to Fig. 3a) involves the continuity of the displacement parameters and stress resultants. In the sequel, these conditions are discussed separately.

\subsection{Continuity of stress resultants}

To define the continuity conditions the equivalent stress resultants can be defined based on the equilibrium equations (Eqs. (28) and (29)) and (31) and the vectors given by Eqs. (25) and (26):

$$
\begin{aligned}
\widehat{\mathbf{M}}_{12}^{(x, x y)(1)}= & \sum_{j=1,2}\left(\left(K_{j 1}^{(0)}+K_{j 2}^{(0)}\right) \mathbf{N}_{j}^{(x, x y)}+\left(K_{j 1}^{(1)}+K_{j 2}^{(1)}\right) \mathbf{M}_{j}^{(x, x y)}\right. \\
& \left.+\left(K_{j 1}^{(2)}+K_{j 2}^{(2)}\right) \mathbf{L}_{j}^{(x, x y)}+\left(K_{j 1}^{(3)}+K_{j 2}^{(3)}\right) \mathbf{P}_{j}^{(x, x y)}\right)^{(1)}
\end{aligned}
$$

$$
\begin{aligned}
\widehat{\mathbf{M}}_{34}^{(x, x y)(1)}= & \sum_{j=3,4}\left(\left(K_{j 1}^{(0)}+K_{j 2}^{(0)}\right) \mathbf{N}_{j}^{(x, x y)}+\left(K_{j 1}^{(1)}+K_{j 2}^{(1)}\right) \mathbf{M}_{j}^{(x, x y)}\right. \\
& \left.+\left(K_{j 1}^{(2)}+K_{j 2}^{(2)}\right) \mathbf{L}_{j}^{(x, x y)}+\left(K_{j 1}^{(3)}+K_{j 2}^{(3)}\right) \mathbf{P}_{j}^{(x, x y)}\right)^{(1)}
\end{aligned}
$$

$$
\begin{aligned}
\widehat{\mathbf{L}}_{1234}^{(x, x y)(1)}= & \sum_{j=1 . .4}\left(K_{j 3}^{(0)} \mathbf{N}_{j}^{(x, x y)}+K_{j 3}^{(1)} \mathbf{M}_{j}^{(x, x y)(1)}+K_{j 3}^{(2)} \mathbf{L}_{j}^{(x, x y)}\right. \\
& \left.+K_{j 3}^{(3)} \mathbf{P}_{j}^{(x, x y)}\right)^{(1)}
\end{aligned}
$$

for the delaminated portion (1), where $\widehat{\mathbf{M}}_{12}$ and $\widehat{\mathbf{M}}_{34}$ are the vectors of equivalent bending/twisting moments, $\widehat{\mathbf{L}}_{1234}$ is the vector of equivalent higher-order stress resultants. Moreover, for the undelaminated region (2) we have:

$$
\begin{aligned}
\widehat{\mathbf{M}}_{12}^{(x, x y)(2)}= & \sum_{j=1,2}\left(\left(K_{j 1}^{(0)}+K_{j 3}^{(0)}\right) \mathbf{N}_{j}^{(x, x y)}+\left(K_{j 1}^{(1)}+K_{j 3}^{(1)}\right) \mathbf{M}_{j}^{(x, x y)}\right. \\
& \left.+\left(K_{j 1}^{(2)}+K_{j 3}^{(2)}\right) \mathbf{L}_{j}^{(x, x y)}+\left(K_{j 1}^{(3)}+K_{j 3}^{(3)}\right) \mathbf{P}_{j}^{(x, x y)}\right)^{(2)} \\
\widehat{\mathbf{M}}_{34}^{(x, x y)(2)}= & \sum_{j=3,4}\left(\left(K_{j 1}^{(0)}+K_{j 3}^{(0)}\right) \mathbf{N}_{j}^{(x, x y)}+\left(K_{j 1}^{(1)}+K_{j 3}^{(1)}\right) \mathbf{M}_{j}^{(x, x y)}\right. \\
& \left.+\left(K_{j 1}^{(2)}+K_{j 3}^{(2)}\right) \mathbf{L}_{j}^{(x, x y)}+\left(K_{j 1}^{(3)}+K_{j 3}^{(3)}\right) \mathbf{P}_{j}^{(x, x y)}\right)^{(2)} \\
\widehat{\mathbf{L}}_{12}^{(x, x y)(2)}= & \sum_{j=1,2}\left(\left(K_{j 2}^{(0)}+K_{j 4}^{(0)}\right) \mathbf{N}_{j}^{(x, x y)}+\left(K_{j 2}^{(1)}+K_{j 4}^{(1)}\right) \mathbf{M}_{j}^{(x, x y)}\right. \\
& \left.+\left(K_{j 2}^{(2)}+K_{j 4}^{(2)}\right) \mathbf{L}_{j}^{(x, x y)}+\left(K_{j 2}^{(3)}+K_{j 4}^{(3)}\right) \mathbf{P}_{j}^{(x, x y)}\right)^{(2)} \\
& \left.+\left(K_{j 2}^{(2)}+K_{j 4}^{(2)}\right) \mathbf{L}_{j}^{(x, x y)}+\left(K_{j 2}^{(3)}+K_{j 4}^{(3)}\right) \mathbf{P}_{j}^{(x, x y)}\right)^{(2)} \\
\widehat{\mathbf{L}}_{34}^{(x, x y)(2)}= & \sum_{j=3,4}\left(\left(K_{j 2}^{(0)}+K_{j 4}^{(0)}\right) \mathbf{N}_{j}^{(x, x y)}+\left(K_{j 2}^{(1)}+K_{j 4}^{(1)}\right) \mathbf{M}_{j}^{(x, x y)}\right.
\end{aligned}
$$

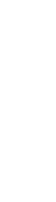

(

The continuity conditions using the equivalent stress resultants are:

$$
\begin{aligned}
& \left.\left(\widehat{\mathbf{M}}_{12}^{(x, x y)}, \widehat{\mathbf{M}}_{34}^{(x, x y)}, \widehat{\mathbf{L}}_{1234}^{(x, x y)}, \sum_{i=1 . .4} \mathbf{N}_{i}^{(x, x y)}\right)\right|_{x=-0} ^{(1)} \\
& =\left.\left(\widehat{\mathbf{M}}_{12}^{(x, x y)}, \widehat{\mathbf{M}}_{34}^{(x, x y)}, \widehat{\mathbf{L}}_{12}^{(x, x y)}+\widehat{\mathbf{L}}_{34}^{(x, x y)}, \sum_{i=1 . .4} \mathbf{N}_{i}^{(x, x y)}\right)\right|_{x=+0} ^{(2)}
\end{aligned}
$$

\subsection{Continuity of displacement parameters}

In the case of the general TSDT the continuity of the in-plane displacement is ensured only if the constant, linear, quadratic and cubic terms are exactly the same in the delamination front $(x=0)$. Because of the parameter elimination based on the SEKC it is not possible to match directly the constant, quadratic and cubic terms in the displacement function from layer by layer. Only the continuity of primary parameters can be defined between each ESL. In spite of that the continuity of the remaining membrane, linear, quadratic and cubic terms can be ensured indirectly (automatically) if certain conditions are met. The requirements of automatic continuity is formulated in the form of a theorem. We define the following set of parameters:

$g_{\alpha}=\left(w_{n}, w_{n}^{\prime}, \theta_{x 2}, \theta_{y 2}, \theta_{x 4}, \theta_{y 4}, \phi_{x 4}, \phi_{y 4}\right)$

which contains the deflection, slope and the mutual primary parameters. The total continuity of the displacement functions involves the following necessary conditions:

$\left.g_{\alpha}^{(1)}\right|_{x=+0}=\left.g_{\alpha}^{(2)}\right|_{x=-0}$

However these are not sufficient. The sufficient conditions are presented through a theorem.

\subsubsection{The theorem of autocontinuity (AC theorem)}

Theorem: If the displacement field in the form of Eq. (14) in a laminated plate with delamination is developed by using the SEKC requirements and $N_{d} \in \mathbb{N}$ and $N_{u d} \in \mathbb{N}$ are the numbers of eliminated parameters in the delaminated and undelaminated parts, respectively, and $N_{d} \neq N_{u d}$, then the total continuity of the first-, secondand third-order terms in the in-plane displacement functions of each ESL in the delaminated and undelaminated plate parts - apart from those imposed by Eq. (48) (mutual primary parameters) - can be ensured by imposing the continuity of $\left|N_{d}-N_{u d}\right| \in \mathbb{N}$ number of parameters. These parameters are the autocontinuity (or simply $A C$ ) parameters, which are at the same time primary parameters too. The autocontinuity is satisfied only if along interfaces $1-2$ and 3-4 and at the plate boundaries (Figs. 1 and 2) the same conditions are imposed in the delaminated and undelaminated portions. Along the delamination plane (interface 2-3) different conditions can be applied. Fig. 4a shows the case when the autocontinuity between the delaminated and undelaminated parts is satisfied, Fig. 4b indicates a case when dissimilar conditions are imposed at interface 1-2 leading to discontinuous displacement field in the bottom plates.

Proof: In the case of the TSDT model $N_{d}=26, N_{u d}=24$ (refer to Sections 4.1.1 and 4.2.1), thus the number of AC parameters is $\left|N_{d}-N_{u d}\right|=2$. The AC parameters can be assigned based on the vector of primary parameters: the comparison of the $\psi_{(p)}$ vectors in Sections 4.1.1 and 4.2.1 reveals that the AC parameters are $\phi_{x 2}$ and $\phi_{y 2}$ in the undelaminated region (2). The comparison of the displacement field (Eq. (14)) for the undelaminated and delaminated regions (Appendix A) reveals the following sufficient conditions: 


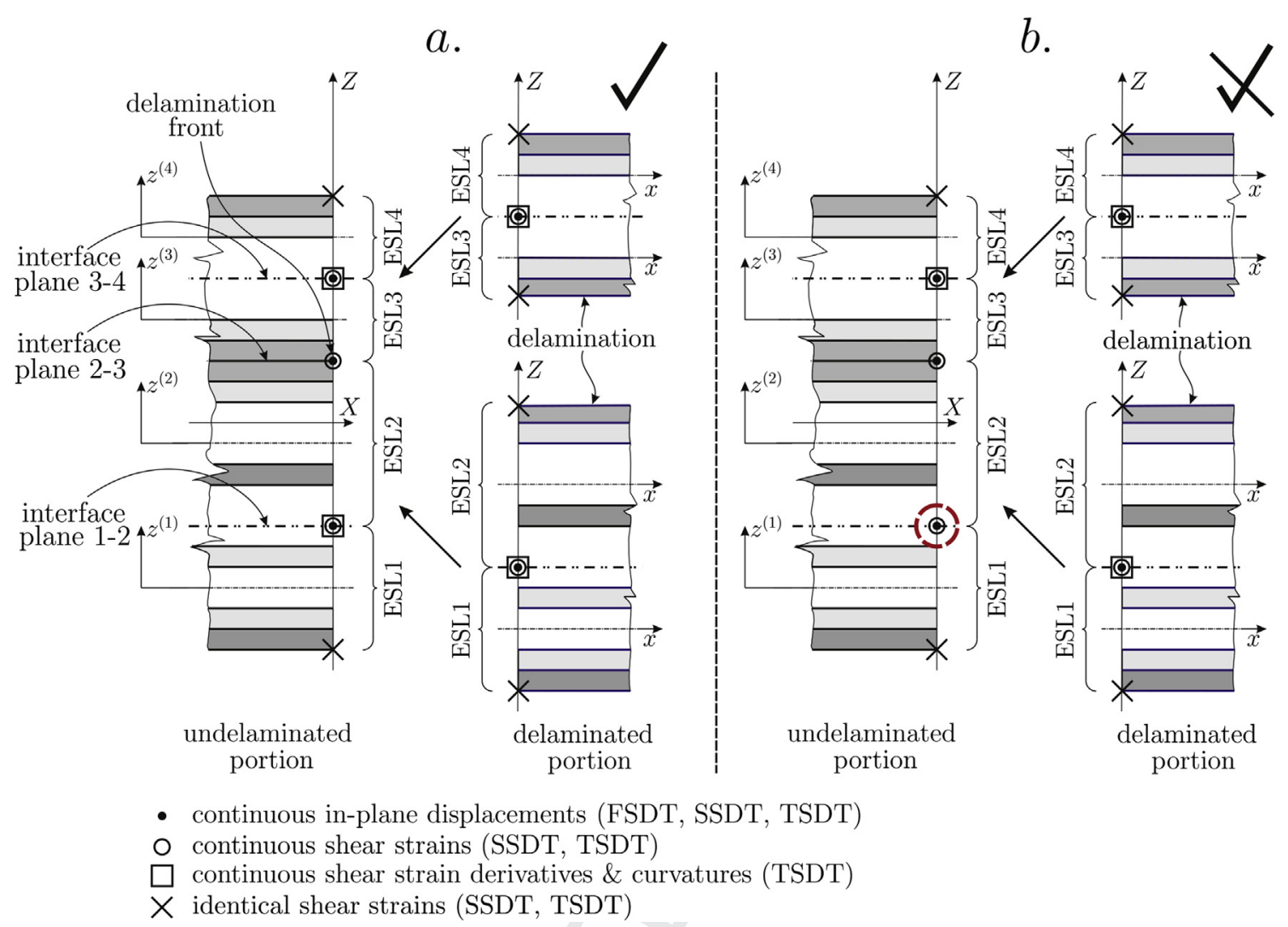

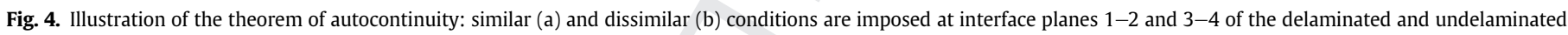
parts.

$\left.\phi_{p 2}\right|_{x=-0} ^{(2)}=\left.\sum_{j=1 . .3} K_{2 j}^{(2)} \psi_{(p) j}\right|_{x=+0} ^{(1)}, \quad p=x, y$

The former conditions ensure the total continuity of the displacement functions, i.e., the linear, quadratic and cubic terms in the displacement fields of regions (1) and (2) at $x=0$ (Fig. 3a) will be continuous apart from those imposed by Eq. (49). Considering the fact that the parameters in $g_{\beta}$ are continuous between regions (1) and (2) and by using the matrix elements given in Appendix A (TSDT) it is possible to have the following expression for $\phi_{p 2}$ at $x=-0$ :

$\left.\phi_{p 2}\right|_{x=-0} ^{(2)}=\left.t_{1}\left(\frac{2 t_{3}\left(\theta_{p 4}-\theta_{p 2}\right)+\phi_{p 4} t_{4}\left(2 t_{3}+t_{4}\right)}{\left(2 t_{1}+t_{2}\right) t_{2} t_{3}}\right)\right|_{x=+0} ^{(1)}$

Taking the former condition back into the displacement functions given by Eq. (14) of each ESL of the delaminated part (1) yields the following at $x=+0$ :

$$
\begin{aligned}
\left.\sum_{j=1 . .3}\left(K_{1 j}^{(1)} \psi_{(p) j}\right)\right|_{x=+0} ^{(1)}= & \left(\frac { 1 } { t _ { 2 } ( 2 t _ { 1 } + t _ { 2 } ) } \left[t_{1}\left(2 t_{1}+t_{2}\right) \theta_{p 2}-\left(t_{1}-t_{2}\right)\right.\right. \\
& \times\left(t_{1}+t_{2}\right) \theta_{p 4}-\frac{t_{4}}{2 t_{3}}\left(t_{1}-t_{2}\right)\left(t_{1}+t_{2}\right) \\
& \left.\left.\times\left(2 t_{3}+t_{4}\right) \phi_{p 4}\right]\right)\left.\right|_{x=+0} ^{(1)}
\end{aligned}
$$

$\left.\sum_{j=1.3}\left(K_{3 j}^{(1)} \psi_{(p) j}\right)\right|_{x=+0} ^{(1)}=-\frac{1}{2} \phi_{p 4} \frac{t_{3}^{2}-t_{4}^{2}}{t_{3}}-\left.\theta_{p 4}\right|_{x=+0} ^{(1)}$

$$
\left.\sum_{j=1 . .3}\left(K_{1 j}^{(2)} \psi_{(p) j}\right)\right|_{x=+0} ^{(1)}=\frac{-2\left(\theta_{p 2}+\theta_{p 4}\right)}{\left(2 t_{1}+t_{2}\right)}-\left.\frac{2 t_{4}\left(t_{3}+t_{4}\right)}{t_{3}\left(2 t_{1}+t_{2}\right)} \phi_{p 4}\right|_{x=+0} ^{(1)}
$$

$$
\left.\sum_{j=1.3}\left(K_{3 j}^{(2)} \psi(p) j\right)\right|_{x=+0} ^{(1)}=-\left.\frac{t_{4}}{t_{3}} \phi_{p 4}\right|_{x=+0} ^{(1)}
$$

$$
\begin{aligned}
\left.\sum_{j=1.3}\left(K_{1 j}^{(3)} \psi_{(p) j}\right)\right|_{x=+0} ^{(1)}= & \left.\sum_{j=1 . .3}\left(K_{2 j}^{(3)} \psi_{(p) j}\right)\right|_{x=+0} ^{(1)} \\
= & \frac{-4\left(\theta_{p 2}-\theta_{p 4}\right)}{3\left(2 t_{1}+t_{2}\right)} \\
& +\left.\frac{2}{3} \frac{t_{4}\left(2 t_{3}+t_{4}\right)}{t_{2} t_{3}\left(2 t_{1}+t_{2}\right)} \phi_{p 4}\right|_{x=+0} ^{(1)} \\
\left.\sum_{j=1.3}\left(K_{3 j}^{(3)} \psi_{(p) j}\right)\right|_{x=+0} ^{(1)}= & \left.\sum_{j=1.3}\left(K_{4 j}^{(3)} \psi_{(p) j}\right)\right|_{x=+0} ^{(1)}=\left.\frac{2}{3 t_{3}} \phi_{p 4}\right|_{x=+0} ^{(1)}
\end{aligned}
$$

At the same time, by taking back Eq. (51) into the displacement functions of every ESLs of the undelaminated part (2) defined by Eq. (14) we have at $x=-0$ : 


$$
\begin{aligned}
\left.\sum_{j=1 . .4}\left(K_{1 j}^{(1)} \psi_{(p) j}\right)\right|_{x=-0} ^{(2)}= & \left(\frac { 1 } { t _ { 2 } ( 2 t _ { 1 } + t _ { 2 } ) } \left[t_{1}\left(2 t_{1}+t_{2}\right) \theta_{p 2}-\left(t_{1}-t_{2}\right)\right.\right. \\
& \times\left(t_{1}+t_{2}\right) \theta_{p 4}-\frac{t_{4}}{2 t_{3}}\left(t_{1}-t_{2}\right)\left(t_{1}+t_{2}\right) \\
& \left.\left.\times\left(2 t_{3}+t_{4}\right) \phi_{p 4}\right]\right)\left.\right|_{x=-0} ^{(2)}
\end{aligned}
$$$$
\left.\sum_{j=1 . .4}\left(K_{3 j}^{(1)} \psi_{(p) j}\right)\right|_{x=-0} ^{(2)}=-\frac{1}{2} \phi_{p 4} \frac{t_{3}^{2}-t_{4}^{2}}{t_{3}}-\left.\theta_{p 4}\right|_{x=-0} ^{(2)}
$$$$
\left.\sum_{j=1 . .4}\left(K_{1 j}^{(2)} \psi_{(p) j}\right)\right|_{x=-0} ^{(2)}=\frac{-2\left(\theta_{p 2}+\theta_{p 4}\right)}{\left(2 t_{1}+t_{2}\right)}-\left.\frac{2 t_{4}\left(t_{3}+t_{4}\right)}{t_{3}\left(2 t_{1}+t_{2}\right)} \phi_{p 4}\right|_{x=-0} ^{(2)}
$$

$\left.\sum_{j=1 . .4}\left(K_{3 j}^{(2)} \psi_{(p) j}\right)\right|_{x=-0} ^{(2)}=-\left.\frac{t_{4}}{t_{3}} \phi_{p 4}\right|_{x=-0} ^{(2)}$

$$
\begin{aligned}
\left.\sum_{j=1 . .4}\left(K_{1 j}^{(3)} \psi_{(p) j}\right)\right|_{x=-0} ^{(2)}= & \left.\sum_{j=1 . .3}\left(K_{2 j}^{(3)} \psi_{(p) j}^{*}\right)\right|_{x=-0} ^{(2)} \\
= & \frac{-4\left(\theta_{p 2}-\theta_{p 4}\right)}{3\left(2 t_{1}+t_{2}\right)} \\
& +\left.\frac{2}{3} \frac{t_{4}\left(2 t_{3}+t_{4}\right)}{t_{2} t_{3}\left(2 t_{1}+t_{2}\right)} \phi_{p 4}\right|_{x=-0} ^{(2)}
\end{aligned}
$$

$\left.g_{\beta}^{(1 q)}\right|_{\chi=x_{0}+d_{0}}=\left.g_{\beta}^{(1 a)}\right|_{\chi=x_{0}+d_{0}},\left.g_{\gamma}^{(1 q)}\right|_{\chi=x_{0}+d_{0}}=\left.g_{\gamma}^{(1 a)}\right|_{X=x_{0}+d_{0}}$

The summary of the equations results in: Eqs. (36)-(39) mean 22 B.C.s, Eqs. (49), (51) and (63) yield 22 conditions between regions (1) and (2). Eqs. (66) and (67) provide $2 \times 22$ conditions. That means $22+22+22+22=88$ conditions altogether in the case of problem a in Fig. 3. Problem b in Fig. 3 can be solved similarly, therefore the details are not given. The B.C.s and the C.C.s for the SSDT model can be defined similarly, in these cases the constants $K_{i j}^{(3)}=0$ in Eq. (14) and in the stress resultants.

It has to be mentioned that although mathematically it is possible to impose traction-free conditions to the plate boundaries (similarly to Reddy theory), but this makes the model over-constrained. Over-constraining means, that mechanically the model becomes too stiff and the bad estimation of the stress field in the transition zone between (1) and (2) takes place. The reason for the bad description of the mechanical problem is that there are not enough conditions to impose the continuity of the primary parameters, the membrane displacements and the corresponding stress resultants. In this respect the models proposed in this paper are well-constrained models.

\section{J-integral}

The J-integral (Rice, 1968; Cherepanov, 1997) for SSDT and TSDT has already been derived for plates with symmetric (Szekrényes, 2013a, 2014e, 2014a, 2014c) and asymmetric (Szekrényes, 2013b, 2014d, 2014b) lay-up. Therefore, in this work the details are not discussed. The mode-II and mode-III J-integrals $\left(J_{I I}=G_{I I}, J_{I I I}=G_{I I I}\right)$ are given in Appendix C.

\section{Results and discussions}

To demonstrate the performance of the analytical models the examples shown in Fig. 3 are solved. The data of the problem depicted in Fig. 3a are: $a=105 \mathrm{~mm}$ (delamination length), $c=55 \mathrm{~mm}$ (undelaminated length), $b=160 \mathrm{~mm}$ (plate width), $t_{t}+t_{b}=4.5 \mathrm{~mm}$ (plate thickness), $Q_{0}=1000 \mathrm{~N}, x_{Q}=31 \mathrm{~mm}$, $y_{Q}=50 \mathrm{~mm}$ and $y_{Q}=80 \mathrm{~mm}$ (point of action coordinates of $Q_{0}$ ), $d_{0}=0.1 \mathrm{~mm}$. For the problem in Fig. $3 \mathrm{~b}$ the data are: $a=55 \mathrm{~mm}$ (delamination length), $c=35 \mathrm{~mm}$ (undelaminated length), $b=90 \mathrm{~mm}$ (plate width), $t_{t}+t_{b}=4.5 \mathrm{~mm}$ (plate thickness), $Q_{0}=10000 \mathrm{~N}, x_{Q}=11 \mathrm{~mm}, y_{Q}=30 \mathrm{~mm}$ and $y_{Q}=45 \mathrm{~mm}$ (point of action coordinates of $\left.Q_{0}\right), d_{0}=0.1 \mathrm{~mm}$. The problem was solved by replacing the concentrated load by distributed force on the distance $2 d_{0}$. The details can be found in (Szekrényes, 2014d). The material of the plates is carbon/epoxy. The lay-up of the plate is $\left[ \pm 45^{f} / 0 / \pm 45_{2}^{f} / \overline{0}\right]_{S}$, the material properties can be found in (Szekrényes, 2014d). Finite element models were also constructed

The autocontinuity theorem is also valid for
difference is that the $K_{i j}^{(3)}$ constants are zero. 
to validate the analytical results. The details of the FE models are presented in a recent paper (Szekrényes, 2014d). The delamination tip elements and the global mesh resolution were chosen in accordance with recommendations of the literature (Raju et al., 1988; Johnston et al., 2014; Mehrabadi, 2014) The position of the delamination was varied in the through thickness direction, these were assigned as cases I, II, III and IV (Szekrényes, 2014d). The problems are solved for some selected cases and different boundary conditions.

\subsection{Displacement and stress distributions}

In this section the solution of the problems in Fig. 3 are discussed including cases II and IV (refer to Szekrényes, 2013b, 2014d). The in-plane displacements and the normal stresses are evaluated at cross sections on the delamination front. Apart from the present 4ESL solutions a previously published 2ESL model based on Reddy third-order theory (Szekrényes, 2014d) is used to assess the performance of the shear strain controlled SSDT and TSDT. Fig. 5 shows the distributions of the in-plane displacements ( $u$ and $v$ ) and the normal stresses $\left(\sigma_{x}\right.$ and $\sigma_{y}$ ) for problem a in Fig. 3 in case II. In the case of the stresses the average of the values at $x=-0$ (undelaminated) and $x=+0$ (delaminated) part are calculated.

The three different solutions agree well in this case for $u, v$ and $\sigma_{y}$. Considering $\sigma_{x}$ the SSDT seems to agree very well with the FE solution, while Reddy theory and TSDT are a little bit worst. The shear stresses are plotted in Fig. 6. For $\tau_{x z}$ the three solutions are reasonable and approximate well the FE solution. On the contrary, $\tau_{y z}$ is badly estimated by the TSDT, at the same time the SSDT and Reddy theory are still good. Because of the fact that the SSDT solution is based on the triangle shape shear strain distribution, this is also called as "triangle" solution in the sequel.

Case IV is documented in Fig. 7. In the case of the in-plane displacement $u$, the TSDT indicates some oscillations in the top part of the plate. The curve obtained by Reddy theory shows a little bit higher slope than that of the FE solution. Apparently the strain controlled SSDT agrees the best with the FE results. These conclusions are equally true for the $v$ displacement and the normal stresses: the SSDT seems to be the most accurate solution.

The shear stress distributions evaluated over the thickness at the delamination front are shown in Fig. 8. It is surprising that the TSDT approximates badly the distribution of shear stresses, although it is also clear that in the plate theories the shear force is equivalent to the area under the distribution. In this respect the result is correct, but the control condition leads to too large oscillations in the shear stress. In contrast, the SSDT (piecewise linear shear strain approximation) approximates much better the set of points from FE analysis and the piecewise second-order distribution by Reddy theory for both components.
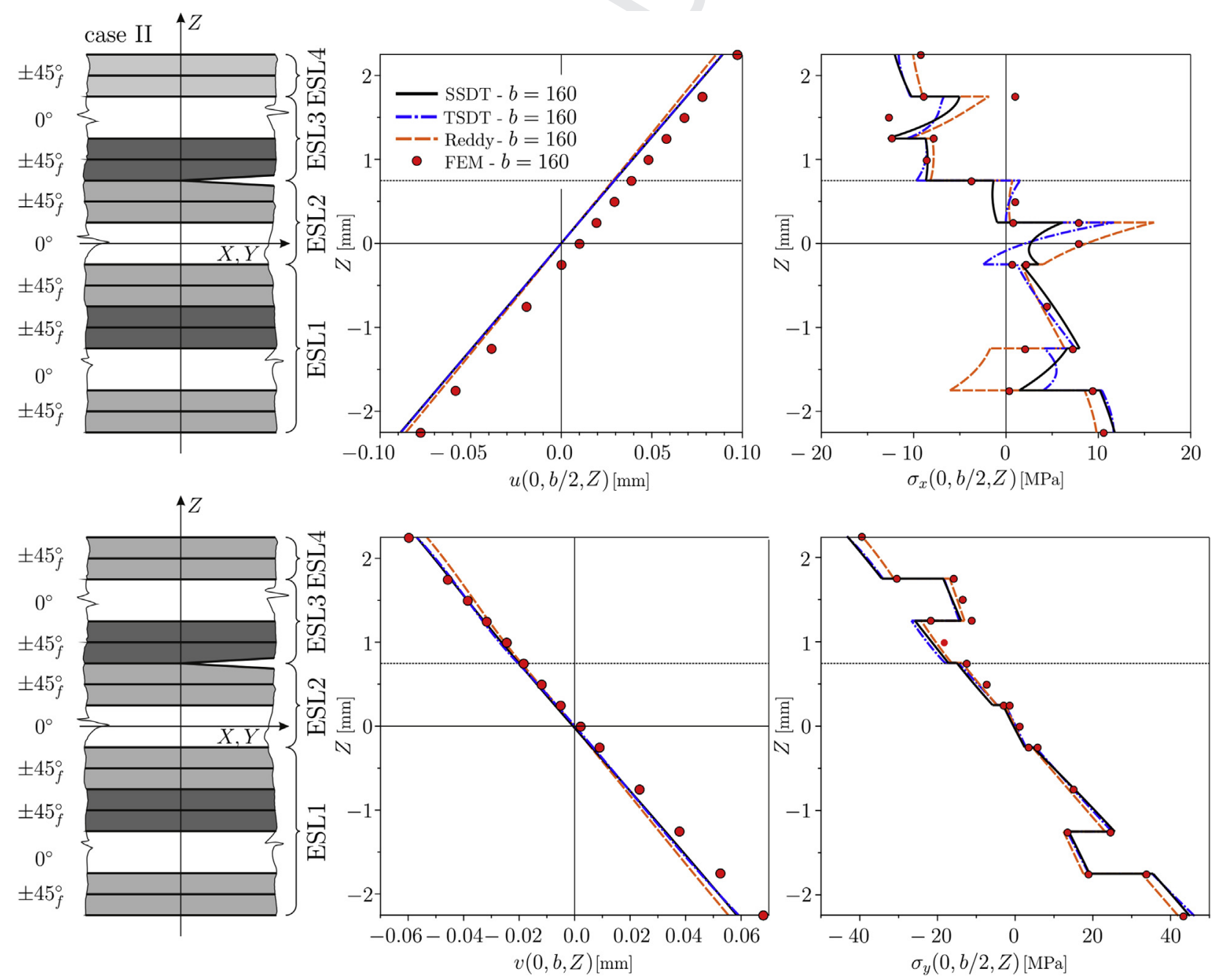

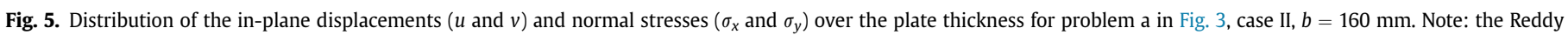
solution is available in (Szekrényes, 2014d). 

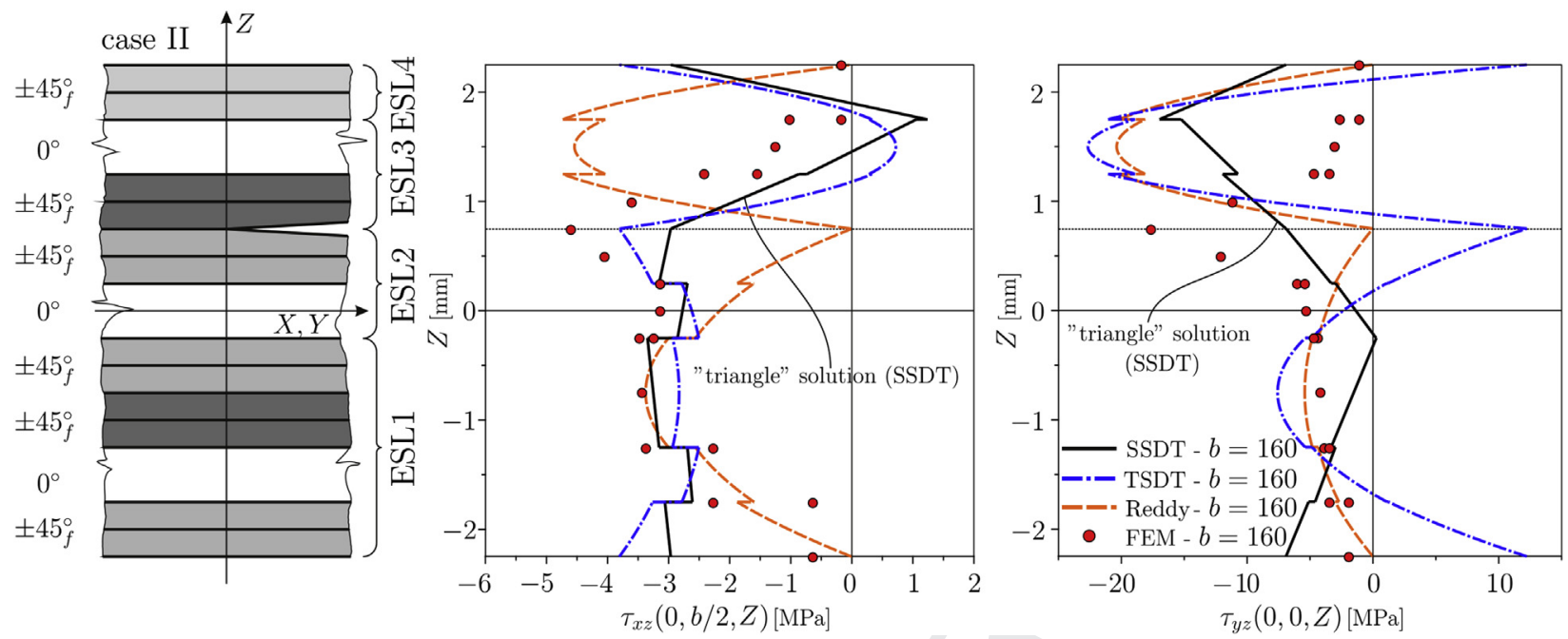

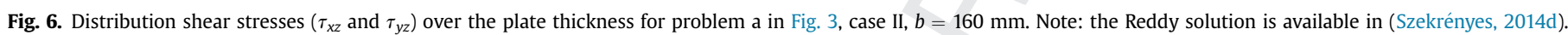
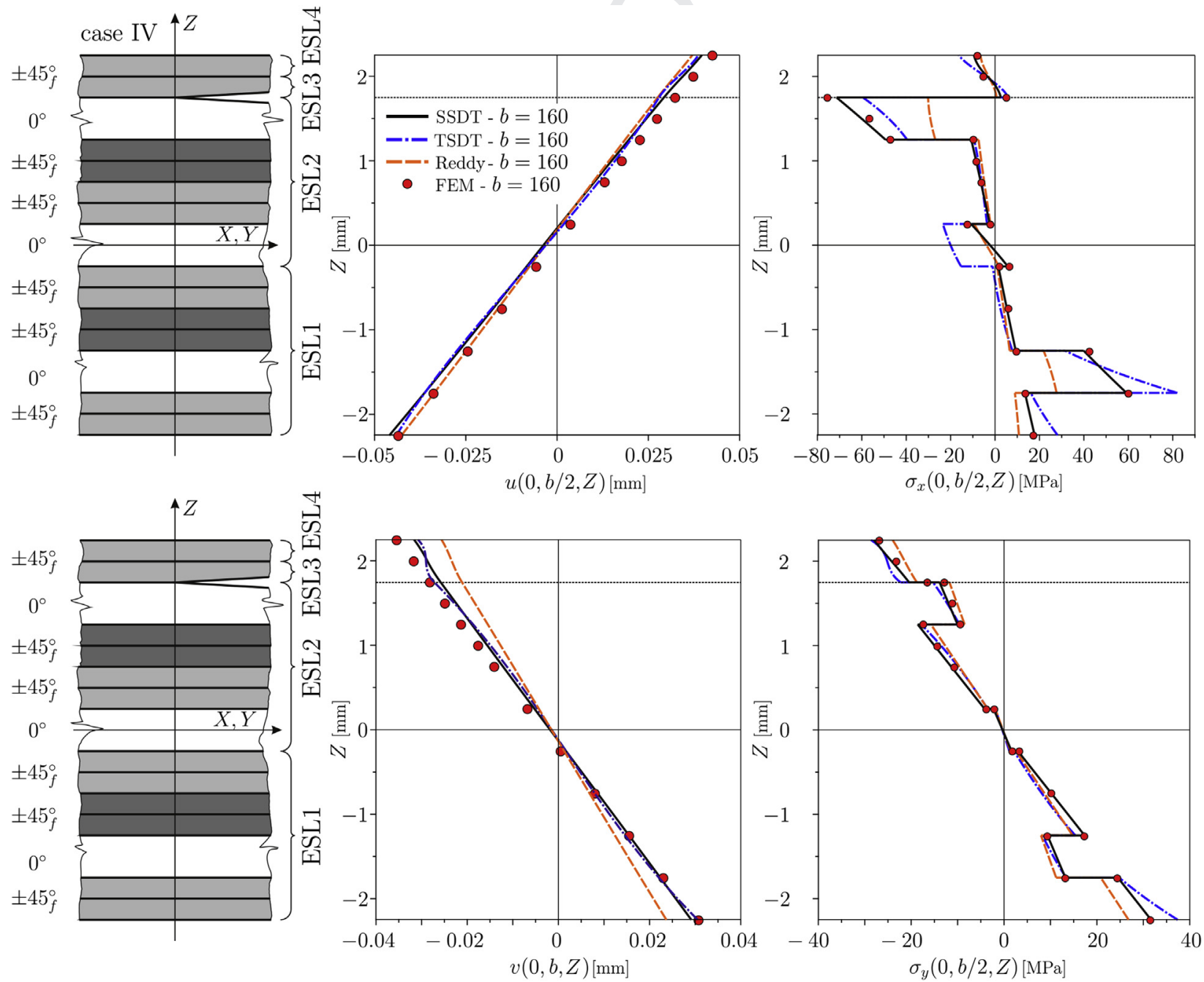

Fig. 7. Distribution of the in-plane displacements ( $u$ and $v$ ) and normal stresses ( $\sigma_{x}$ and $\sigma_{y}$ ) over the plate thickness for problem a in Fig. 3, case IV, $b=160 \mathrm{~mm}$. Note: the Reddy solution is available in (Szekrényes, 2014d). 

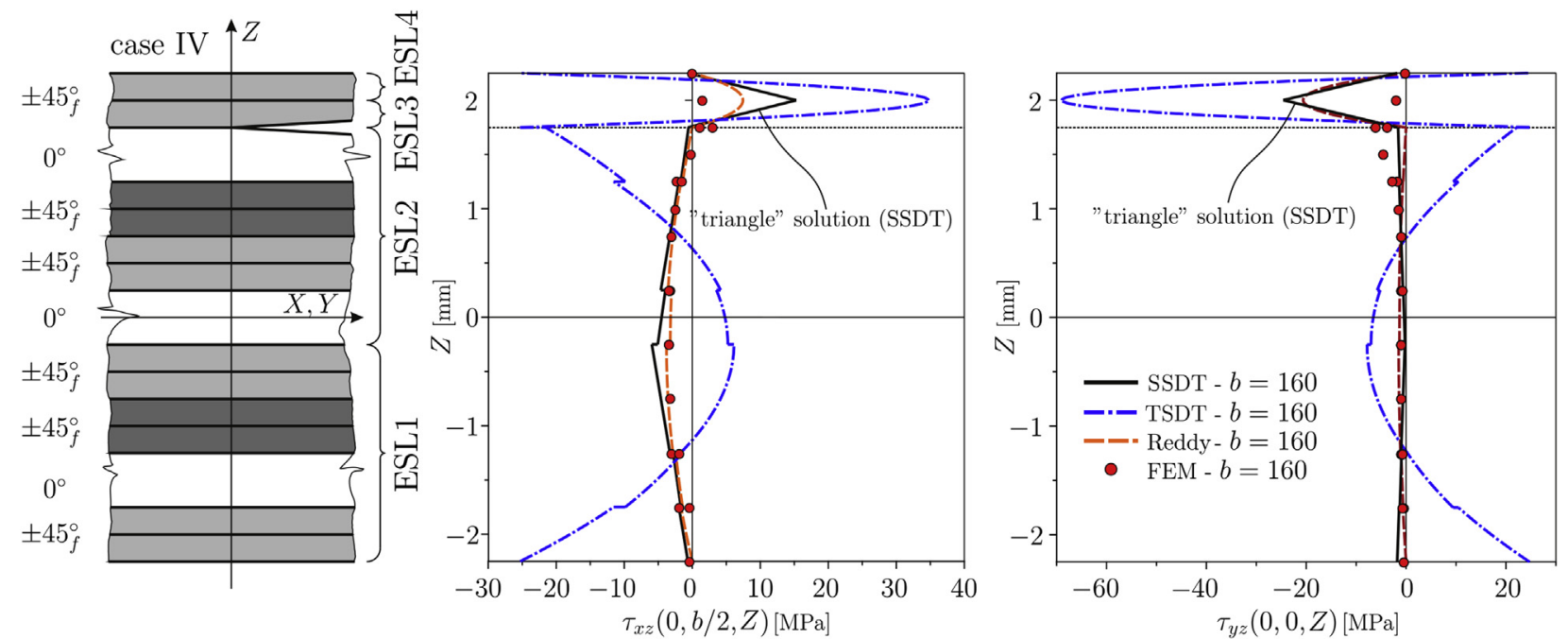

Fig. 8. Distribution shear stresses ( $\tau_{x z}$ and $\tau_{y z}$ ) over the plate thickness for problem a in Fig. 3, case IV, $b=160 \mathrm{~mm}$. Note: the Reddy solution is available in (Szekrényes, 2014d).
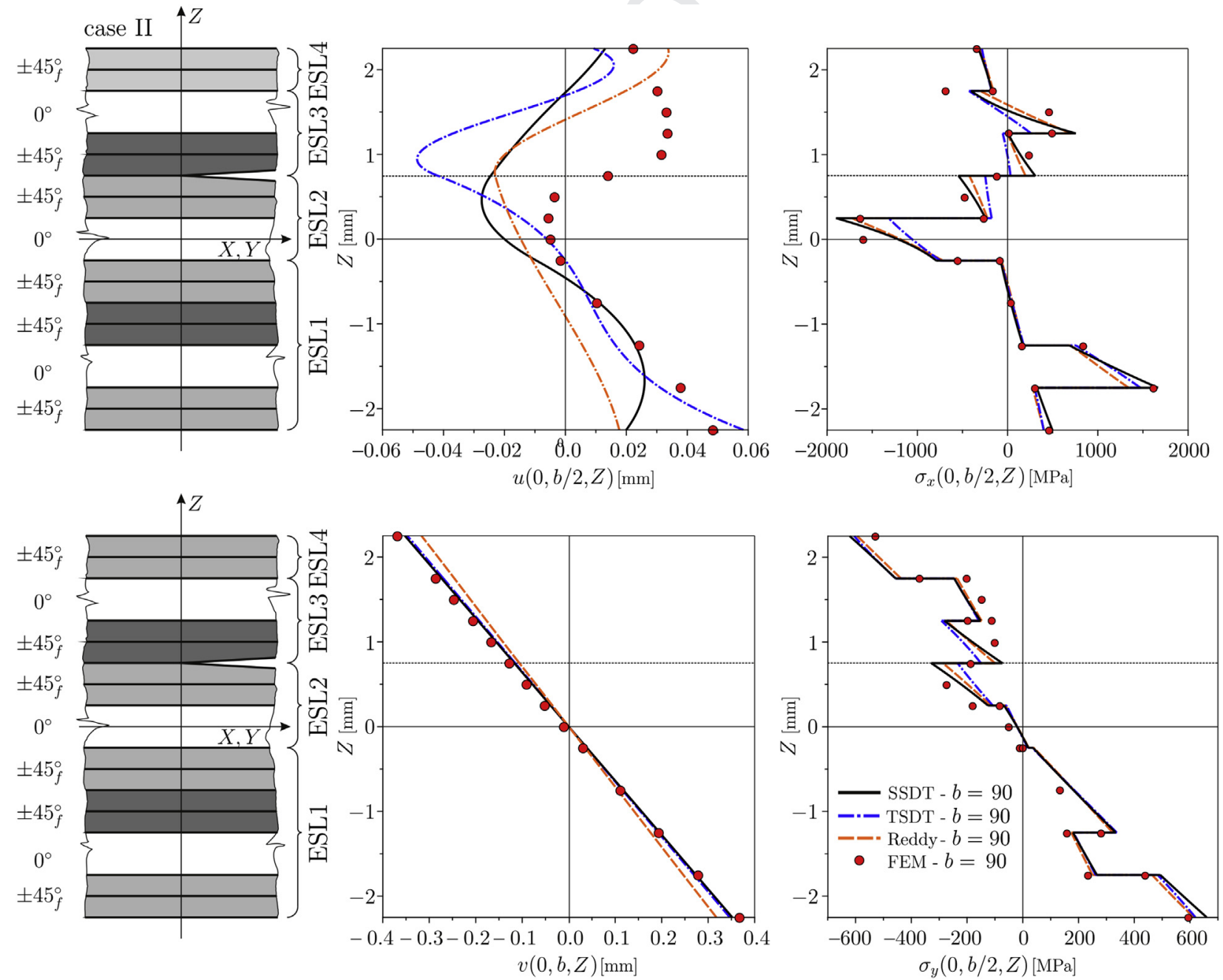

Fig. 9. Distribution of the in-plane displacements $(u$ and $v)$ and normal stresses $\left(\sigma_{x}\right.$ and $\left.\sigma_{y}\right)$ over the plate thickness for problem b in Fig. 3 , case II, $b=90 \mathrm{~mm}$. Note: the Reddy solution is available in (Szekrényes, 2014d). 

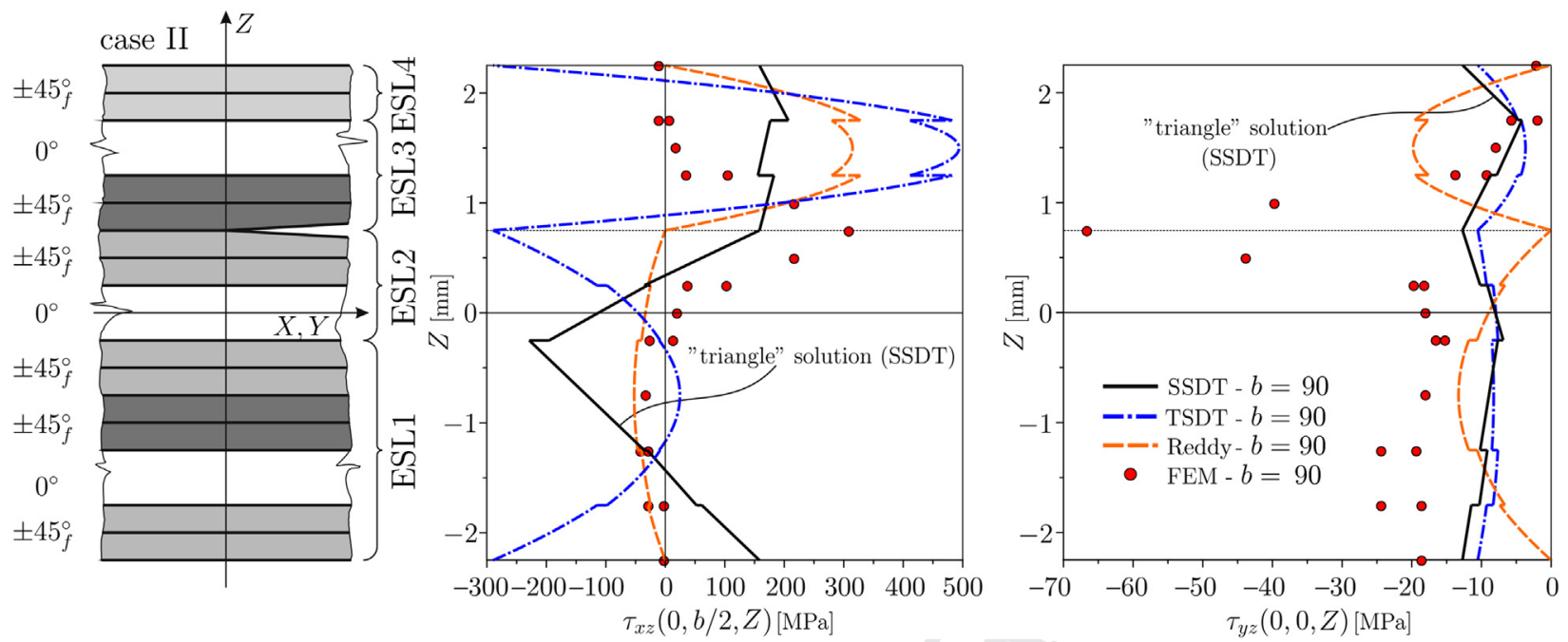

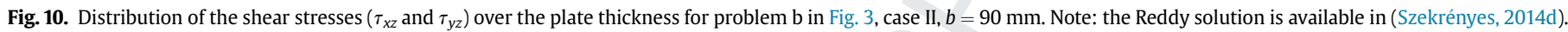

The results of problem b (Fig. 3b) are documented in Figs. 9-12. This example involves smaller plate dimensions and since the point of action of the force is closer to the delamination front, higher influence of the load on the fields is experienced. In case II (Fig. 9) it is apparent that the displacement component $u$ is perturbated more intensively than in problem a. The highest oscillations are provided by the TSDT, while the SSDT and Reddy theory give better agreement with the FE results. The stresses are approximated with
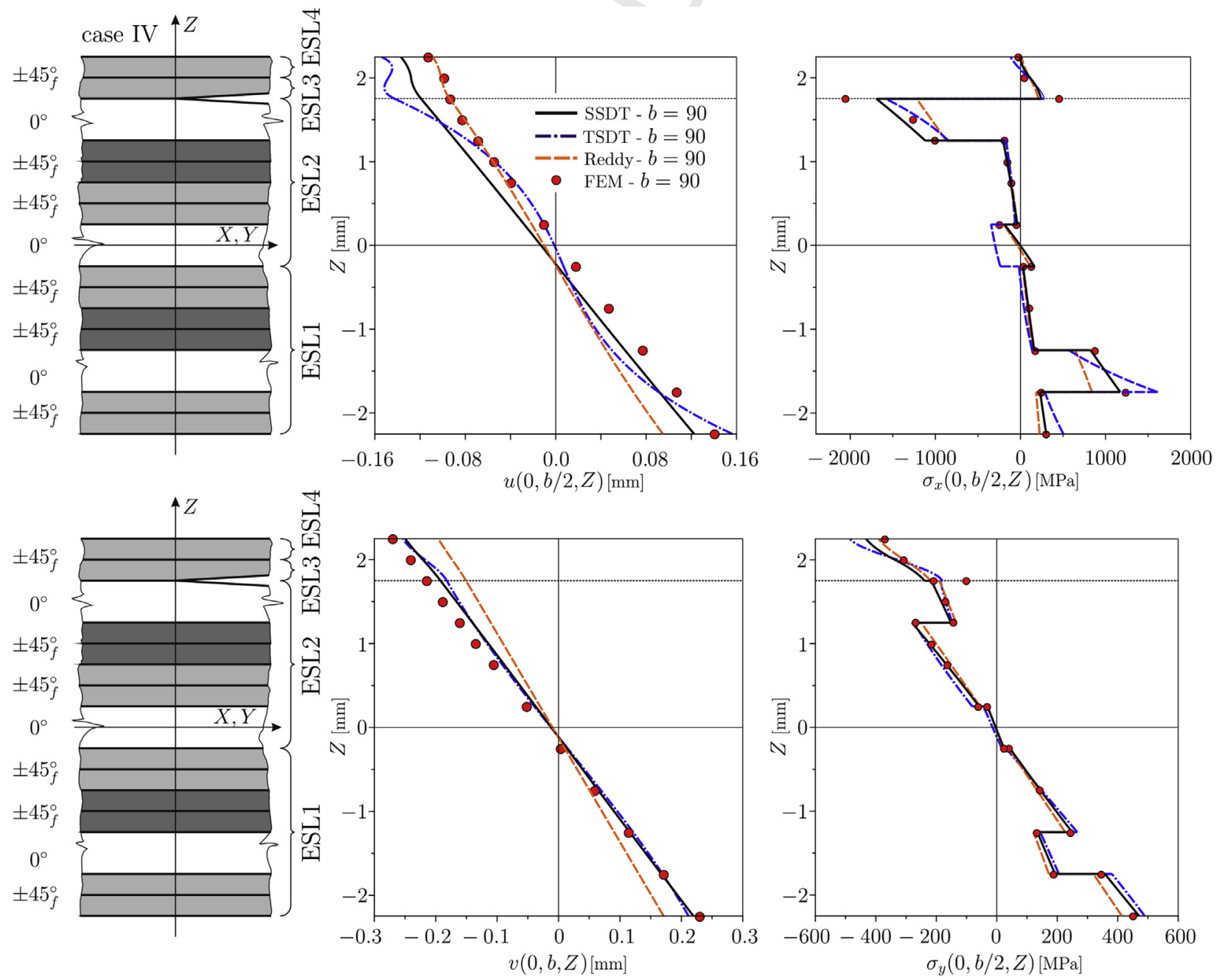

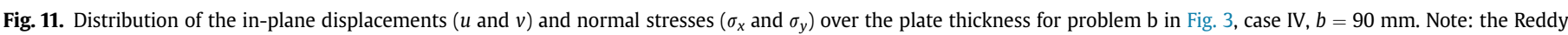
solution is available in (Szekrényes, 2014d). 

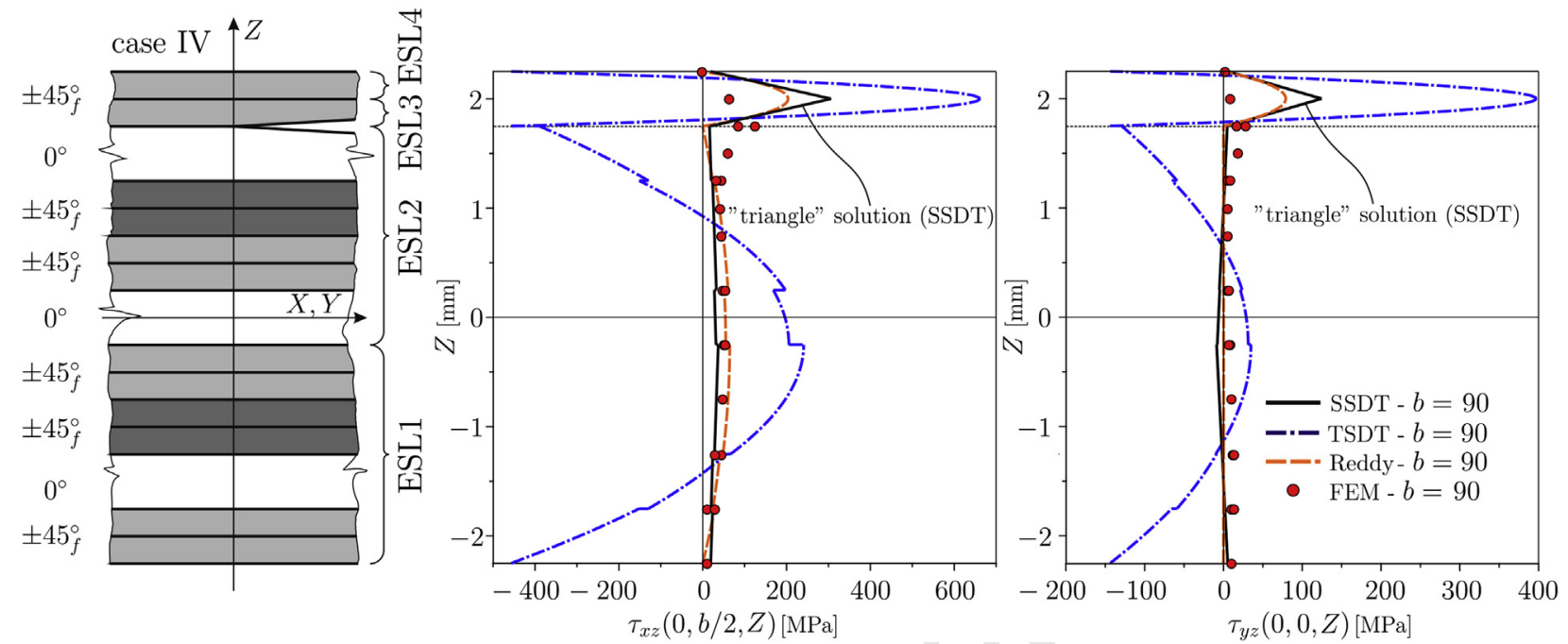

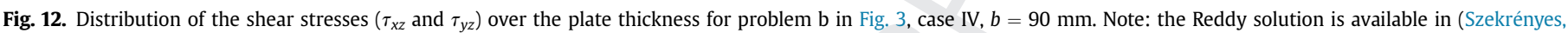
2014d).

similar accuracy by each theory. In Fig. 10 the shear stresses are plotted. The SSDT and Reddy theory is better again than the TSDT for $\tau_{x z}$. By each solution the shear stress $\tau_{y z}$ disagrees with the FE results.

Fig. 11 presents the results of case IV in problem b. Based on the comparison of analytical results to those by FE computations, for both the in-plane displacement components and the stresses the SSDT performs better than the strain controlled TSDT and Reddy theory (Fig. 11). A similar behavior of TSDT is observed in the shear stress distributions in Fig. 12 to that by Fig. 8. On the contrary the SSDT and Reddy theory lead to more correct results.

To further assess the accuracy of the different theories the shear stresses are also evaluated behind and ahead of the delamination front. In Fig. 13 problem a, case IV is evaluated in this respect showing that the shear strain controlled TSDT and SSDT theories approximate very well the FE distributions in both shear stress components, while the Reddy theory underestimates $\tau_{x z}$, but follows well $\tau_{y z}$ at the chosen locations. Fig. 14 demonstrates the shear stresses obtained from the solution of problem $b$ in Fig. 3 for case IV.
This time the difference between the three different solutions is very small and the agreement with the FE results is established. In Table 1 the displacements at the point of action of $Q_{0}$ are collected by SSDT, TSDT, Reddy theory and FE solution for case IV. While the SSDT and TSDT agree excellently with the FE results, the model based on Reddy theory seems to be too stiff in case IV. This can be explained by the imposition of traction-free boundaries. For the other cases similar behavior was experienced.

\section{J-integral and mode ratio}

The J-integral is equivalent to the ERR under quasi-static conditions and linear elastic material behavior. The solution of problem a is shown in Fig. 15 in case II. In fact each theory provides good results compared to the numerical solution of the ERRs and the mode ratio. The solution of case IV is plotted in Fig. 16. Reddy thirdorder theory approximates excellently the mode-III ERR (Fig. 16), however, the mode-II ERR and so the mode ratio differs significantly from the VCCT results. The TSDT solution is moderately
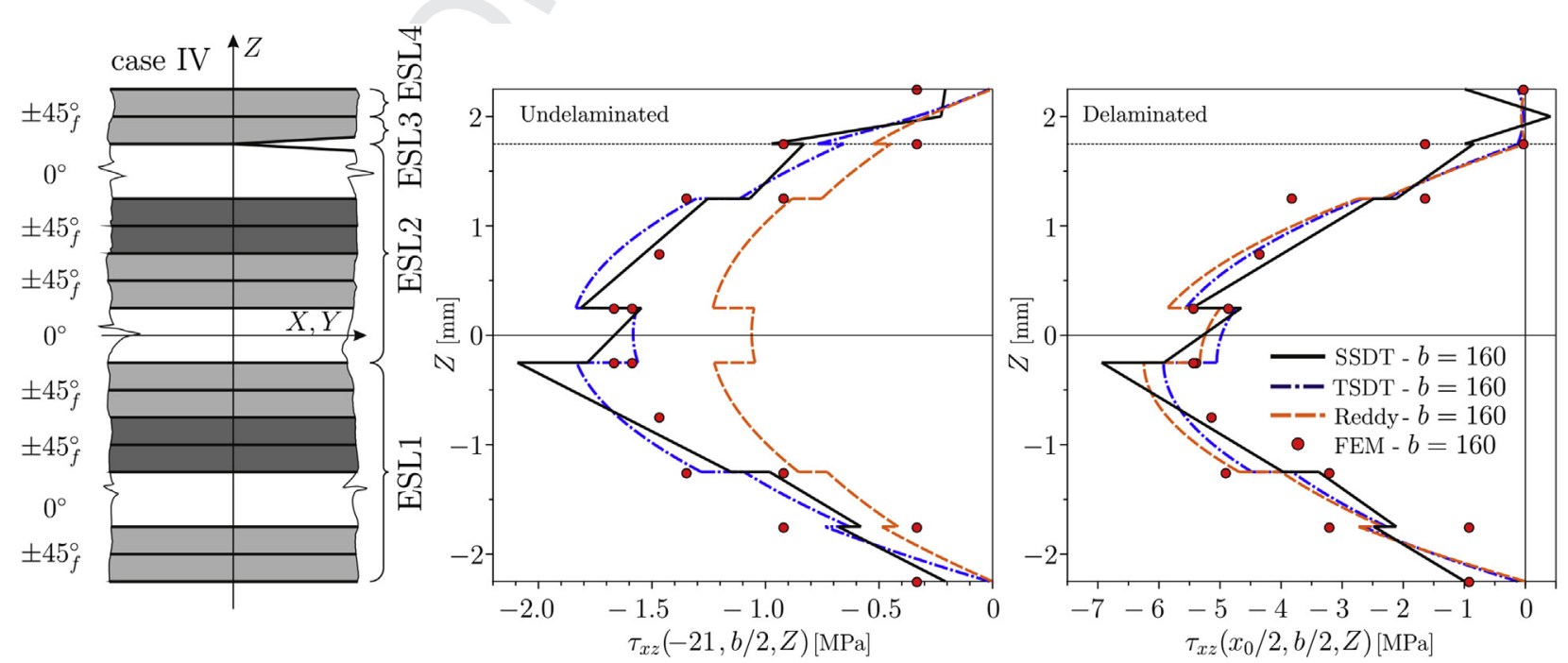

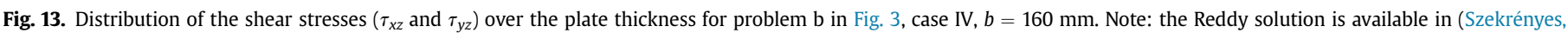
2014d). 

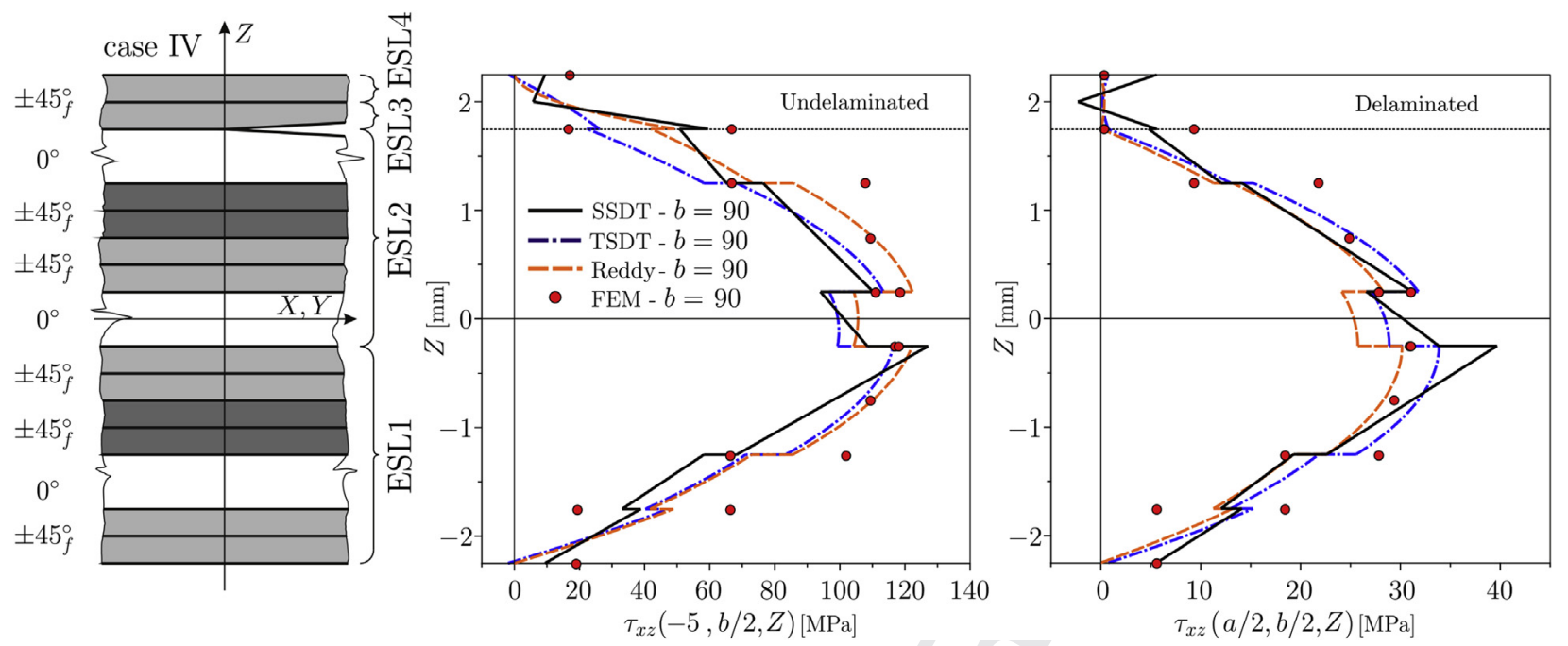

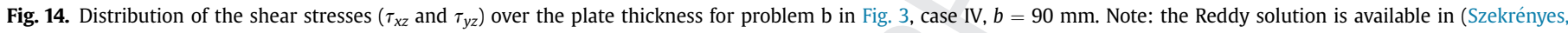
2014d).

Table 1

Comparison of the displacement at the point of action of $Q_{0}$ from the different theories for case IV.

\begin{tabular}{llllll}
\hline Deflection at $x=x_{0}$ & $b[\mathrm{~mm}]$ & SSDT & TSDT & Reddy & FEM \\
\hline$w_{0}[\mathrm{~mm}]$ & 160 (problem a) & -1.379 & -1.377 & -1.234 & -1.423 \\
$w_{0}[\mathrm{~mm}]$ & 90 (problem $\mathrm{b})$ & -4.519 & -4.519 & -3.768 & -4.699 \\
\hline
\end{tabular}

coarse for $G_{I I I}$ and extremely wrong for $G_{I I}$ in the middle of the plate $(y=60 \ldots 100 \mathrm{~mm})$. On the contrary, the triangle solution (SSDT) provides the best overall agreement with the VCCT results. In spite of that it has to be mentioned the in the middle part of the delamination ( $y=60 \ldots 100 \mathrm{~mm}$ ) a very small overprediction of the FE results is observed. The mode ratio is again accurately predicted by the controlled SSDT. For problem b, case II the results are plotted in Fig. 17. The Reddy theory is the best this time, however the SSDT is also good in the estimation. Problem b in case IV is documented in Fig. 18. As a summary, neither the presented theories is able to accurately follow the FE results, however the best choice is the SSDT among the models presented. Especially the overprediction of the mode II ERR by Reddy theory in problem a, case IV is highlighted. It should be noted that problem $b$ involves smaller plate dimensions and the stress concentration effect in the FE model is more significant in this case than in problem a. This could be one of the reasons for the bad agreement between FEM and analysis.

Some more examples were solved under different boundary conditions in Appendix D. Fig. D.20 depicts the ERR and mode ratio distributions for problem b, case I in Fig. 3 with simply supported edge at $x=-c$ and free edge at $x=a$ (SF). Apparently the three methods predict the same results in this case, with underprediction
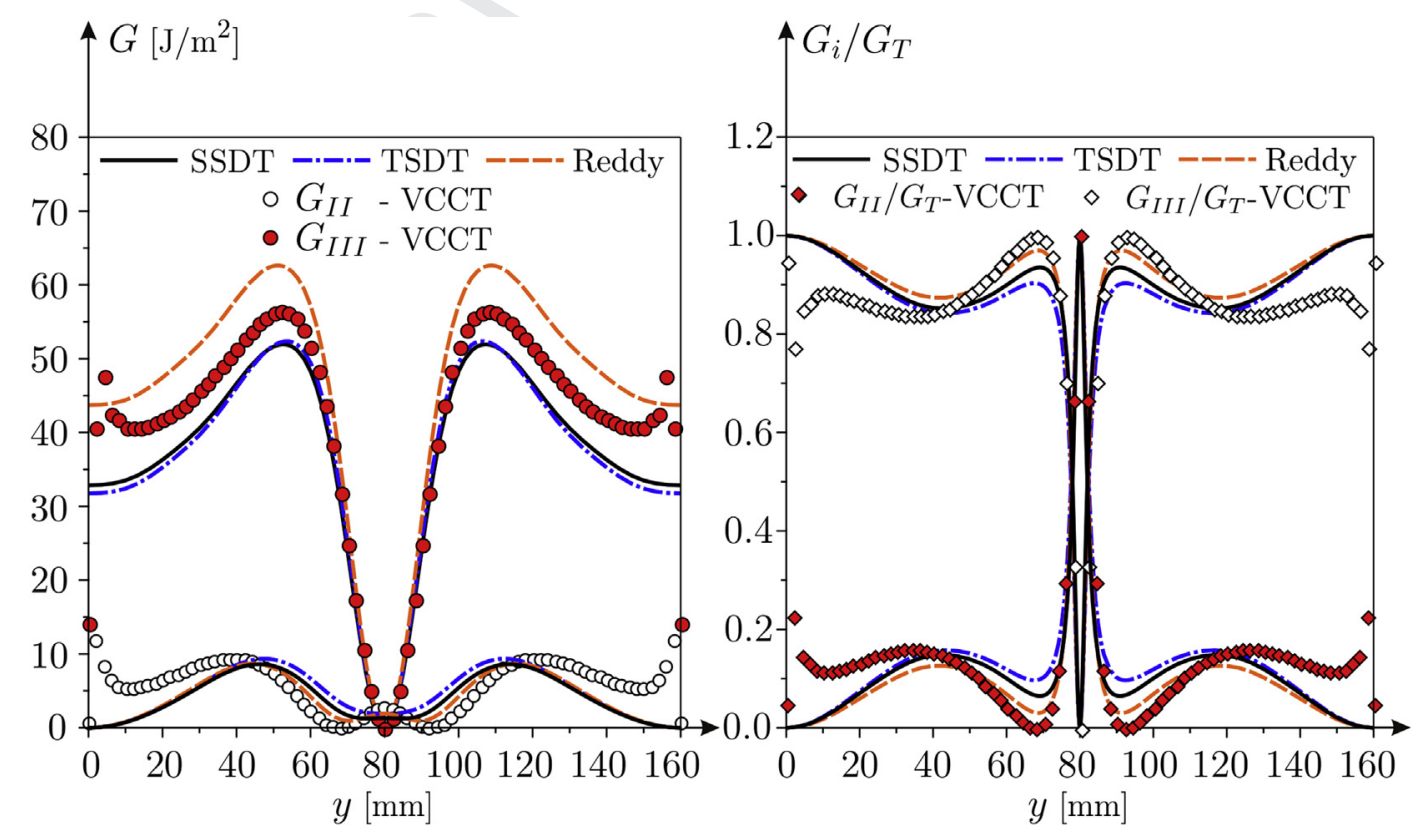

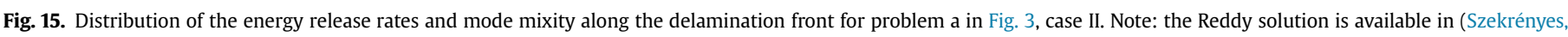
2014d). 

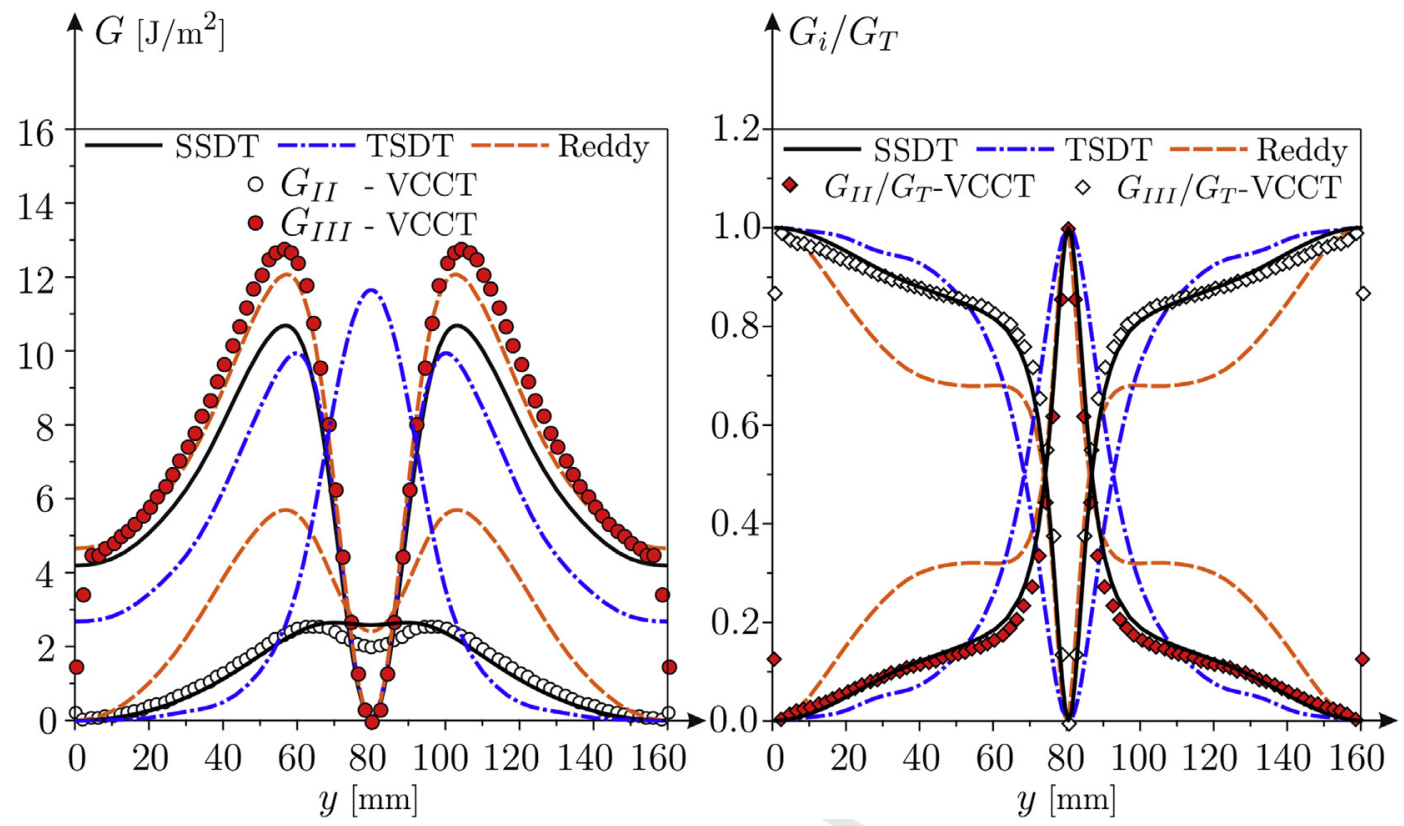

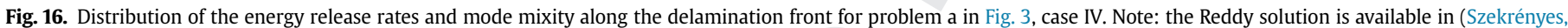
2014d).

of the mode-III component. In Fig. D.21 the same problem is solved in case III, which shows that Reddy theory is very good, the SSDT is acceptable, while the TSDT is the worst. In spite of that the mode ratios approximate reasonably the FE results. Fig. D.23 was created based on problem a in Fig. 3 with clamped-clamped (CC) conditions at $x=-c$ and $x=a$. Although in case II Reddy theory is the best again, in case IV plotted in Fig. D.24 it is the SSDT that provides the best overall performance. It should be mentioned that each solution provides negative mode-II ERR in the middle of the plate, however this is very moderate in the SSDT solution but significant for the other two ones.
To investigate the behavior of the system under crack propagation the normalized distributions of the ERRs by SSDT with different crack lengths are displayed in Fig. 19 for case IV and $b=100 \mathrm{~mm}$. Each edge was simply supported. The point of action of the force was in the middle of the plate for each crack length. The length of the plate was $a+c=150 \mathrm{~mm}$ in each model. It has to be mentioned that the crack propagation requires some experimental data, and the delamination front does not remain straight under crack propagation, which was assumed in these computations. Fig. 19 shows that the self-similarity (Anderson, 2005) condition is
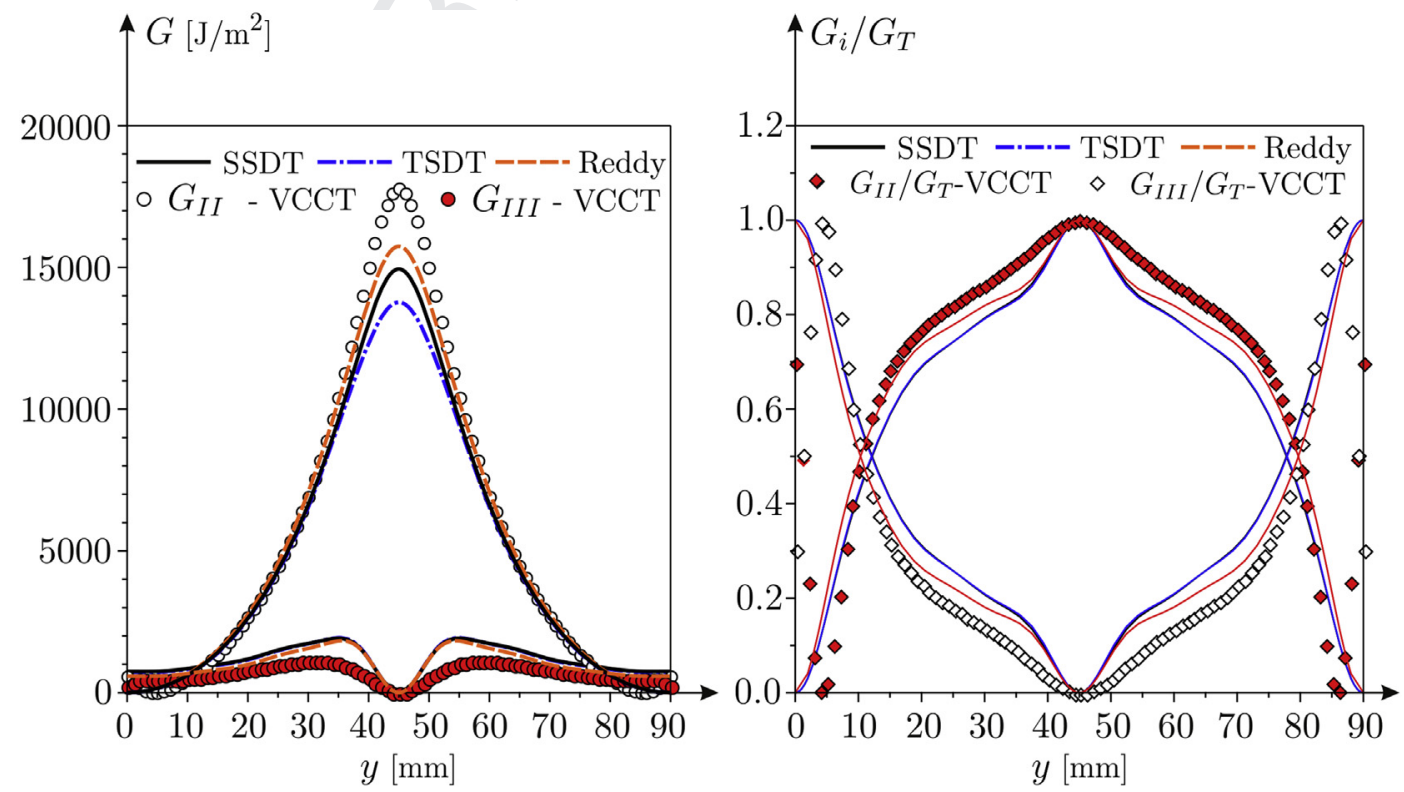

Fig. 17. Distribution of the energy release rates and mode mixity along the delamination front for problem b in Fig. 3, case II. Note: the Reddy solution is available in (Szekrényes, 2014d). 

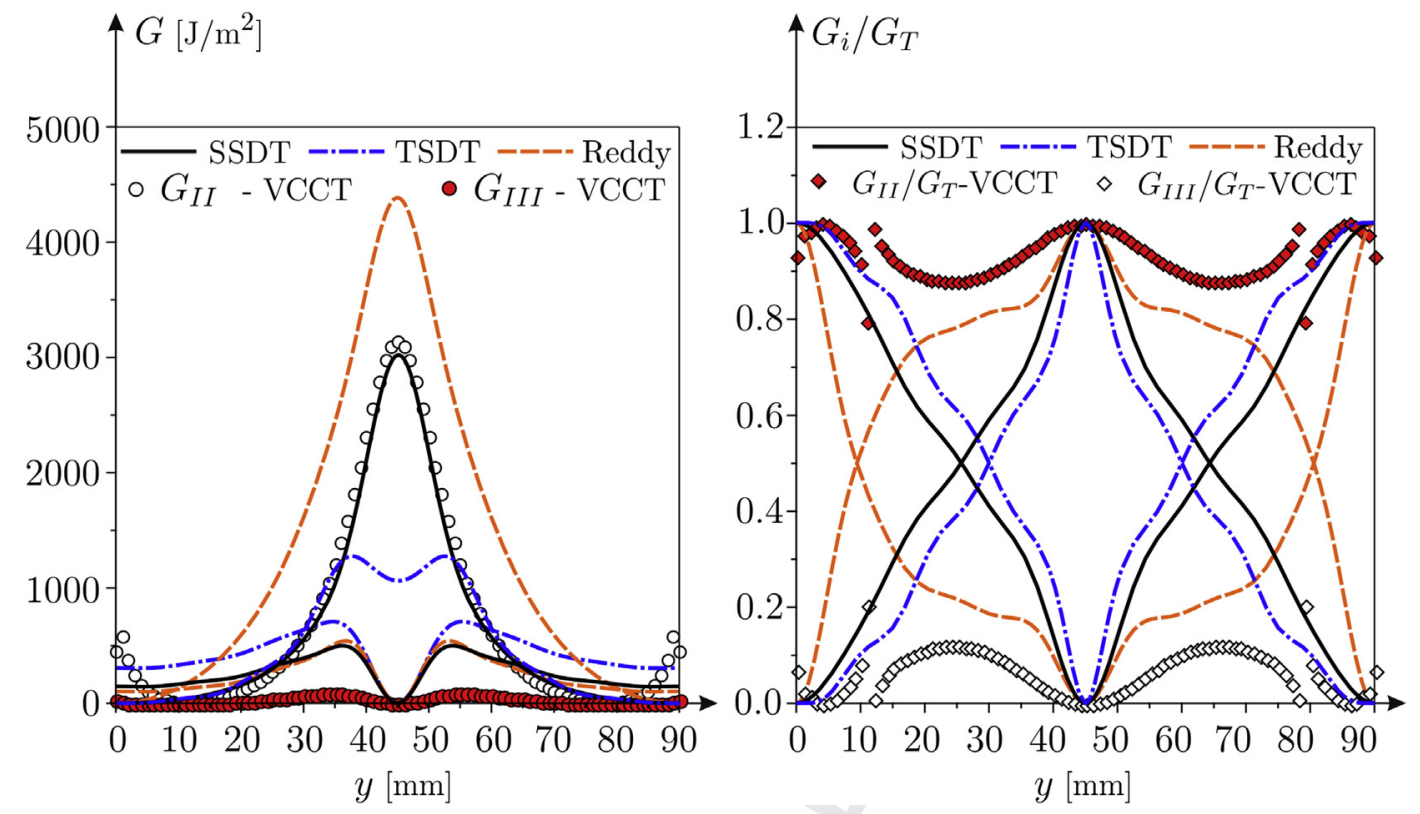

Fig. 18. Distribution of the energy release rates and mode mixity along the delamination front for problem b in Fig. 3, case IV. Note: the Reddy solution is available in (Szekrényes, 2014d).

violated significantly under mixed-mode II/III case, viz. the distribution is not the same if the delamination length increases.

\section{Conclusions}

The method of four equivalent single layers is presented in this paper for the modelling of delaminated orthotropic composite plates. The in-plane displacement functions were captured by the second- and third-order plate theories. The problem of a plate with straight delamination front was considered, each region was captured by four equivalent single layers. The kinematic continuity between the equivalent single layers was established by the system of exact kinematic conditions. It is important to note that the set of conditions was complemented with the continuity of the derivative and the curvature of the shear strains between the adjacent layers of third-order plates. A so-called shear strain control condition was also introduced for second- and third-order plate theory. With the aid of the kinematic conditions the number of parameters in the displacement functions was reduced significantly. The strain and stress fields were derived using the basic equations of elasticity. The equilibrium equations of the delaminated and undelaminated parts were derived based on variational calculus. To exemplify the developed models layered plates with different boundary conditions were considered with concentrated load. The problems were solved by the state-space approach.

An important contribution of this paper compared to similar previous developments is the introduction of the theorem of autocontinuity (AC theorem) for second- and third-order plates. Because of the parameter elimination the number of parameters in the displacement field that continuity is required against is higher than the available constants in the state-space model. Thus, there are no free constants for the matching of certain first-, second- and

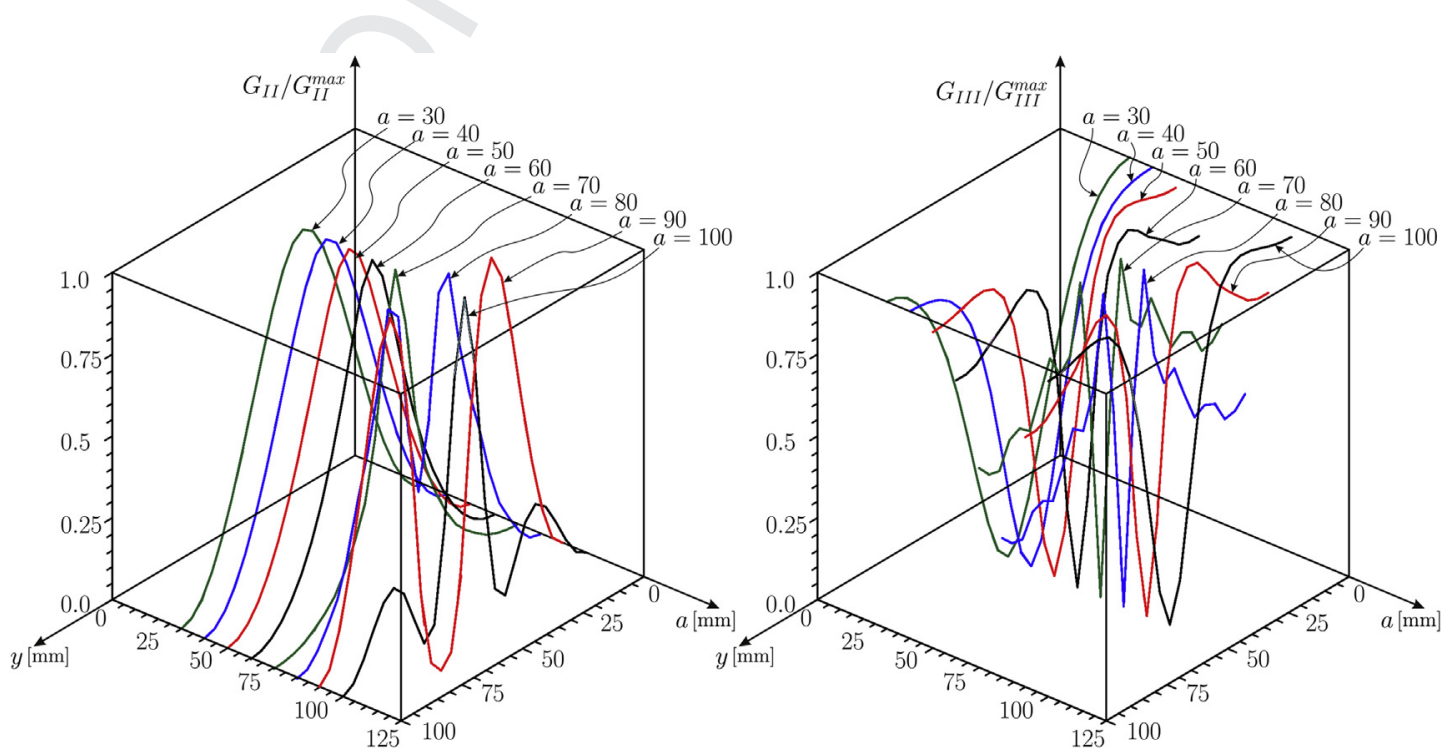

Fig. 19. Normalized energy release rate distributions along the delamination front for different crack lengths in case IV using SSDT $(b=100$ mm). 
third-order displacement parameters. However, in accordance with the $\mathrm{AC}$ theorem the continuity of these parameters can be achieved by imposing the continuity of certain autocontinuity (AC) parameters. An important requirement is that the autocontinuity is satisfied only if in each interface plane between the adjacent equivalent single layers and on the plate boundaries the same conditions are imposed in the delaminated and undelaminated plate regions, except for the plane of delamination, where different conditions are necessary to be specified because of the presence of the delamination front. Using the proposed conditions and the AC theorem the examples were solved and the mechanical fields were compared to the results of 3D finite element calculations. A previous solution based on Reddy third-order theory was also used for comparison purposes.

Several cases were investigated with respect to the position of the delamination in the through the thickness direction, and it was shown that in problem a the second-order plate theory provides the highest accuracy compared to the finite element calculations. It was elaborated that the shear strain control condition leads to large oscillations in the third-order plate theory solution. In problem $b$ the more intense perturbation because of the load and geometry led to the fact that the analytical models gave inaccurate results. However, among the theories applied the second-order plate theory with shear strain control condition was found to be the closest to the finite element calculations in most of the cases. The updated system of exact kinematic conditions and the theorem of autocontinuity work well and can be implemented into more accurate plate and also beam and shell theories. Also, it was discussed that the dynamic boundary condition leads to a slight stiffening in the case of the model based on Reddy third-order theory. However, in the method of four equivalent single layers these conditions make the model overconstrained leading to continuity problems between the delaminated and undelaminated portions, and thus these were not considered in this work.

The next step could be the application of the system of exact kinematic conditions, the AC theorem and the shear strain control conditions to models built by six equivalent single layers, or a full layerwise model, where the system parameters can be reduced significantly to obtain state-space models with the same dimensions as those of the method of four layers.

\section{Acknowledgments}

This work was supported by the János Bolyai Research Scholarship of the Hungarian Academy of Sciences and the Hungarian National Scientific Research Fund (OTKA) under grant No. 44615066-15 (108414).

\section{Appendix A. TSDT constants}

In this Appendix the constants in Eq. (14) denoted by $K_{i j}^{(0)}, K_{i j}^{(1)}$, $K_{i j}^{(2)}$ and $K_{i j}^{(3)}$ are collected.

\section{Appendix A.1. Undelaminated region}

In accordance with Section 4.1.1 the following constants can be obtained:

$K_{11}^{(0)}=\frac{\alpha_{2}}{\alpha_{1}}\left(a_{1} z_{R}^{(2)}+a_{2}\left(z_{R}^{(2)}\right)^{2}+a_{3} t_{1}^{2}+a_{4} t_{2}^{2}+a_{5}\right)$

$$
\begin{aligned}
a_{1}= & -\frac{1}{3} t_{3}\left(t_{3}+t_{4}\right)\left(t_{1}+t_{2}\right), a_{2}=\frac{2}{3} t_{3}\left(t_{3}+t_{4}\right), \\
a_{3}= & -\frac{11}{6} t_{3}\left(t_{3}+t_{4}\right)-\frac{1}{2} t_{4}^{2}, a_{4}=-\frac{1}{3} t_{3}\left(t_{3}+t_{4}\right), \\
a_{5}= & -\frac{5}{3} t_{1} t_{2} t_{3}\left(t_{3}+t_{4}\right)-\frac{1}{2} t_{1} t_{2} t_{4}^{2} \\
K_{12}^{(0)}= & \frac{\alpha_{2}}{\alpha_{1}}\left(b_{1}\left(z_{R}^{(2)}\right)^{2}+b_{2} t_{1}^{2}+b_{3} t_{2}^{2}+b_{4} t_{1}^{3}+b_{5} t_{2}^{3}+b_{6}\right) \\
b_{1}= & -\frac{2}{3} t_{2} t_{3}\left(t_{3}+t_{4}\right)-\frac{1}{3} t_{4}^{2}\left(t_{1}+t_{2}\right)-\frac{4}{3} t_{1} t_{3}\left(t_{3}+t_{4}\right) \\
b_{2}= & -\frac{1}{3} z_{R}^{(2)}\left(4 t_{3}^{2}+4 t_{3} t_{4}+t_{4}^{2}\right)+\frac{1}{6} t_{2}\left(7 t_{3}^{2}+7 t_{3} t_{4}+\frac{3}{2} t_{4}^{2}\right) \\
c_{1}= & \frac{4}{3} t_{3}\left(t_{3}+t_{4}\right), c_{2}=-z_{R}^{(2)}\left(2 t_{3}+t_{4}\right)^{2}, c_{3}=-z_{R}^{(2)} t_{3}\left(t_{3}+t_{4}\right) \\
c_{4}= & -z_{R}^{(2)} t_{1} t_{2}\left(4 t_{3}^{2}+4 t_{3} t_{4}+t_{4}^{2}\right) \\
K_{21}^{(0)}= & \frac{1}{\alpha_{1}}\left(c_{1}\left(z_{R}^{(2)}\right)^{3}+c_{2} t_{1}^{2}+c_{3} t_{2}^{2}+c_{4}\right) \\
b_{3}= & -\frac{1}{6} z_{R}^{(2)}\left(t_{3}^{2}+t_{3} t_{4}+t_{4}^{2}\right)+\frac{7}{12} t_{1} t_{3}\left(t_{3}+t_{4}\right), b_{4}=\frac{1}{6}\left(2 t_{3}+t_{4}\right)^{2} \\
b_{5}= & \frac{1}{12}\left(t_{3}^{2}+t_{3} t_{4}-t_{4}^{2}\right), b_{6}=-z_{R}^{(2)} t_{1} t_{2}\left(t_{3}^{2}+t_{3} t_{4}+\frac{1}{6} t_{4}^{2}\right) \\
K_{14}^{(0)}= & -\frac{\alpha_{2}}{12 \alpha_{1}} t_{4}\left(t_{3}+t_{4}\right)\left(2 t_{3}+t_{4}\right)\left(\left(t_{1}+t_{2}\right)^{2}-2 z_{R}^{(2)}\right. \\
K_{13}^{(0)}= & -\frac{\alpha_{2}}{6 \alpha_{1}} t_{3}\left(t_{3}+t_{4}\right)\left(\left(t_{1}+t_{2}\right)^{2}-2 z_{R}^{(2)}\left(t_{1}+t_{2}-2 z_{R}^{(2)}\right)\right)
\end{aligned}
$$

$$
K_{22}^{(0)}=\frac{1}{\alpha_{1}}\left(d_{1}\left(z_{R}^{(2)}\right)^{2}+d_{2} t_{1}^{2}+d_{3} t_{2}^{2}-d_{4}\right)
$$

$d_{1}=-\frac{4}{3} t_{3}^{2}\left(2 t_{1}+t_{2}\right)-\frac{2}{3} t_{4}^{2}\left(t_{1}+t_{2}\right)-\frac{4}{3} t_{3} t_{4}\left(t_{1}+t_{2}\right)$,

$d_{2}=-\left(z_{R}^{(2)}\right)^{2}\left(t_{4}+2 t_{3}\right)^{2}, d_{3}=-\left(z_{R}^{(2)}\right)^{2} t_{3}\left(t_{3}+t_{4}\right)$,

$d_{4}=-z_{R}^{(2)} t_{1} t_{2}\left(4 t_{3} t_{4}+4 t_{3}^{2}+t_{4}^{2}\right)$

$$
\begin{aligned}
K_{23}^{(0)} & =-\frac{4}{3 \alpha_{1}}\left(z_{R}^{(2)}\right)^{3} t_{3}\left(t_{3}+t_{4}\right), K_{24}^{(0)} \\
& =-\frac{2}{3 \alpha_{1}}\left(z_{R}^{(2)}\right)^{3} t_{4}\left(t_{3}+t_{4}\right)\left(2 t_{3}+t_{4}\right)
\end{aligned}
$$

$$
K_{31}^{(0)}=\frac{1}{\alpha_{1}}\left(e_{1} z_{R}^{(2)}+e_{2}\left(z_{R}^{(2)}\right)^{3}+e_{3} t_{1}^{2}+e_{4} t_{2}^{2}+e_{5} t_{2}^{3}+e_{6}\right)
$$




$$
\begin{aligned}
& e_{1}= \alpha_{1}, e_{2}=\frac{4}{3} t_{3}\left(t_{3}+t_{4}\right), \\
& e_{3}=-z_{R}^{(2)}\left(4 t_{3}^{2}+4 t_{3} t_{4}+t_{4}^{2}\right)+t_{3}^{2}\left(\frac{7}{6} t_{3}+\frac{3}{2} t_{4}+2 t_{2}\right) \\
&+t_{4}\left(\frac{1}{2} t_{3} t_{4}+\frac{1}{2} t_{2} t_{4}+2 t_{2} t_{3}\right) \\
& e_{4}=-z_{R}^{(2)}\left(t_{3}^{2}+t_{3} t_{4}\right)+t_{1}\left(\frac{1}{2} t_{4}^{2}+2 t_{3} t_{4}+2 t_{3}^{2}\right), \\
& e_{5}= \frac{1}{3} t_{3}\left(t_{3}+t_{4}\right), \\
& e_{6}= z_{R}^{(2)} t_{1}^{2}\left(4 t_{3}^{2}+4 t_{3} t_{4}+t_{4}^{2}\right)+z_{R}^{(2)} t_{2}^{2} t_{3}\left(t_{3}+t_{4}\right) \\
&+t_{3} t_{1}\left(\frac{3}{2} t_{3} t_{4} t_{2}+\frac{1}{2} t_{4}^{2} t_{2}+\frac{7}{6} t_{3} t_{2}\right) \\
& K_{32}^{(0)}= \frac{1}{\alpha_{1}}\left(g_{1} z_{R}^{(2)}+g_{2}\left(z_{R}^{(2)}\right)^{3}+g_{3} t_{2}^{2}+g_{4} t_{1}^{2}+g_{5} t_{3}^{3}+g_{6} t_{2}^{4}+g_{7}\right) \\
& g_{1}= \alpha_{1}, g_{2}=-\frac{4}{3} t_{2} t_{3}\left(t_{3}+t_{4}\right)-\frac{8}{3} t_{1} t_{3}\left(t_{3}+t_{4}\right)-\frac{2}{3} t_{4}^{2}\left(t_{2}+t_{3}\right) \\
& g_{3}= \frac{1}{4} t_{3} t_{4}\left(3 t_{3}+t_{4}\right)+\frac{4}{3} t_{1} t_{3}\left(t_{3}+t_{4}\right)+\frac{1}{3} t_{1} t_{4}^{2}+\frac{7}{12} t_{3}^{3}, \\
&\left.+t_{2}^{(2)}\right)^{2}\left(\frac{1}{4} t_{2} t_{4}^{2}+t_{2} t_{3}^{2}+\frac{7}{6} t_{3}^{3}\right) \\
&\left.g_{4}+4 t_{3} t_{4}+t_{4}^{3}\right)+t_{2} t_{3} t_{4}\left(\frac{3}{2} t_{3}+\frac{1}{2} t_{4}+t_{2}\right) \\
&\left.g_{1}\right)
\end{aligned}
$$

$$
\begin{aligned}
& g_{5}= \frac{7}{12} t_{2}\left(t_{1}+t_{2}\right)\left(2 t_{1}+t_{2}\right), g_{6}=\frac{1}{12}\left(5 t_{3}^{2}+5 t_{3} t_{4}+t_{4}^{2}\right) \\
& g_{7}=\left(z_{R}^{(2)}\right)^{2} t_{1}^{2}\left(4 t_{3}^{2}+4 t_{3} t_{4}+t_{4}^{3}\right)+t_{1} t_{2} t_{3} t_{4}\left(\frac{3}{4} t_{2} t_{4}+\frac{9}{4} t_{2} t_{3}\right) \\
&+\frac{7}{6} t_{2} t_{3}^{3}\left(t_{1}^{2}+t_{2}^{2}\right) \\
& K_{33}^{(0)}= \frac{1}{\alpha_{1}}\left(h_{1}\left(z_{R}^{(2)}\right)^{3}+h_{2} t_{2}^{3}+h_{3} t_{1}^{2}+h_{4} t_{3}^{3}+h_{5}\right) \\
& h_{1}=-\frac{4}{3} t_{3}\left(t_{3}+t_{4}\right), h_{2}=\frac{1}{6} t_{3}\left(t_{3}+t_{4}\right), h_{3}=\frac{1}{6} t_{3}^{2}\left(5 t_{3}+3 t_{4}\right) \\
& h_{4}= \frac{5}{6} t_{1}^{2}+\frac{1}{2} t_{2}^{2}+\frac{5}{6} t_{1} t_{2}, h_{5}=\frac{1}{2} t_{3}^{2}\left(-\frac{5}{3} t_{3} t_{1}^{2}+t_{2}^{2} t_{4}+t_{1} t_{2} t_{4}\right) \\
& K_{34}^{(0)}= \frac{1}{\alpha_{1}}\left(i_{1}\left(z_{R}^{(2)}\right)^{3}+i_{2} t_{2}^{3}+i_{3} t_{1}^{2}+i_{4} t_{3}^{3}+i_{5} t_{3}^{2}+i_{6}\right) \\
& i_{6}=--\frac{2}{3} t_{4}\left(t_{3}+t_{4}\right)\left(2 t_{3}+t_{4}\right), i_{2}=\frac{1}{12} t_{4}\left(t_{3}+t_{4}\right)\left(2 t_{3}+t_{4}\right) \\
& i_{5}= \frac{1}{12} t_{3}\left(t_{3}+t_{4}\right)\left(-3 t_{4}^{2}-3 t_{3}^{2} t_{4}+2 t_{3}^{2}\right) \\
& i_{3}=- \frac{1}{12} t_{3}^{2}\left(4 t_{3}+3 t_{4}\right)\left(2 t_{3}+t_{4}\right) \\
& i_{4}=- \frac{1}{12} t_{4}\left(10 t_{1}^{2}-t_{2}^{2}+10 t_{1} t_{2}\right) \\
& i_{1}\left(\frac{5}{6} t_{1}^{2}-\frac{1}{12} t_{2}^{2}\right)
\end{aligned}
$$

$$
\begin{aligned}
K_{41}^{(0)}= & \frac{1}{\alpha_{1}}\left(j_{1}\left(z_{R}^{(2)}\right)^{3}+j_{2} t_{2}^{3}+j_{3} t_{1}^{2}+j_{4} t_{3}^{3}+j_{5} t_{2}^{2}+j_{6}\right) \\
j_{1}= & \frac{4}{3} t_{3}\left(t_{3}+t_{4}\right), j_{2}=\frac{1}{3} t_{3}\left(t_{3}+t_{4}\right) \\
j_{3}= & \frac{1}{6} t_{3}^{2}\left(2 t_{3}+t_{4}\right)^{2}\left(2 t_{3}-6 z_{R}^{(2)}+3 t_{2}+t_{4}\right) \\
j_{4}= & \frac{4}{3} t_{1}\left(t_{1}+t_{2}\right), j_{5}=-z_{R}^{(2)}\left(t_{3}^{2}+t_{3} t_{4}\right)+t_{1}\left(\frac{1}{2} t_{4}^{2}+2 t_{3}^{2}+t_{3} t_{4}\right) \\
j_{6}= & -z_{R}^{(2)} t_{1} t_{2}\left(t_{4}^{2}+4 t_{3}^{2}+4 t_{3} t_{4}\right)+t_{1} t_{2} t_{3} t_{4}\left(2 t_{3}+t_{4}\right) \\
& -t_{1}\left(\frac{4}{3} t_{1} t_{3}^{3}-\frac{1}{6} t_{2} t_{4}^{3}\right)
\end{aligned}
$$$$
K_{42}^{(0)}=\frac{1}{\alpha_{1}}\left(k_{1}\left(z_{R}^{(2)}\right)^{2}+k_{2}\left(z_{R}^{(2)}\right)^{3}+k_{3} t_{2}^{3}+k_{4} t_{1}^{2}+k_{5} t_{3}^{3}+k_{6} t_{4}^{3}\right.
$$$$
\left.+k_{7} t_{2}^{4}+k_{8}\right)
$$

$k_{1}=\alpha_{1}, k_{2}=-\frac{4}{3} t_{2} t_{3}\left(t_{3}+t_{4}\right)-\frac{2}{3} t_{4}^{2}\left(t_{1}+t_{2}\right)-\frac{8}{3} t_{1} t_{3}\left(t_{3}+t_{4}\right)$,$$
k_{3}=\frac{1}{12}\left(2 t_{3}+t_{4}\right)^{2}\left(2 t_{3}+4 t_{1}+t_{4}\right) \text {, }
$$$$
k_{4}=\frac{1}{12}\left(2 t_{3}+t_{4}\right)^{2}\left(4 t_{2} t_{3}+3 t_{2}^{2}+2 t_{2} t_{4}-12\left(z_{R}^{(2)}\right)^{2}\right)
$$

$$
\begin{aligned}
k_{5}= & \frac{2}{3} t_{2}\left(t_{1}+t_{2}\right)\left(2 t_{1}+t_{2}\right), k_{6}=\frac{1}{12} t_{2}\left(t_{1}+t_{2}\right)\left(2 t_{1}+t_{2}\right), \\
k_{7}= & \frac{1}{12}\left(t_{4}^{2}+5 t_{3}^{2}+4 t_{3} t_{4}\right) \\
k_{8}= & -z_{R}^{(2)} t_{1}^{2}\left(t_{4}^{2}+4 t_{3}^{2}+4 t_{3} t_{4}\right)+t_{1} t_{2}^{2} t_{3} t_{4}\left(\frac{3}{2} t_{4}+3 t_{3}\right) \\
& -t_{1}^{2} t_{2}\left(\frac{1}{6} t_{4}^{3}+\frac{4}{3} t_{3}^{3}\right)-t_{2}^{3}\left(\frac{2}{3} t_{3}^{3}+\frac{1}{12} t_{4}^{3}\right)
\end{aligned}
$$$$
K_{43}^{(0)}=\frac{1}{\alpha_{1}}\left(l_{1}\left(z_{R}^{(2)}\right)^{3}+l_{2} t_{2}^{3}+l_{3} t_{1}^{2}+l_{4} t_{3}^{3}+l_{5} t_{4}^{3}+l_{6} t_{2}^{2}+l_{7}\right)
$$

$$
\begin{aligned}
& l_{1}=\frac{4}{3} t_{3}\left(t_{3}+t_{4}\right), l_{2}=\frac{1}{6} t_{3}\left(t_{3}+t_{4}\right), l_{3}=\frac{1}{3}\left(2 t_{3}+t_{4}\right)^{2}, \\
& l_{4}=\frac{8}{3} t_{1}\left(t_{1}+t_{2}\right)+t_{2}^{2} \\
& l_{5}=\frac{1}{3} t_{1}\left(t_{1}+t_{2}\right), l_{6}=\frac{1}{2} t_{3}\left(t_{3}+t_{4}\right)\left(2 t_{3}+t_{4}\right) \\
& l_{7}=t_{3}^{2}\left(-t_{3} t_{2}^{2}+4 t_{1} t_{2} t_{4}-\frac{8}{3} t_{3} t_{1}^{2}\right)+t_{1} t_{4}^{2}\left(-\frac{1}{3} t_{1} t_{4}+2 t_{2} t_{3}\right)
\end{aligned}
$$

$K_{44}^{(0)}=\frac{1}{\alpha_{1}}\left(m_{1}\left(z_{R}^{(2)}\right)^{3}+m_{2} t_{2}^{3}+m_{3} t_{1}^{2}+m_{4} t_{3}^{3}+m_{5} t_{4}^{3}+m_{6} t_{2}^{2}+m_{7}\right)$ 


$$
\begin{aligned}
m_{1}= & -\frac{2}{3} t_{4}\left(t_{3}+t_{4}\right)\left(2 t_{3}+t_{4}\right), m_{2}=\frac{1}{12} t_{4}\left(t_{3}+t_{4}\right)\left(2 t_{3}+t_{4}\right), \\
m_{3}= & -\frac{1}{12}\left(2 t_{3}+t_{4}\right)^{4}, m_{4}=-\frac{1}{3} t_{4}\left(8 t_{1}\left(t_{1}+t_{2}\right)+t_{2}^{2}\right. \\
m_{5}= & \frac{1}{3} t_{3}\left(t_{2}^{2}-2 t_{1}^{2}-2 t_{1} t_{2}\right)-\frac{2}{3}\left(z_{R}^{(2)}\right)^{3}+\frac{1}{12} t_{2}^{3}, \\
m_{6}= & -\frac{1}{12}\left(2 t_{3}+t_{4}\right)^{2}\left(t_{3}-t_{4}\right)\left(t_{3}+t_{4}\right) \\
m_{7}= & \frac{1}{3} t_{4}^{3}\left(-t_{3}\left(t_{2}^{2}-2 t_{1}^{2}\right)+2\left(z_{R}^{(2)}\right)^{3}\right)+\frac{1}{3} t_{4} t_{3}^{2}\left(8 t_{1}^{2}+t_{2}^{2}\right) \\
& -t_{1} t_{2} t_{4}^{2}\left(2 t_{3}^{2}+\frac{1}{12} t_{4}^{2}\right)-\frac{1}{12} t_{2}^{3} t_{4}^{3}-\frac{4}{3} t_{1} t_{2} t_{3}^{4} \\
K_{11}^{(1)}= & \frac{t_{1}}{\alpha_{1}}\left(\left(t_{3}^{2}+t_{3} t_{4}\right)\left(3 t_{1}+2 t_{2}\right)+t_{4}^{2}\left(t_{1}+t_{2}\right)\right) \\
K_{12}^{(1)}= & \frac{-\left(t_{1}+t_{2}\right)}{2 \alpha_{1}}\left(t_{1}^{2}\left(4 t_{3}^{2}+4 t_{3} t_{4}+t_{4}^{2}\right)\right. \\
& \left.+t_{2}\left(2 t_{1} t_{3}^{2}+2 t_{1} t_{3} t_{4}-t_{2} t_{4}^{2}\right)\right) \\
K_{13}^{(1)}= & \frac{t_{3}}{\alpha_{1}}\left(t_{1}+t_{2}\right)^{2}\left(t_{3}+t_{4}\right), K_{14}^{(1)}=\frac{t_{4}}{2 \alpha_{1}}\left(t_{1}+t_{2}\right)^{2}\left(t_{3}+t_{4}\right)\left(2 t_{3}+t_{4}\right) \\
K_{21}^{(1)}= & 1, K_{22}^{(1)}=K_{23}^{(1)}=K_{24}^{(1)}=0
\end{aligned}
$$$$
K_{31}^{(1)}=\frac{t_{1}}{\alpha_{1}}\left(t_{2}+t_{3}\right)^{2}\left(t_{1}+t_{2}\right), K_{32}^{(1)}=\frac{t_{2}}{2 \alpha_{1}}\left(t_{1}+t_{2}\right)\left(t_{3}+t_{4}\right)^{2}\left(2 t_{1}+t_{2}\right)
$$$$
K_{33}^{(1)}=\frac{t_{3}}{\alpha_{1}}\left(\left(t_{1}^{2}+t_{1} t_{2}\right)\left(3 t_{3}+2 t_{4}\right)+t_{2}^{2}\left(t_{3}+t_{4}\right)\right)
$$

$$
K_{34}^{(1)}=-\frac{\left(t_{3}+t_{4}\right)}{2 \alpha_{1}}\left(t_{3}^{2}\left(4 t_{1}^{2}+4 t_{1} t_{2}+t_{2}^{2}\right)\right.
$$$$
\left.+t_{4}\left(2 t_{3} t_{1}^{2}+2 t_{1} t_{2} t_{3}-t_{4} t_{2}^{2}\right)\right)
$$$$
K_{41}^{(1)}=K_{42}^{(1)}=0, K_{43}^{(1)}=1, K_{44}^{(1)}=0
$$$$
K_{11}^{(2)}=\frac{2 t_{3}}{\alpha_{1}}\left(t_{3}+t_{4}\right)\left(t_{1}+t_{2}\right)
$$$$
K_{12}^{(2)}=-\frac{t_{2}}{\alpha_{1}}\left(t_{2}\left(t_{3}^{2}+t_{3} t_{4}+t_{4}^{2}\right)+t_{1}\left(2 t_{3}^{2}+2 t_{2} t_{3}-t_{4}^{2}\right)\right)
$$$$
K_{13}^{(2)}=-\frac{2 t_{3}}{\alpha_{1}}\left(t_{3}+t_{4}\right)\left(t_{1}+t_{2}\right)
$$$$
K_{14}^{(2)}=-\frac{t_{4}}{\alpha_{1}}\left(t_{3}+t_{4}\right)\left(2 t_{3}+t_{4}\right)\left(t_{1}+t_{2}\right)
$$$$
K_{21}^{(2)}=0, K_{22}^{(2)}=1, K_{23}^{(2)}=K_{24}^{(2)}=0
$$$$
K_{31}^{(2)}=-\frac{2 t_{1}}{\alpha_{1}}\left(t_{3}+t_{4}\right)\left(t_{1}+t_{2}\right)
$$$$
K_{32}^{(2)}=-\frac{t_{2}}{\alpha_{1}}\left(t_{1}+t_{2}\right)\left(2 t_{1}+t_{2}\right)\left(t_{3}+t_{4}\right)
$$

$$
\begin{aligned}
& K_{33}^{(2)}=\frac{2 t_{1}}{\alpha_{1}}\left(t_{3}+t_{4}\right)\left(t_{1}+t_{2}\right), \\
& K_{34}^{(2)}=-\frac{t_{4}}{\alpha_{1}}\left(t_{4}\left(t_{1}^{2}+t_{1} t_{2}+t_{2}^{2}\right)+t_{3}\left(2 t_{1}^{2}+2 t_{1} t_{2}+t_{2}^{2}\right)\right) \\
& K_{41}^{(2)}=K_{42}^{(2)}=K_{43}^{(2)}=0, K_{44}^{(2)}=1
\end{aligned}
$$

$$
\begin{aligned}
& K_{11}^{(3)}=K_{21}^{(3)}=-\frac{4 t_{3}}{3 \alpha_{1}}\left(t_{3}+t_{4}\right), K_{13}^{(3)}=K_{23}^{(3)}=\frac{4 t_{3}}{3 \alpha_{1}}\left(t_{3}+t_{4}\right) \\
& K_{12}^{(3)}=K_{22}^{(3)}=\frac{2}{3 \alpha_{1}}\left(t_{4}\left(2 t_{3} t_{4}+t_{1} t_{4}+4 t_{1} t_{3}\right)+t_{2}\left(2 t_{3}^{2}+2 t_{3} t_{4}+t_{4}^{2}\right)\right)
\end{aligned}
$$

$$
\begin{aligned}
& K_{14}^{(3)}=K_{24}^{(3)}=\frac{2 t_{4}}{3 \alpha_{1}}\left(2 t_{3}+t_{4}\right)\left(t_{3}+t_{4}\right), K_{31}^{(3)}=K_{41}^{(3)}=\frac{4 t_{1}}{3 \alpha_{1}}\left(t_{1}+t_{2}\right) \\
& K_{32}^{(3)}=K_{42}^{(3)}=\frac{2 t_{2}}{3 \alpha_{1}}\left(2 t_{1}+t_{2}\right)\left(t_{1}+t_{2}\right), K_{33}^{(3)}=K_{43}^{(3)}=-\frac{4 t_{1}}{3 \alpha_{1}}\left(t_{1}+t_{2}\right)
\end{aligned}
$$

$$
K_{34}^{(3)}=K_{44}^{(3)}=\frac{2}{3 \alpha_{1}}\left(t_{4}\left(2 t_{1}^{2}+2 t_{1} t_{2}+t_{2}^{2}\right)+t_{3}\left(t_{2}^{2}+4 t_{1} t_{2}+4 t_{1}^{2}\right)\right)
$$

where:

$$
\begin{aligned}
& \alpha_{1}=\left(t_{1} t_{4}+t_{2} t_{4}+2 t_{1} t_{3}+t_{2} t_{3}\right)\left(t_{1} t_{4}+2 t_{1} t_{3}+t_{2} t_{3}\right), \\
& \alpha_{2}=t_{1}+t_{2}+2 z_{R}^{(2)}
\end{aligned}
$$

\section{Appendix A.2. Delaminated region}

In accordance with Section 4.2.1 the following constants can be obtained for the delaminated region:

$$
\begin{aligned}
& K_{11}^{(0)}=-\frac{1}{6} \frac{\left(3 t_{1}^{2}+6 t_{1} t_{2}+2 t_{2}^{2}\right)}{2 t_{1}+t_{2}}, K_{12}^{(0)}=\frac{1}{6} \frac{3 t_{1}^{2}-t_{2}^{2}}{\left(2 t_{1}+t_{2}\right)}, \\
& K_{13}^{(0)}=\frac{1}{12} \frac{t_{4}\left(3 t_{1}^{2}-t_{2}^{2}\right)\left(2 t_{3}+t_{4}\right)}{t_{3}\left(2 t_{1}+t_{2}\right)} \\
& K_{21}^{(0)}=\frac{1}{6} \frac{t_{1}\left(2 t_{1}^{2}+6 t_{1} t_{2}+3 t_{2}^{2}\right)}{t_{2}\left(2 t_{1}+t_{2}\right)}, K_{22}^{(0)}=-\frac{1}{3} \frac{t_{1}^{3}}{t_{2}\left(2 t_{1}+t_{2}\right)}, \\
& K_{23}^{(0)}=-\frac{1}{6} \frac{t_{4} t_{3}^{2}\left(2 t_{3}+t_{4}\right)}{t_{2} t_{3}\left(2 t_{1}+t_{2}\right)} \\
& K_{31}^{(0)}=0, K_{32}^{(0)}=-\frac{1}{4} t_{4}, K_{33}^{(0)}=\frac{1}{12} \frac{t_{4}\left(3 t_{3}^{2}-t_{4}^{2}\right)}{t_{3}}, K_{41}^{(0)}=0, \\
& K_{42}^{(0)}=\frac{1}{3} t_{3}, K_{43}^{(0)}=-\frac{1}{6} t_{3}^{2} \\
& K_{11}^{(1)}=\frac{t_{1}\left(t_{1}+2 t_{2}\right)}{t_{2}\left(2 t_{1}+t_{2}\right)}, K_{12}^{(1)}=-\frac{\left(t_{1}-t_{2}\right)\left(t_{1}+t_{2}\right)}{t_{2}\left(2 t_{1}+t_{2}\right)}, \\
& K_{13}^{(1)}=-\frac{1}{2} \frac{t_{4}\left(t_{1}-t_{2}\right)\left(t_{1}+t_{2}\right)\left(2 t_{3}+t_{4}\right)}{t_{2} t_{3}\left(2 t_{1}+t_{2}\right)}
\end{aligned}
$$


$K_{21}^{(1)}=1, K_{22}^{(1)}=0, K_{23}^{(1)}=0, K_{31}^{(1)}=0, K_{32}^{(1)}=1$,

$K_{33}^{(1)}=-\frac{1}{2} \frac{\left(t_{3}-t_{4}\right)\left(t_{3}+t_{4}\right)}{t_{3}}$

$K_{41}^{(1)}=0, K_{42}^{(1)}=1, K_{43}^{(1)}=0, K_{11}^{(2)}=\frac{2}{2 t_{1}+t_{2}}$,

$K_{12}^{(2)}=-\frac{2}{2 t_{1}+t_{2}}, K_{13}^{(2)}=-\frac{1}{2} \frac{t_{4}\left(2 t_{3}+t_{4}\right)}{t_{3}\left(2 t_{1}+t_{2}\right)}$

$K_{21}^{(1)}=1, K_{22}^{(1)}=0, K_{23}^{(1)}=0, K_{31}^{(1)}=0, K_{32}^{(1)}=1$,

$K_{33}^{(1)}=-\frac{1}{2} \frac{\left(t_{3}-t_{4}\right)\left(t_{3}+t_{4}\right)}{t_{3}}$

$K_{41}^{(1)}=0, K_{42}^{(1)}=1, K_{43}^{(1)}=0, K_{11}^{(2)}=\frac{2}{2 t_{1}+t_{2}}$,

$K_{12}^{(2)}=-\frac{2}{2 t_{1}+t_{2}}, K_{13}^{(2)}=-\frac{1}{2} \frac{t_{4}\left(2 t_{3}+t_{4}\right)}{t_{3}\left(2 t_{1}+t_{2}\right)}$

$K_{33}^{(2)}=-\frac{t_{4}}{t_{3}}, K_{41}^{(2)}=0, K_{42}^{(2)}=0, K_{43}^{(2)}=1$,

$K_{11}^{(3)}=K_{12}^{(3)}=K_{21}^{(3)}=K_{22}^{(3)}=\frac{4}{3 t_{2}\left(2 t_{1}+t_{2}\right)}$

$K_{13}^{(3)}=K_{23}^{(3)}=\frac{2}{3} \frac{t_{4}\left(2 t_{3}+t_{4}\right)}{t_{3} t_{2}\left(2 t_{1}+t_{2}\right)}, K_{31}^{(3)}=K_{32}^{(3)}=K_{41}^{(3)}=K_{42}^{(3)}=0$,

$K_{33}^{(3)}=K_{43}^{(3)}=\frac{2}{t_{3}}$

(A.50)

\section{Appendix B. SSDT constants}

This Appendix contains the constants of Eq. (14) denoted by $K_{i j}^{(0)}$, $K_{i j}^{(1)}$ and $K_{i j}^{(2)}$ for the SSDT solution. Obviously $K_{i j}^{(3)}=0$ in this case.

\section{Appendix B.1. Undelaminated region}

According to Section 4.1.2 the following constants are obtained:

$K_{11}^{(0)}=-\frac{3}{8} t_{1}-z_{R}^{(2)}-\frac{1}{2} t_{2}, K_{12}^{(0)}=\frac{3}{8} t_{1} t_{2}-\left(z_{R}^{(2)}\right)^{2}+\frac{1}{2} t_{2}^{2}$,

$K_{13}^{(0)}=-\frac{1}{8} t_{1} K_{14}^{(0)}=-\frac{1}{8} t_{1} t_{4}, K_{22}^{(0)}=-z_{R}^{(2)}, K_{22}^{(0)}=-\left(z_{R}^{(2)}\right)^{2}$,

$K_{23}^{(0)}=K_{24}^{(0)}=0$

$$
\begin{aligned}
& K_{31}^{(0)}=\frac{3}{8} t_{3}-z_{R}^{(2)}+\frac{1}{2} t_{2}, K_{32}^{(0)}=\frac{3}{8} t_{3} t_{2}-\left(z_{R}^{(2)}\right)^{2}+\frac{1}{4} t_{2}^{2}, \\
& K_{33}^{(0)}=\frac{1}{8} t_{3}, K_{34}^{(0)}=-\frac{1}{8} t_{3} t_{4} K_{41}^{(0)}=\frac{1}{2} t_{3}-z_{R}^{(2)}+\frac{1}{2} t_{2}, \\
& K_{42}^{(0)}=\frac{1}{2} t_{3} t_{2}-\left(z_{R}^{(2)}\right)^{2}+\frac{1}{4} t_{2}^{2}, K_{43}^{(0)}=\frac{1}{2} t_{3}+\frac{1}{2} t_{4}, \\
& K_{44}^{(0)}=-\frac{1}{4} t_{4}\left(t_{4}+2 t_{3}\right) \\
& K_{11}^{(1)}=\frac{1}{2}, K_{12}^{(1)}=-\frac{1}{2} t_{2}, K_{13}^{(1)}=\frac{1}{2}, K_{14}^{(1)}=\frac{1}{4} t_{4}, K_{21}^{(1)}=1, \\
& K_{22}^{(1)}=0, K_{23}^{(1)}=0, K_{24}^{(1)}=0 \\
& K_{31}^{(1)}=\frac{1}{2}, K_{32}^{(1)}=\frac{1}{2} t_{2}, K_{33}^{(1)}=\frac{1}{2}, K_{34}^{(1)}=-\frac{1}{4} t_{4}, K_{41}^{(1)}=0, \\
& K_{42}^{(1)}=0, K_{43}^{(1)}=1, K_{44}^{(1)}=0 \\
& K_{11}^{(2)}=\frac{1}{2 t_{1}}, K_{12}^{(2)}=-\frac{1}{2} \frac{t_{2}}{t_{1}}, K_{13}^{(2)}=-\frac{1}{2 t_{1}}, K_{14}^{(2)}=-\frac{1}{2} \frac{t_{4}}{t_{1}}, \\
& K_{21}^{(2)}=0, K_{22}^{(2)}=1 \\
& K_{23}^{(2)}=0, K_{24}^{(2)}=0, K_{31}^{(2)}=-\frac{1}{2 t_{3}}, K_{32}^{(2)}=-\frac{1}{2} \frac{t_{2}}{t_{3}}, K_{33}^{(2)}=\frac{1}{2 t_{3}}, \\
& K_{34}^{(2)}=-\frac{1}{2} \frac{t_{4}}{t_{3}} \\
& K_{41}^{(2)}=0, K_{42}^{(2)}=0, K_{43}^{(2)}=0, K_{44}^{(2)}=1
\end{aligned}
$$

\section{Appendix B.2. Delaminated region}

Following Section 4.2.2 the contants of the delaminated region become:

$$
\begin{aligned}
& K_{11}^{(0)}=-\frac{1}{4} \frac{t_{2}\left(2 t_{1}+t_{2}\right)}{t_{1}}, K_{32}^{(0)}=\frac{1}{4} \frac{t_{2}^{2}}{t_{1}}, K_{33}^{(0)}=\frac{1}{4} \frac{t_{2}^{2} t_{4}}{t_{1}}, \\
& K_{21}^{(0)}=\frac{1}{4} \frac{\left(3 t_{1}^{2}-t_{2}^{2}+t_{1} t_{2}\right)}{t_{1}} \\
& K_{22}^{(0)}=-\frac{1}{4} \frac{\left(t_{1}^{2}-t_{2}^{2}+t_{1} t_{2}\right)}{t_{1}}, K_{23}^{(0)}=-\frac{1}{4} \frac{t_{4}\left(t_{1}^{2}-t_{2}^{2}+t_{1} t_{2}\right)}{t_{1}} \\
& K_{31}^{(0)}=0, K_{32}^{(0)}=-\frac{1}{2} t_{4}, K_{33}^{(0)}=\frac{1}{4} \frac{t_{4}^{3}}{t_{3}} \\
& K_{41}^{(0)}=0, K_{42}^{(0)}=\frac{1}{2} t_{3}, K_{43}^{(0)}=-\frac{1}{4} \frac{t_{4}\left(t_{3}^{2}-t_{4}^{2}+t_{3} t_{4}\right)}{t_{3}} \\
& K_{11}^{(1)}=1, K_{12}^{(1)}=K_{13}^{(1)}=0, K_{21}^{(1)}=1, K_{22}^{(1)}=K_{23}^{(1)}=0 \\
& K_{31}^{(1)}=0, K_{32}^{(1)}=1, K_{33}^{(1)}=0, K_{41}^{(1)}=0, K_{42}^{(1)}=1, K_{43}^{(1)}=0 \\
& K_{11}^{(2)}=\frac{1}{t_{1}}, K_{12}^{(2)}=-\frac{1}{t_{1}}, K_{13}^{(2)}=-\frac{t_{4}}{t_{1}}, K_{21}^{(2)}=-\frac{1}{t_{2}}, K_{22}^{(2)}=\frac{1}{t_{2}}, K_{23}^{(2)}=\frac{t_{4}}{t_{2}} \\
& K_{31}^{(2)}=0, K_{32}^{(2)}=0, K_{33}^{(2)}=-\frac{t_{4}}{t_{3}}, K_{41}^{(2)}=0, K_{42}^{(2)}=0, K_{43}^{(2)}=1
\end{aligned}
$$




\section{Appendix C. J-integral - mode-II and mode-III ERRs}

The J-integral has already been derived in previous papers Szekrényes (2014d, 2013b, 2014b) for similar problems to those considered in this paper. The mode-II and mode-III integrals are:

$$
\begin{aligned}
& \left(\widehat{M}_{12}^{(x, x y)}, \widehat{M}_{34}^{(x, x y)}, \widehat{L}_{12}^{(x, x y)}\right. \\
& \quad+\widehat{L}_{34}^{(x, x y)}, \sum_{i=1 . .2} N_{i}^{(x, x y)}, \sum_{i=3 . .4} N_{i}^{(x, x y)},\left.\sum_{i=1 . .4} Q_{x i}\right|_{x=a} ^{(1)}
\end{aligned}
$$

$J_{I I I}=\frac{1}{2} \sum_{i=1 . .4}\left\{\begin{array}{l}\left(\left.N_{x y 1(i)} \widehat{\gamma}_{x y 1(i)}^{(0)}\right|_{x=+0}-\left.N_{x y 2(i)} \widehat{\gamma}_{x y 2(i)}^{(0)}\right|_{x=-0}\right)+\left(\left.M_{x y 1(i)} \widehat{\gamma}_{x y 1(i)}^{(1)}\right|_{x=+0}-\left.M_{x y 2(i)} \widehat{\gamma}_{x y 2(i)}^{(1)}\right|_{x=-0}\right)+ \\ \left(\left.L_{x y 1(i)} \widehat{\gamma}_{x y 1(i)}^{(2)}\right|_{x=+0}-\left.L_{x y 2(i)} \widehat{\gamma}_{x y 2(i)}^{(2)}\right|_{x=-0}\right)+\left(\left.P_{x y 1(i)} \widehat{\gamma}_{x y 1(i)}^{(3)}\right|_{x=+0}-\left.P_{x y 2(i)} \widehat{\gamma}_{x y 2(i)}^{(3)}\right|_{x=-0}\right)\end{array}\right\}$

The corresponding distributions for cases I and III are shown in where the notations can be found in the former papers.

Figs. D.20 and D.21.
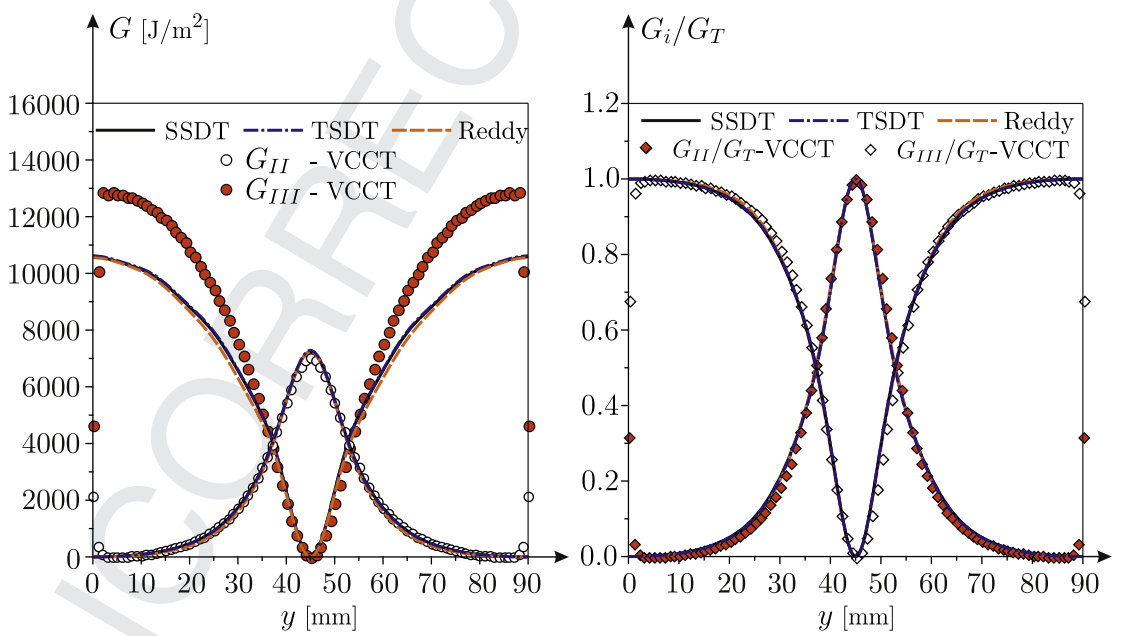

Fig. 20. Distribution of the energy release rates and mode mixity along the delamination front for problem b in Fig. 3, case I. Note: the Reddy solution is available in (Szekrényes, 2014d).

\section{Appendix D. ERR and mode ratio distribution for SF and CC plates}

For problem b with simply supported edge at $x=-c$ the conditions are given by Eqs. (38)-(39), at $x=a$ the free edge involves the following conditions instead of those given by Eqs. (36)-(37):
The clamped-clamped conditions for problem a in Fig. 3 at $x=a$ and $x=-c$ involve:

$\left.\left(w, u_{0 b}, u_{0 t}, v_{0 b}, v_{0 t}, \theta_{x 2}, \theta_{x 4}, \phi_{x 4}, \theta_{y 2}, \theta_{y 4}, \phi_{y 4}\right)^{(1 a)}\right|_{x=a}=0$

$\left.\left(w, u_{0}, v_{0}, \theta_{x 2}, \theta_{x 4}, \phi_{x 2}, \phi_{x 4}, \theta_{y 2}, \theta_{y 4}, \phi_{y 2}, \phi_{y 4}\right)^{(2)}\right|_{x=-c}=0$ 

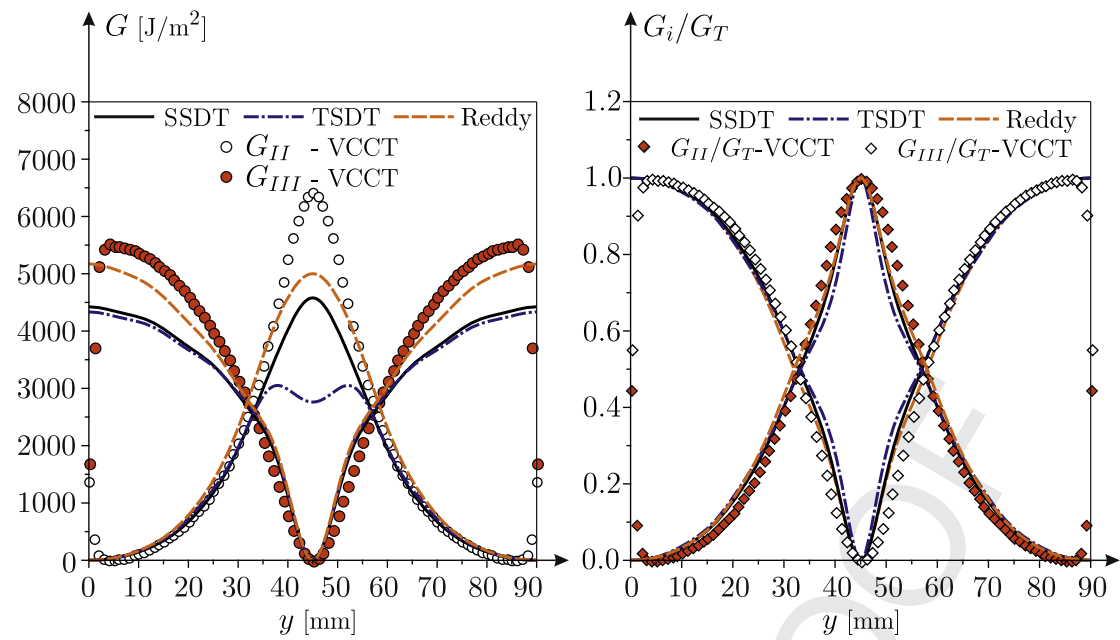

Fig. 21. Distribution of the energy release rates and mode mixity along the delamination front for problem b in Fig. 3, case III. Note: the Reddy solution is available in (Szekrényes, 2014d).

The distributions ot the ERRs and mode ratios are shown in Figs. D.22 and D23.
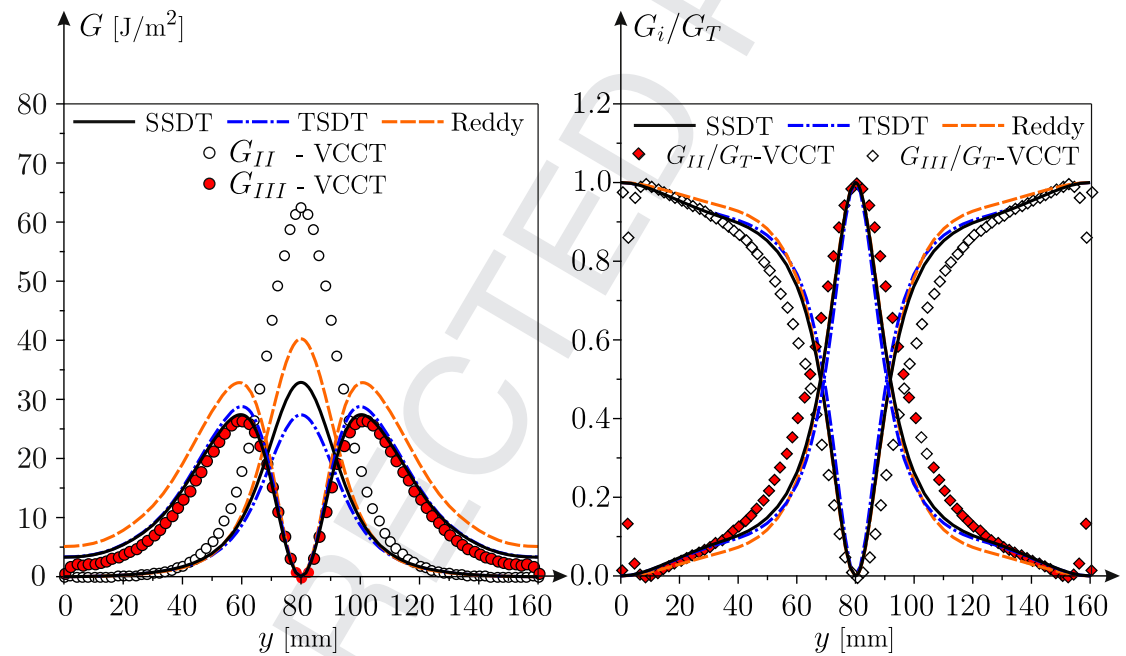

Fig. 22. Distribution of the energy release rates and mode mixity along the delamination front for problem a in Fig. 3, case II. Note: the Reddy solution is available in (Szekrényes, 2014d).
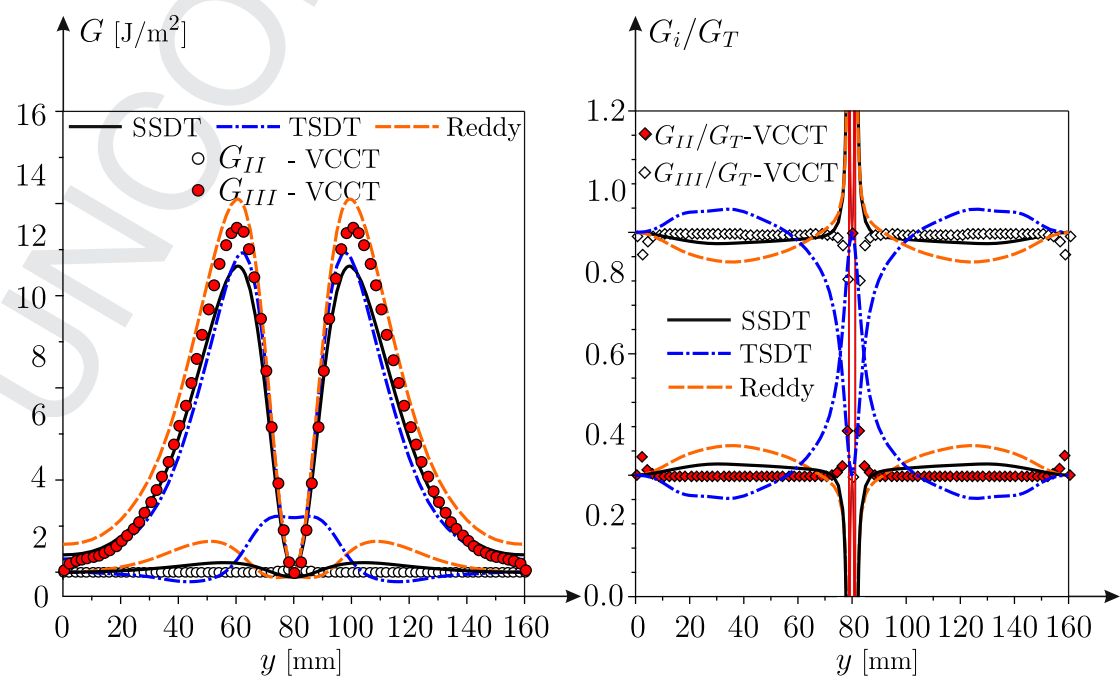

Fig. 23. Distribution of the energy release rates and mode mixity along the delamination front for problem a in Fig. 3, case IV. Note: the Reddy solution is available in (Szekrényes, 2014d). 


\section{References}

Ahn, J.S., Woo, K.S., Lee, D.W., 2012. Delamination analysis of carbon fiberreinforced peek using coarse mesh. Adv. Mater. Res. 538-541, 1624-1629.

Ahn, J.S., Kim, Y.W., Woo, K.S., 2013. Analysis of circular free edge effect in composite laminates by p-convergent global-local model. Int. J. Mech. Sci. 66 149-155.

Alibeigloo, A., Zanoosi, A.P., 2013. Static analysis of rectangular nano-plate using three-dimensional theory of elasticity. Appl. Math. Model. 37, 7016-7026.

Anderson, T.L., 2005. Fracture Mechanics - Fundamentals and Applications, third ed. CRC Press, Taylor \& Francis Group, Boca Raton, London, New York, Singapore.

Aragh, B.S., Farahani, E.B., Barati, A.N., 2013. Natural frequency analysis of continuously graded carbon nanotube-reinforced cylindrical shells based on thirdorder shear deformation theory. Math. Mech. Solids 18, 264-284.

Argüelles, A., Viña, J., Canteli, A.F., Bonhomme, J., 2011. Influence of resin type on the delamination behavior of carbon fiber reinforced composites under mode-Il loading. Int. J. Damage Mech. 20, 963-977.

Arrese, A., Carbajal, N., Vargas, G., Mujika, F., 2010. A new method for determining mode II R-curve by the end-notched flexure test. Eng. Fract. Mech. 77, 51-70.

Arya, H., Shimpi, R., Naik, N., 2002. A zigzag model for laminated composite beams Compos. Struct. 56, 21-24.

Assie, A., Kabeel, A., Mahmoud, F., 2012. Optimum design of laminated composite plates under dynamic excitation. Appl. Math. Model. 36, 668-682.

Baddour, N. (Ed.), 2011. Recent Advances in Vibration Analysis. Intech chapter 4. pp. 60-78. A Shahrjerdi and F Mustapha, Second order shear deformation theory (SSDT) for free vibration analyis on a functionally graded quadrangle plate.

Batista, M., 2012. Comparison of Reissner, Mindlin and Reddy plate models with exact three dimensional solution for simply supported isotropic and transverse inextensible rectangular plate. Meccanica 47, 257-268.

Bodaghi, M., Saidi, A.R., 2010. Lévy-type solution for buckling analysis of thick functionally graded rectangular plates based on the higher-order shear deformation plate. Appl. Math. Model. 34, 3659-3673.

Bonhomme, J., Argüelles, A., Castrillo, M.A., Viña, J., 2010. Computational models for mode i composite fracture failure: the virtual crack closure technique versus the two-step extension method. Meccanica 45, 297-304.

Bruno, D., Greco, F., 2001. Delamination in composite plates: influence of shear deformability on interfacial debonding. Cem. Concr. Compos. 23, 33-45.

Bruno, D., Greco, F., Lonetti, P., 2003. A coupled interface-multilayer approach for mixed mode delamination and contact analysis in laminated composites. Int. J. Solids Struct. 40, 7245-7268.

Bruno, D., Greco, F., Lonetti, P., 2005. A 3D delamination modelling technique based on plate and interface theories for laminated structures. Eur. J. Mech. A/Solids 24, 127-149.

Burlayenko, V.N., Sadowski, T., 2012. A numerical study of the dynamic response of sandwich plates initially damaged by low-velocity impact. Comput. Mater. Sci. 52, 212-216.

Chang, H.H., Tarn, J.Q., 2012. Three-dimensional elasticity solutions for rectangular orthotropic plates. J. Elast. 108, 49-66.

Chaudhuri, R.A., Balaraman, K., 2007. A novel method for fabrication of fiber reinforced plastic laminated plates. Compos. Struct. 77, 160-170.

Cherepanov, G.P., 1997. Methods of Fracture Mechanics: Solid Matter Physics Kluwer Academic Publishers, Dordrecht, Boston, London.

Chirica, I., 2013. Torsion dynamic behaviour of the ship hull made out of layered composites. Math. Probl. Eng. 1-7. Article ID 793412.

Chirica, I., Musat, S.D., Chirica, R., Beznea, E.F., 2011. Torsional behaviour of the ship hull composite model. Comput. Mater. Sci. 50, 1381-1386.

Chou, P.C., Pagano, N.J., 1967. Elasticity - Tensor, Dyadic, and Engineering Approaches. D. Van Nostrand Company, Inc., Princeton, New Jersey, Toronto London.

Christoforou, A.P., Elsharkawy, A.A., Guedoua, L.H., 2008. An inverse solution for low-velocity impact in composite plates. Comput. Struct. 86, 988-996.

Czigány, T., Deák, T., 2012. Preparation and manufacturing techniques for macroand microcomposites. Polym. Compos. 1, 111-134.

Davidson, B.D., Sediles, F.O., 2011. Mixed-mode I-II-III delamination toughness determination via a shear-torsion-bending test. Compos. A Appl. Sci. Manuf. 42 589-603.

Davidson, B.D., Yu, L., Hu, H., 2000. Determination of energy release rate and mode mix in three-dimensional layered structures using plate theory. Int. J. Fract. 105, 81-104.

Davidson, B., Bansal, A., Bing, Q., Sun, X., 2009. Geometrically nonlinear determination of energy release rate and mode ratio in single leg bending tests. J. Reinf. Plast. Compos. 28, 1881-1901.

de Baere, I., Jacques, S., Van Paepegem, W., Degrieck, J., 2012. Study of the mode I and mode II interlaminar behaviour of a carbon fabric reinforced thermoplastic Polym. Test. 31, 322-332.

Eftekhari, S., Jafari, A., 2012. A mixed method for free and forced vibration of rectangular plates. Appl. Math. Model. 36, 2814-2831.

Endo, M., 2015. Study on an alternative deformation concept for the Timoshenko beam and Mindlin plate models. Int. J. Eng. Sci. 87, 32-46.

Endo, M., Kimura, N., 2007. An alternative formulation of the boundary value problem for the Timoshenko beam and Mindlin plate. J. Sound Vib. 301, 355-373.
Fernández, M.V., Moura, M.F.S.F., da Silva, A.T., Marques, L.F.M., 2013. Mixed-mode fatigue/fracture characterization of composite bonded joints using the singleleg bending test. Compos. A Appl. Sci. Manuf. 44, 63-69.

Ferreira, A.J.M., Roque, C.M.C., Carrera, E., Cinefra, M., Polit, O., 2011. Two higher order zig-zag theories for the accurate analysis of bending, vibration and buckling response of laminated plates by radial basis functions collocation and a unified formulation. J. Compos. Mater. 45, 2523-2536.

Ganapathy, S., Rao, K., 1998. Failure analysis of laminated composite cylindrical/ spherical shell panels subjected to low-velocity impact. Comput. Struct. 68, 627-641.

Gheshlaghi, R., Hojjati, M., Daniali, H., 2006. Analysis of composite pressure vessels. In: Gdoutos, E. (Ed.), Fracture of Nano and Engineering Materials and Structures. Springer Netherlands, pp. 335-336.

Goch, G., Knapp, W., Härtig, F., 2012. Precision engineering for wind energy systems. CIRP Annal. Manuf. Technol. 61, 611-634.

Goodmiller, G., TerMaath, S., 2014. Investigation of composite patch performance under low-velocity impact loading. In: 55th AIAA/ASME/ASCE/AHS/SC Structures, Structural Dynamics, and Materials Conference. National Harbor, Maryland, USA.

Gracia, J.D., Boyano, A., Arrese, A., Mujika, F., 2015. A new approach for determining the R-curve in DCB tests without optical measurements. Eng. Fract. Mech. 135, 274-285.

Hajheidari, H., Mirdamadi, H.R., 2013. Frequency-dependent vibration analysis of symmetric cross-ply laminated plate of levy-type by spectral element and finite strip procedures. Appl. Math. Model. 37, 7193-7205.

Hajikazemi, M., Sadr, M., 2014a. Stiffness reduction of cracked general symmetric laminates using a variational approach. Int. J. Solids Struct. 51, 1483-1493.

Hajikazemi, M., Sadr, M., 2014b. A variational model for stress analysis in cracked laminates with arbitrary symmetric lay-up under general in-plane loading. Int. J. Solids Struct. 51, 516-529.

Hosseini-Hashemi, S., Fadaee, M., Taher, H.R.D., 2011. Exact solutions for free flexural vibration of Lévy-type rectangular thick plates via third-order shear deformation. Appl. Math. Model. 35, 708-727.

Islam, M.M., Kapania, R.K., 2014. Global-local finite element analysis of adhesive joints and crack propagation. J. Aircr. 51, 310-319.

Ivančević, D., Smojver, I., 2011. Hybrid approach in bird strike damage prediction on aeronautical composite structures. Compos. Struct. 94, 15-23.

Izadi, M., Tahani, M., 2010. Analysis of interlaminar stresses in general cross-ply laminates with distributed piezoelectric actuators. Compos. Struct. 757-768.

Jiang, G., 2014. Impact of new composite material technology on the performance of the tennis rackets. Appl. Mech. Mater. 484-485, 114-117. Cited By 0.

Jianqiao, Y., 2003. Laminated Composite Plates and Shells - 3D Modelling. Springer, London, Berlin, Heidelberg, New York, Hong Kong, Milan, Paris, Tokyo.

Johnston, A., Davidson, B., 2014. Intrinsic coupling of near-tip matrix crack formation to mode III delamination advance in laminated polymeric matrix composites. Int. J. Solids Struct. 51, 2360-2369.

Johnston, A., Davidson, B., Simon, K., 2014. Assessment of split-beam-type tests for mode III delamination toughness determination. Int. J. Fract. 185, 31-48.

Jumel, J., Budzik, M.K., Shanahan, M.E.R., 2011a. Beam on elastic foundation with anticlastic curvature: application to analysis of mode I fracture tests. Eng. Fract. Mech. 78, 3253-3269.

Jumel, J., Budzik, M.K., Shanahan, M.E.R., 2011b. Process zone in the single cantilever beam under transverse loading. part I: theoretical analysis. Theor. Appl. Fract. Mech. 56, 7-12.

Kapuria, S., Kumari, P., 2012. Boundary layer effects in levy-type rectangular piezoelectric composite plates using a coupled efficient layerwise theory. Eur. J. Mech. A/Solids 36, 122-140.

Kenane, M., Benmedakhene, S., Azari, Z., 2010. Fracture and fatigue study of unidirectional glass/epoxy laminate under different mode of loading. Fatigue Fract. Eng. Mater. Struct. 33, 285-293.

Khan, L., Mahmood, A., Hassan, B., Sharif, T., Khushnod, S., Khan, Z., 2014. Costeffective manufacturing process for the development of automotive from energy efficient composite materials and sandwich structures. Polym. Compos. 35 , 97-104. Cited By 0.

Khoshravan, M.R., Moslemi, M., 2014. Investigation on mode III interlaminar fracture of glass/epoxy laminates using a modified split cantilever beam test. Eng. Fract. Mech. (available online)

Kim, S., Kim, J.S., Yoon, H., 2011. Experimental and numerical investigations of mode I delamination behaviors of woven fabric composites with carbon, kevlar and their hybrid fibers. Int. J. Precis. Eng. Manuf. 12, 321-329.

Kollár, L.P., Springer, G.S., 2003. Mechanics of Composite Structures. Cambridge University Press, Cambridge, New York, Melbourne, Madrid, Cape Town, Singapore, São Paolo.

Kondo, A., Sato, Y., Suemasu, H., Gouzu, K., Aoki, Y., 2010. Characterization of fracture resistance of carbon/epoxy composite laminates during mixed-mode II and III stable damage propagation. J. Jpn. Soc. Compos. Mater. 36, 179-188.

Kondo, A., Sato, Y., Suemasu, H., Aoki, Y., 2011. Fracture resistance of carbon/epoxy composite laminates under mixed-mode II and III failure and its dependence on fracture morphology. Adv. Compos. Mater. 20, 405-418.

Kotousov, A., Berto, F., Lazzarin, P., Pegorin, F., 2012. Three dimensional finite element mixed fracture mode under anti-plane loading of a crack. Theor. Appl. Fract. Mech. 62, 26-33.

Kotousov, A., Lazzarin, P., Berto, F., Pook, L., 2013. Three-dimensional stress states at crack tip induced by shear and anti-plane loading. Eng. Fract. Mech. 108, 65-74. 
Kreja, I., Schmidt, R., 2006. Large rotations in first-order shear deformation FE analysis of laminated shells. Int. J. Non-Linear Mech. 41, 101-123.

Langdon, G., Cantwel, W., Guan, Z., Nurick, G., 2014. The response of polymeric composite structures to air-blast loading: a state-of-the-art. Int. Mater. Rev. 59, 159-177. Cited By 0.

Lerpiniere, A., Caron, J.F., Diaz, A.D., Sab, K., 2014. The LS1 model for delamination propagation in multilayered materials at interfaces: a comparison between experimental and finite elements strain energy release rates. Int. J. Solids Struct. 51, 3973-3986.

Li, L., Jing, H., 2014. Research on the application of fiber-reinforced composite materials on sports equipments. Appl. Mech. Mater. 687-691, 4244-4247. Cited By 0.

Liu, P., Yang, J., Wang, B., Zhou, Z., Zheng, J., 2015. A study on the intralaminar damage and interlaminar delamination of carbon fiber composite laminates under three-point bending using acoustic emission. J. Fail. Anal. Prev. 15, $101-121$.

López-Menéndez, A., Viňa, J., Argüelles, A., Bonhomme, J., Mollón, V., Lozano, M., 2014. A new methodology for testing composite materials in mode III of fracture. In: 16th European Conference on Composite Materials, ECCM 2014, June 22-26, Sevilla, Spain.

Lu, G., Zhao, B., Wu, X., 2013. Refined theory and decomposed theorem of transversely isotropic thermoporoelastic beam. Compt. Rend. Méc. 341, 701-708.

Marat-Mendes, R.M., Freitas, M.M., 2009. Characterisation of the edge crack torsion (ECT) test for the measurement of the mode III interlaminar fracture toughness. Eng. Fract. Mech. 76, 2799-2809.

Marat-Mendes, R.M., Freitas, M.M., 2010. Failure criteria for mixed mode delamination in glass fibre epoxy composites. Compos. Struct. 92, 2292-2298.

Mehrabadi, F.A., 2013. Analysis of pure mode III and mixed mode (III+ II) interlaminar crack growth in polymeric woven fabrics. Mater. Des. 44, 429-437.

Mehrabadi, F.A., 2014. The use of ECT and 6PBP tests to evaluate fracture behavior of adhesively bonded steel/epoxy joints under mode-III and mixed mode III/II. Appl. Adhes. Sci. 2, 1-15.

Mehrabadi, F.A., Khosravan, M., 2013. Mode III interlaminar fracture in woven glass/ epoxy composite laminates. World Acad. Sci. Eng. Technol. 73, 479-483.

Mészáros, L., Deák, T., Balogh, G., Czvikovszky, T., Czigány, T., 2013. Preparation and mechanical properties of injection moulded polyamide 6 matrix hybrid nanocomposite. Compos. Sci. Technol. 75, 22-27.

Miura, M., Shindo, Y., Takeda, T., Narita, F., 2012. Interlaminar fracture characterization of woven glass/epoxy composites under mixed-mode II/III loading conditions at cryogenic temperatures. Eng. Fract. Mech. 96, 615-625.

Miura, M., Shindo, Y., Takeda, T., Narita, F., 2014. Mixed-mode I/III fatigue delamination growth in woven glass/epoxy composite laminates at cryogenic temperatures. J. Compos. Mater. 48, 1251-1259.

Mladensky, A.S., Rizov, V., 2013. Analysis of mixed mode II/III crack in bilayered composite beam. J. Theor. Appl. Mech. 42, 41-52.

Nanda, N., Sahu, S.K., 2012. Free vibration analysis of delaminated composite shells using different shell theories. Int. J. Press. Vessel. Pip. 98, 111-118.

Nikbakht, M., Choupani, N., 2008. Fracture toughness characterization of carbonepoxy composite using arcan specimen. World Acad. Sci. Eng. Technol. 41, 738-744.

Nikbakht, M., Choupani, N., Hosseini, S.R., 2010. 2D and 3D interlaminar fracture assessment under mixed-mode loading conditions. Mater. Sci. Eng. A 516, 162-168.

Norhidayah, M., Hambali, A., Yuhazri, Y., Zolkarnain, M., Taufik, H.Y., Saifuddin, H. 2014. A review of current development in natural fiber composites in automotive applications. Appl. Mech. Mater. 564, 3-7.

Oktem, A.S., Alankaya, V., Soares, C.G., 2013. Boundary-discontinuous Fourier analysis of simply supported cross-ply plates. Appl. Math. Model. 37, 1378-1389.

Ovesy, H., Totounferoush, A., Ghannadpour, S., 2015. Dynamic buckling analysis of delaminated composite plates using semi-analytical finite strip method. J. Sound Vib. 343, 131-143.

Panda, S.K., Singh, B.N., 2009. Nonlinear free vibration of spherical shell panel using higher order shear deformation theory - a finite element approach. Int. J. Press. Vessel. Pip. 86, 373-383.

Panda, S.K., Singh, B.N., 2011. Large amplitude free vibration analysis of thermally post-buckled composite doubly curved panel using nonlinear FEM. Finite Elem. Anal. Des. 47, 378-386.

Peng, L., Zhang, J., Zhao, L., Bao, R., Yang, H., Fei, B., 2011. Mode I delamination growth of multidirectional composite laminates under fatigue loading. J. Compos. Mater. 45, 1077-1090.

Peng, L., Xu, J., Zhang, J., Zhao, L., 2012. Mixed mode delamination growth of multidirectional composite laminates under fatigue loading. Eng. Fract. Mech. 96, 676-686.

Pereira, F., de Moura, M., Dourado, N., Morais, J., Dias, M., 2014. Bone fracture characterization under mixed-mode I+II loading using the single leg bending test. Biomech. Model. Mechanobiol. 13, 1331-1339.

Petrolito, J., 2014. Vibration and stability analysis of thick orthotropic plates using hybrid-Trefftz elements. Appl. Math. Model. (Available online).

Petrova, V.E., Sadowski, T., 2012. Theoretical analysis of mode II cracks in a compact shear specimen. Comput. Mater. Sci. 64, 248-252.

Petrova, V.E., Marsavina, L., Sadowski, T., 2012. Revisit of compact mode II crack specimen: analysis and fracture interpretation. Theor. Appl. Fract. Mech. 59, $41-48$.
Plain, K.P., Tong, L., 2011. An experimental study on mode I and II fracture toughness of laminates stitched with a one-sided stitching technique. Compos. A Appl. Sci. Manuf. 42, 203-210.

Radosavljević, V., Dražić, M., 2010. Exact solution for buckling of FCFC stepped rectangular plates. Appl. Math. Model. 34, 3841-3849.

Raju, I., jr Crews, J., Aminpour, M., 1988. Convergence of strain energy release rate components for edge-delaminated composite laminates. Eng. Fract. Mech. 30, $383-396$.

Reddy, J.N., 2004. Mechanics of Laminated Composite Plates and Shells - Theory and Analysis. CRC Press, Boca Raton, London, New York, Washington D.C.

Rice, J.R., 1968. A path independent integral and the approximate analysis of strain concentration by notches and cracks. J. Appl. Mech. 35, 379-386.

Rizov, V.I., 2012a. Fracture in composites - an overview (Part I). J. Theor. Appl. Mech. 42, 3-42. Sofia.

Rizov, V.I., 2012b. Fracture in composites - an overview (Part II). J. Theor. Appl Mech. 42, 23-32. Sofia.

Rizov, V., Mladensky, A.S., 2012. Analysis of mode II crack in bilayered composite beam. J. Theor. Appl. Mech. 42, 67-78.

Rizov, V., Shipsha, A., Zenkert, D., 2005. Indentation study of foam core sandwich composite panels. Compos. Struct. 69, 95-102.

Rizov, V., Shindo, Y., Horiguchi, K., Narita, F., 2006. Mode III interlaminar fracture behaviour of glass fiber reinforced polymer woven laminates at 293 to $4 \mathrm{k}$. Appl. Compos. Mater. 13, 287-304.

Rodríguez-González, J., May-Pat, A., Avilés, F., 2014. A beam specimen to measure the face/core fracture toughness of sandwich materials under a tearing loading mode. Int. J. Mech. Sci. 79, 84-94.

Sabik, A., Kreja, I., 2013. Large thermo-elastic displacement and stability FEM analysis of multilayered plates and shells. Thin-Wall. Struct. 71, 119-133.

Saeedi, N., Sab, K., Caron, J.F., 2012a. Delaminated multilayered plates under uniaxial extension. part I: analytical analysis using a layerwise stress approach. Int. J. Solids Struct. 49, 3711-3726.

Saeedi, N., Sab, K., Caron, J.F., 2012b. Delaminated multilayered plates under uniaxial extension. part II: efficient layerwise mesh strategy for the prediction of delamination onset. Int. J. Solids Struct. 49, 3727-3740.

Saeedi, N., Sab, K., Caron, J.F., 2013a. Cylindrical bending of multilayered plates with multi-delamination via a layerwise stress approach. Compos. Struct. 95, 728-739.

Saeedi, N., Sab, K., Caron, J.F., 2013b. Stress analysis of long multilayered plates subjected to invariant loading: analytical solutions by a layerwise stress model. Compos. Struct. 100, 307-322.

Sahoo, R. Singh, B., 2013a. A new inverse hyperbolic zigzag theory for the static analysis of laminated composite and sandwich plates. Compos. Struct. 105 385-397.

Sahoo, R., Singh, B., 2013b. A new shear deformation theory for the static analysis of laminated composite and sandwich plates. Int. J. Mech. Sci. 75, 324-336.

Sahoo, R., Singh, B., 2014a. A new trigonometric zigzag theory for buckling and free vibration analysis of laminated composite and sandwich plates. Compos. Struct. 117, 316-332.

Sahoo, R., Singh, B., 2014b. A new trigonometric zigzag theory for static analysis of laminated composite and sandwich plates. Aerosp. Sci. Technol. 35, 15-28.

Salem, N.B., Budzik, M.K., Jumel, J., Shanahan, M.E.R., Lavelle, F., 2013. Investigation of the crack front process zone in the double cantilever beam test with backface strain monitoring technique. Eng. Fract. Mech. 98, 272-283.

Sarvestani, H.Y., Sarvestani, M.Y., 2012. Free-edge stress analysis of general composite laminates under extension, torsion and bending. Appl. Math. Model. 36 1570-1588

Shahrjerdi, A., Bayat, M., Mustapha, F., Sapuan, S.M., Zahari, R., 2010. Second-order shear deformation theory to analyze stress distribution for solar functionally graded plates. Mech. Based Des. Struct. Mach. 38, 348-361.

Shahrjerdi, A., Mustapha, F., Bayat, M., Majid, D.L.A., 2011. Free vibration analysis of solar functionally graded plates with temperature-dependent material properties using second order shear deformation theory. J. Mech. Sci. Technol. 25, $1-15$

Shi, G., 2007. A new simple third-order shear deformation theory of plates. Int. J. Solids Struct. 44, 4399-4417.

Shimpi, R., Patel, H., 2006. A two variable refined plate theory for orthotropic plate analysis. Int. J. Solids Struct. 43, 6783-6799.

Singh, V.K., Panda, S.K., 2014. Nonlinear free vibration analysis of single/doubly curved composite shallow shell panels. Thin-Wall. Struct. 85, 341-349.

Smojver, I., Ivančević, D., 2010. Numerical simulation of bird strike damage prediction in airplane flap structure. Compos. Struct. 92, 2016-2026.

Smojver, I., Ivančević, D., 2011. Bird strike damage analysis in aircraft structures using abaqus/explicit and coupled. Compos. Sci. Technol. 71, 489-498.

Smojver, I., Ivančević, D., 2012. Advanced modelling of bird strike on high lift devices using hybrid. Aerosp. Sci. Technol. 23, 224-232.

Steigmann, D.J., 2012. Refined theory for linearly elastic plates: laminae and laminates. Math. Mech. Solids 17, 351-363.

Su, D., 2014. Application of fiber reinforced composites for sports instruments. Appl. Mech. Mater. 687-691, 4256-4259. Cited By 0.

Suemasu, H., Kondo, A., Gozu, K., Aoki, Y., 2010. Novel test method for mixed mode II and III interlaminar fracture toughness. Adv. Compos. Mater. 19, 349-361.

Szekrényes, A., 2007. Delamination fracture analysis in the $G_{I I}-G_{I I I}$ plane using prestressed composite beams. Int. J. Solids Struct. 44, 3359-3378.

Szekrényes, A., 2009a. Improved analysis of the modified split-cantilever beam for mode III fracture. Int. J. Mech. Sci. 51, 682-693. 
Szekrényes, A., 2009b. Interlaminar fracture analysis in the $G_{I}-G_{I I I}$ plane using prestressed transparent composite beams. Compos. A Appl. Sci. Manuf. 40 1621-1631.

Szekrényes, A., 2011a. The influence of crack length and delamination width on the mode-III energy release rate of laminated composites. J. Compos. Mater. 45, 279-294.

Szekrényes, A., 2011b. Interlaminar fracture analysis in the $G_{I}-G_{I I}-G_{I I I}$ space using prestressed transparent composite beams. J. Reinf. Plast. Compos. 30, 1655-1669.

Szekrényes, A., 2012. Interlaminar fracture analysis in the $G_{I I}-G_{I I I}$ plane using prestressed transparent composite beams. Compos. A Appl. Sci. Manuf. 43, 95-103.

Szekrényes, A., 2013a. Interface fracture in orthotropic composite plates using second-order shear deformation theory. Int. J. Damage Mech. 22, 1161-1185.

Szekrényes, A., 2013b. The system of exact kinematic conditions and application to delaminated first-order shear deformable composite plates. Int. J. Mech. Sci. 77, $17-29$.

Szekrényes, A., 2014a. Analysis of classical and first-order shear deformable cracked orthotropic plates. J. Compos. Mater. 48, 1441-1457.

Szekrényes, A., 2014b. Antiplane-inplane shear mode delamination between two second-order shear deformable composite plates. Math. Mech. Solids. http:/ dx.doi.org/10.1177/1081286515581871.

Szekrényes, A., 2014c. Application of Reddy's third-order theory to delaminated orthotropic composite plates. Eur. J. Mech. A/Solids 43, 9-24.

Szekrényes, A., 2014d. Bending solution of third-order orthotropic Reddy plates with asymmetric interfacial crack. Int. J. Solids Struct. 51, 2598-2619.

Szekrényes, A., 2014e. Stress and fracture analysis in delaminated orthotropic composite plates using third-order shear deformation theory. Appl. Math. Model. 38, 3897-3916.

Taj, M.G., Chakrabarti, A., Sheikh, A.H., 2013. Analysis of functionally graded plates using higher order shear. Appl. Math. Model. 37, 8484-8494.

Takeda, T., Miura, M., Shindo, Y., Narita, F., 2013. Fatigue delamination growth in woven glass/epoxy composite laminates under mixed-mode II/III loading conditions at cryogenic temperatures. Cryogenics 58, 55-61.

Talha, M., Singh, B., 2010. Static response and free vibration analysis of FGM plates using higher order shear deformation theory. Appl. Math. Model. 34 3991-4011.

Tang, D., 2014. The application of carbon fiber materials in sports equipment. Appl. Mech. Mater. 443, 613-616.

Thai, H.T., Choi, D.H., 2013. Analytical solutions of refined plate theory for bending, buckling and vibration analyses of thick plates. Appl. Math. Model. 37, 8310-8323.
Thai, H.T., Kim, S.E., 2012. Lévy-type solution for free vibration analysis of orthotropic plates based on two variable refined plate theory. Appl. Math. Model. 36, 3870-3882.

Thai, H.T., Vo, T.P., 2013. A new sinusoidal shear deformation theory for bending, buckling, and vibration of functionally graded plates. Appl. Math. Model. 37, 3269-3281.

Thai, C.H., Tran, L.V., Tran, D.T., Nguyen-Thoi, T., Nguyen-Xuan, H., 2012. Analysis of laminated composite plates using higher-order shear deformation plate theory and node-based smoothed discrete shear gap method. Appl. Math. Model. 36, 5657-5677.

Valvo, P.S., 2012. A revised virtual crack closure technique for physically consistent fracture mode partitioning. Int. J. Fract. 173, 1-20.

Wang, C., Zhang, H., Shi, G., 2012. 3-D finite element simulation of impact damage of laminated plates using solid-shell interface elements. Appl. Mech. Mater. 130-132, 766-770.

Wennberg, D., Stichel, S., 2014. Multi-functional design of a composite high-speed train body structure. Struct. Multidiscip. Optim. 50, 475-488.

Xiang, S., Kang, G.W., Xing, B., 2012. A nth-order shear deformation theory for the free vibration analysis on the isotropic plates. Meccanica 47, 1913-1921.

Yang, B., Ding, H.J., Chen, W.Q., 2012. Elasticity solutions for functionally graded rectangular plates with two opposite edges simply supported. Appl. Math. Model. 36, 488-503.

Yoshihara, H., 2006. Examination of the 4-ENF test for measuring the mode III Rcurve of wood. Eng. Fract. Mech. 73, 42-63.

Yoshihara, H., Satoh, A., 2009. Shear and crack tip deformation correction for the double cantilever beam and three-point end-notched flexure specimens for mode I and mode II fracture toughness measurement of wood. Eng. Fract. Mech. 76, 335-346.

Zammit, A.D., Feih, S., Orifici, A.C., 2011. 2D numerical investigation of pre-tension on low velocity impact damage of sandwich structures, 21-26 Aug. In: 18th International Conference on Composite Materials (ICCM18). Jeju International Convention Center, Jeju Island, SOUTH KOREA, pp. 1-6.

Zhang, L., 2014. Application of new materials in the field of sports apparel. Adv. Mater. Res. 978, 31-35.

Zhang, J., Fox, B.L., 2007. Manufacturing influence on the delamination fracture behavior of the $\mathrm{T} 800 \mathrm{H} / 3900-2$ carbon fiber reinforced polymer composites. Mater. Manuf. Process. 22, 768-772.

Zhao, B., Wu, D., Wang, M., 2013. The refined theory and the decomposed theorem of a transversely isotropic elastic plate. Eur. J. Mech. A/Solids 39, 243-250.

Zhou, W., Liang, X., Li, Y., You, S., Liu, R., Chai, H., Lv, Z., 2013. Acoustic emission monitoring for delaminated composites under bending damage failure condition. Appl. Mech. Mater. 310, 51-54. 